\title{
G Protein-Coupled Receptor Allosterism and Complexing
}

\section{ARTHUR CHRISTOPOULOS AND TERRY KENAKIN}

Department of Pharmacology, University of Melbourne, Parkville, Victoria, Australia (A.C.); and 7TM Pharmacology Systems Research, Glaxo Smith-Kline Research and Development, Research Triangle Park, North Carolina (T.K.)

This paper is available online at http://pharmrev.aspetjournals.org

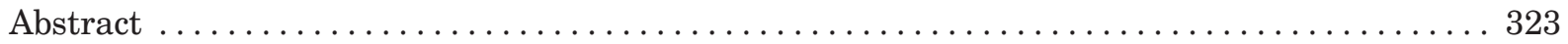

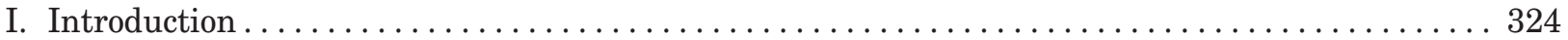

II. Allosteric receptor models of $\mathrm{G}$ protein-coupled receptors. . . . . . . . . . . . . . . . . . . 325

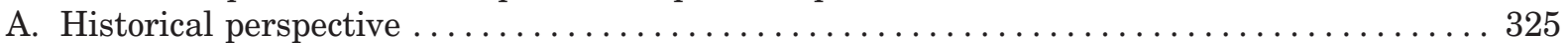

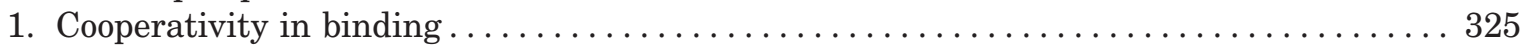

2. Allosteric transitions: multistate models of receptor action $\ldots \ldots \ldots \ldots \ldots \ldots \ldots \ldots \ldots$

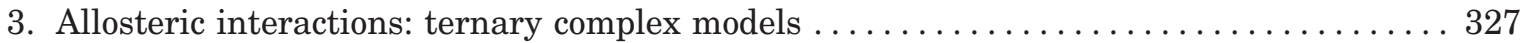

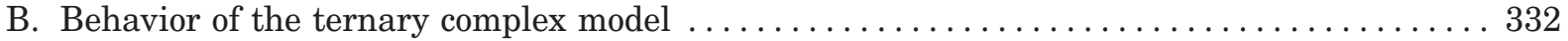

C. The molecular nature of allosterism at $\mathrm{G}$ protein-coupled receptors $\ldots \ldots \ldots \ldots \ldots \ldots \ldots 33$

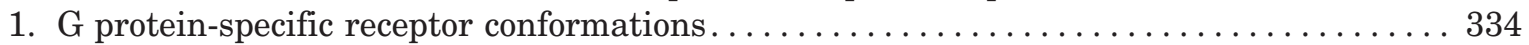

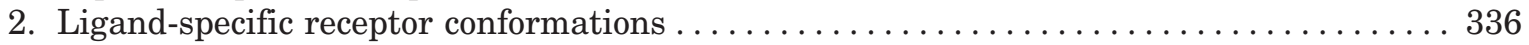

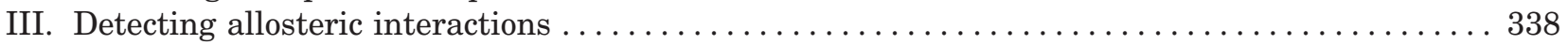

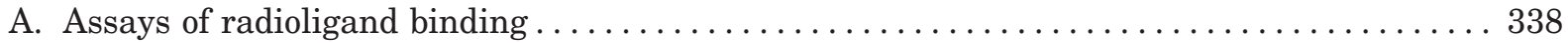

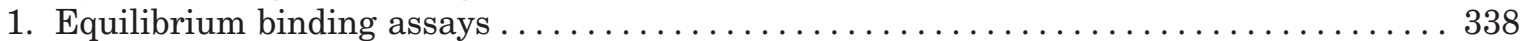

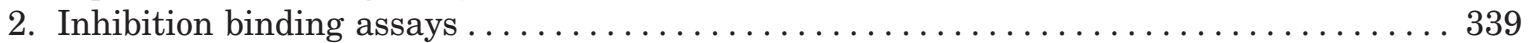

3. Nonequilibrium (kinetic) studies. . . . . . . . . . . . . . . . . . . . . . . . 344

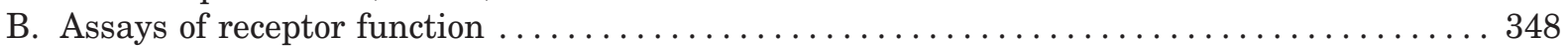

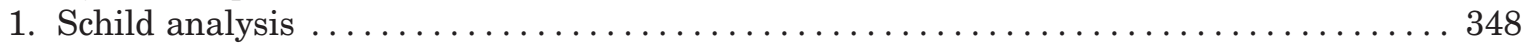

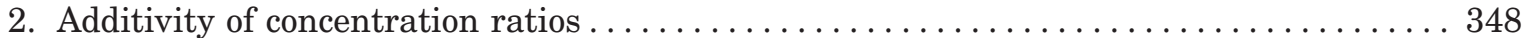

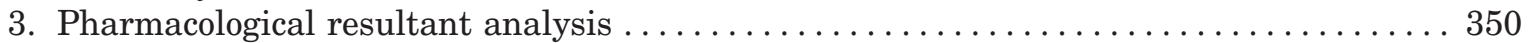

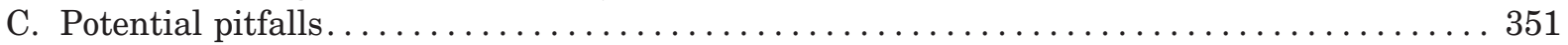

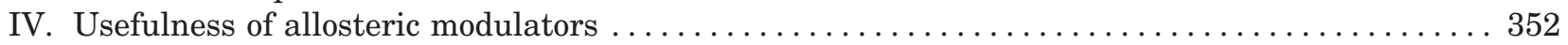

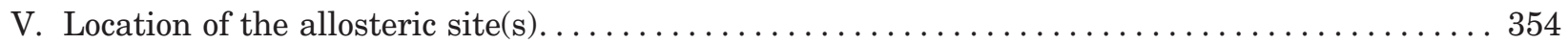

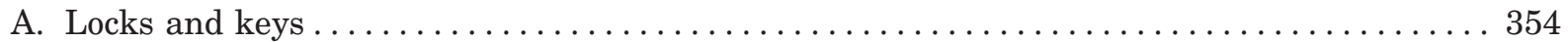

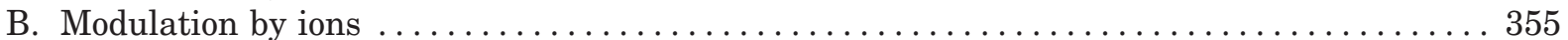

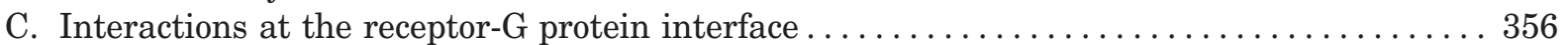

D. Extracellular allosteric sites . . . . . . . . . . . . . . . . . . . . . . . . . . . . . 357

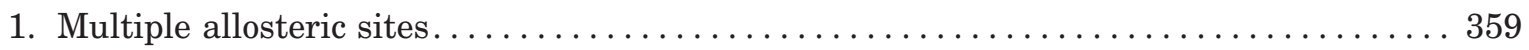

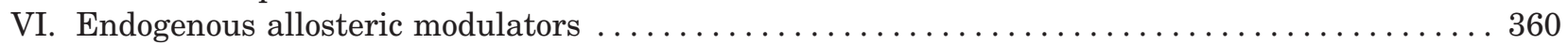

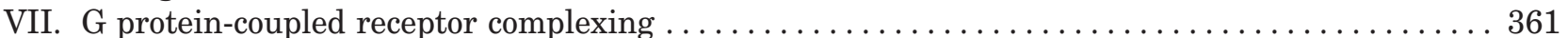

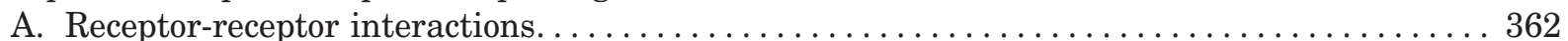

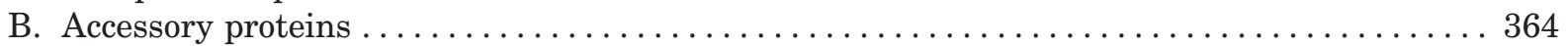

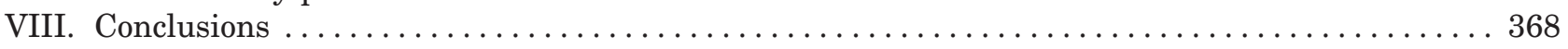

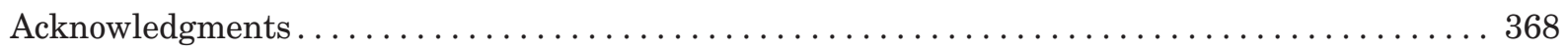

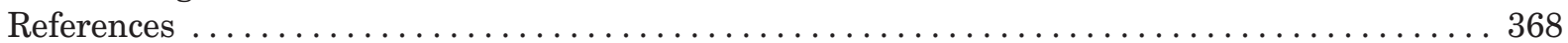




\section{Introduction}

A general property of all receptors is the ability to interact with their endogenous ligands (hormones and neurotransmitters) to alter cellular responsiveness without changing the chemical nature of the ligand. This is in contrast to enzymes, where oftentimes a substrate is made to bind in an energetically unfavorable mode that leads to its eventual modification. G protein-coupled receptors (GPCRs) constitute the largest superfamily of receptors and, not surprisingly, mediate the majority of transmembrane signal transduction in living cells. These receptors respond to a wide range of relatively small and structurally diverse chemicals such as biogenic amines, peptides, hormones, and even light with global changes in receptor conformation that then lead to larger scale protein-protein interactions.

Traditionally, the unifying feature of GPCRs has been their interaction with $\mathrm{G}$ protein(s) to transduce stimuli imparted to the receptor from the extracellular environment to the intracellular response machinery of the cell. Implicit in this mechanism, therefore, is the fact that the intracellular contact points on the GPCR recognized by the G protein are necessarily distinct from the extracellular domains used by endogenous ligands. The lateral translocation of GPCRs in the cell membrane to interact with their cognate $\mathrm{G}$ protein(s) is the best known example of GPCR-protein interaction, but it is by no means the only such example, because additional protein coupling partners are now being rapidly identified for the GPCR superfamily (vide infra). The entire surface of a

\footnotetext{
${ }^{1}$ Abbreviations: GPCR, G protein-coupled receptor; ICI-174,864, $N, N$-diallyl-Tyr-Aib-Aib-Phe-Leu-OH; NalBzOH, naloxone benzoylhydrazone; PI, phosphoinositide; CTC, cubic ternary complex; ETC, extended ternary complex; QCM, quaternary complex model; CHA, $N^{6}$-cyclohexyladenosine; MIA, methylisobutylamiloride; EPA, 5-(Nethyl- $N$-isopropyl)-amiloride; W84, hexane-1,6-bis-(dimethyl-3'pthalimidopropyl) ammonium bromide; MPEP, 2-methyl-6-(phenylethynyl)-pyridine; RAMP, receptor activity modifying protein; CRLR, calcitonin receptor-like receptor; HEK, human embryonic kidney; IP, inositol phosphate; CHO, Chinese hamster ovary; 5-HT, 5-hydroxytryptamine; GABA, $\gamma$-aminobutyric acid; TM, transmembrane; mGluR, metabotropic glutamate; QNB, quinuclidinyl benzilate; NMS, $N$-methylscopolamine; THA, tetrahydroaminacridine; CGRP, calcitonin gene-related peptide; TCM, ternary complex model.
}

GPCR can be considered a potential binding site for biologically active molecules, both proteins and small molecules such as drugs. It is a major premise of this review that a tripartite system composed of a ligand, a GPRC, and an additional GPCR coupling partner represents a general motif for ligand action at GPCRs extending beyond the $\mathrm{G}$ protein example. In other words, the requisite interaction between topographically distinct binding sites on a GPCR to effect change in cellular function identifies these receptors as natural allosteric proteins.

Drugs have traditionally been discovered through the screening of numerous chemical structures on a biological system. The greater the number of structures tested, the greater is the probability of detecting a biologically active ligand. Throughout this process, it is clear that the type of receptor screen employed to detect biologically active molecules will greatly define the types of molecules detected. Thus, if the tracer molecule in the screen is a radioligand, then the ligands most readly detected by that screen will be those that obstruct the access of the radioligand to its specific binding site. Notably, the current emphasis away from radioligand binding and toward high throughput functional screening is beginning to reveal ligands that can change biological function without exerting apparent effects on radioligand binding. It is possible that such ligands are not interacting with the classic, agonist-binding domain of the receptor but rather with other topographically distinct domains.

This raises an interesting philosophical point in drug discovery, namely the current paucity of allosteric ligands in the known population of biologically active molecules. On one hand it could be assumed that this paucity reflects their relative unimportance and rarity in chemical space. However, another point of view would suggest that this paucity reflects the bias imposed on the drug screening process through the use of radioligand binding. As outlined above, the need for high throughput screening has, in the past, required radioligand binding assays to achieve the required volume of sampling of chemical space for drug discovery. However, the improved technology of functional screening in the new millennium will certainly test the potential effects of 
efficacy (vide infra). Similarly, allosteric modulators could block agonist stimulation of the receptor without necessarily interfering with agonist binding to the receptor. Allosteric agonists could activate receptors without being subject to appreciable blockade by classic antagonists. This review will discuss examples of these types of ligands and the different manifestations of allosterism at GPCRs.

\section{Allosteric Receptor Models of G Protein- Coupled Receptors}

\section{A. Historical Perspective}

Most of the theoretical framework associated with the study of ligand-receptor interactions was developed in the first half of the twentieth century, when very little was known about the actual identity of receptors themselves. By borrowing from studies in the field of enzyme kinetics, pharmacologists and physiologists adopted the law of mass action as a minimal mechanistic descriptor of the interaction between a ligand and its receptor. Often, the simplest form of the mass action model-a reversible, saturable, one-to-one interaction between ligand and receptor-was deemed compatible with experimental observations. Even today, where much has been accomplished in terms of identifying the proteinaceous nature and molecular properties of the major receptor families, the starting point for the qualitative or quantitative analysis of drug-receptor data remains the concept of the drug interacting at a "primary" binding site recognized by agonists and competitive antagonists.

The classical view of ligand-receptor interactions mentioned above has served pharmacologists faithfully in studies of receptor mechanisms, classification, and drug discovery, yet as early as the 1930s one of the pioneers of analytical pharmacology, A. J. Clark (1937), postulated the existence of a "complex receptor with which one drug can unite without displacing the other drug". In an extensive treatise on drug-receptor theory, Ariëns et al. (1956) formalized and extended Clark's speculation by developing a mathematical model for a noncompetitive interaction between "a substance A and a receptor system $R$, the latter being partly inactivated or sensitized as a result of the interaction of a substance alongside the better-known and by far better-studied concept of competitive drug-receptor interactions (Gaddum, 1936; Arunlakshana and Schild, 1959; Kenakin, 1997c).

Much of the early drug-receptor theory was developed to describe the behavior of receptors that would later be identified as GPCRs. Unfortunately, detailed mechanistic studies on these receptors were initially hampered by the fact that the requisite dissociation of the ligandreceptor binding process from the subsequent signal transduction events that characterize GPCR activity meant that there were no sufficiently detailed tools with which to dissect drug actions at these receptors at the molecular level. This meant that for some time, drugGPCR theory remained largely operational. In contrast, early studies of enzymes and voltage- and ligand-gated ion channels did not suffer from the same drawbacks as their GPCR counterparts and, thus, the two most important mechanistic insights that led directly to the current models of allosterism at GPCRs were derived from the enzyme and ion channel arena.

1. Cooperativity in Binding. The first important development in allosteric theory came from experimental evidence indicating that more than one molecule of ligand was able to bind to certain enzymes or ion channels to effect a change in the properties of the protein, a phenomenon termed "cooperativity". In fact, the well known Hill equation commonly used nowadays to empirically fit concentration-response data was originally derived to describe cooperative binding (Hill, 1910). Figure 1 illustrates two classic examples of cooperative binding proteins, the enzyme hemoglobin and the $\mathrm{GABA}_{\mathrm{A}}$ ion channel-receptor complex. Simple mass-action kinetics predict that the binding of a single molecule of ligand to a single binding site on a protein would yield a hyperbolic isotherm (when plotted on a linear scale) with a slope coefficient equal to unity. However, the binding of oxygen to hemoglobin (Fig. 1A) or GABA to the $\mathrm{GABA}_{\mathrm{A}}$ receptor (Fig. 1B) are characterized by distinctly sigmoid curves when plotted on a linear scale, reflecting the multiple equivalents of ligand binding to the same protein complex. Studies such as these conducted on a variety of ion channel-linked receptors, thus, led to the conclusion that certain receptors can possess 


\section{$\left[\mathrm{O}_{2}\right]\left(10^{-5} \mathrm{M}\right)$}

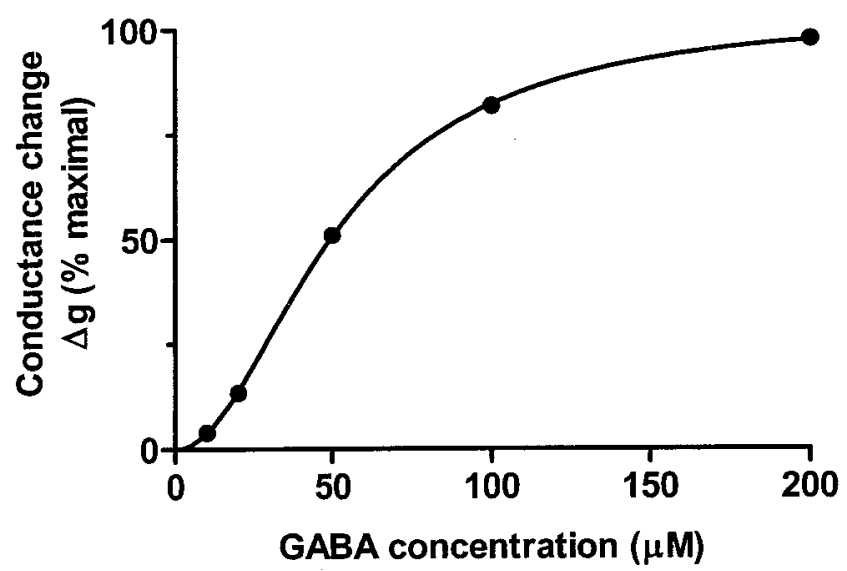

FIG 1. Cooperative binding in enzymes and ion channel-linked receptors. A, the binding of oxygen to hemoglobin dimers (curve D, Hill slope = 1 ) and tetramers (curve T, Hill slope $=3.3$ ). Concentrations of hemoglobin range from $40 \mathrm{nM}$ (D) to $100 \mu \mathrm{M}$ (T). Data taken from Ackers et al. (1992). B, conductance change at the crustacean neuromuscular junction produced by $\gamma$-aminobutyric acid (GABA). Redrawn from Colquhoun (1973) based on data of Takeuchi and Takeuchi (1969).

more than one binding site for ligands. This concept invoked another phenomenon that was also originally described in the field of enzymology, that is, the idea of allosteric (or allotopic) binding sites.

The term "allosteric" (from the Greek meaning "other site") was first used by Monod and Jacob (1961) and subsequently defined by Monod et al. (1963) in a paper describing the ability of enzymes to have their biological activity modified, in either a positive or negative fashion, by the binding of ligands to sites that were topographically distinct from the substrate-binding site. Monod et al. (1963) defined these accessory binding sites as allosteric sites, in contrast to the substrate-binding (active) site, which was defined as the isosteric site. In their original paper, Monod et al. (1963) outlined three general classes of interactions between two ligands on the one enzyme molecule. Class I interactions represented classic competition, where the substrate and inhibitor competed for overlapping regions on the receptor. "allosteric". These interactions arise when the binding of a ligand to the allosteric site induces a conformational change in the protein and modulates the binding of the substrate to the isosteric site, and vice versa. The biological activity of the enzyme was subsequently assumed to arise from the modified properties of the substratebinding site, and not through a direct effect of the allosteric modulator itself. Monod et al. (1963) referred to this conformational change in the enzyme as an allosteric transition, although that term has since come to encompass a slightly different concept (see below).

With regards to receptor proteins, the primary binding site recognized by the endogenous agonist or hormone is conceptually equivalent to an enzyme's isosteric site, and has been referred to as the orthosteric site (Proska and Tucek, 1994; Christopoulos, 2002). Any binding site on a receptor protein that is able to modulate the binding properties of the orthosteric site by mediating a conformational change in the receptor may be classed as an allosteric site. Hence, many of the cooperative interactions that had been reported for ion channel-linked receptors in the literature in the past, such as the binding of two acetylcholine molecules to a single nicotinic acetylcholine receptor (Galzi et al., 1991) or the binding of two GABA molecules to a $\mathrm{GABA}_{\mathrm{A}}$ receptor (Sigel and Buhr, 1997), are also allosteric interactions because the binding of one equivalent of ligand actually alters the affinity of the subsequent binding of the next equivalent(s) of ligand.

2. Allosteric Transitions: Multistate Models of Receptor Action. Before discussing allosteric mechanisms in greater detail, it is necessary to address some of the issues that have arisen in the past regarding the terminology applied to allosteric proteins (Table 1). The term "allosteric" has been used by a number of authors in different ways, and this has led to some confusion in the literature as to what it actually means (e.g., see Colquhoun, 1998). Nowadays, it seems that a distinction is necessary between the terms "allosteric interaction" and "allosteric transition". For the purposes of this review, an allosteric interaction is defined as an interaction that occurs between two (or more) topographically distinct binding sites on the same receptor complex. The essential features of a simple allosteric interaction are 
ior. In essence, the two-state model of receptor action is a mechanism of conformational selection, whereby a ligand selectively binds to a pre-existing receptor conforas follows: (a) The binding sites are not overlapping, that is, there is no mutual exclusivity in binding. (b) The binding of one ligand to its site affects the binding of the second ligand at the other site and vice versa. Allosteric interactions are, thus, reciprocal in nature. (c) The effect of an allosteric modulator can be either negative or positive with respect to the binding and/or function of an orthosteric ligand.

Although Monod et al. (1963) initially defined the conformational change in protein structure associated with an allosteric interaction as an allosteric transition, they subsequently presented a more formalized model of allosteric proteins that gave rise to the second major development in allosteric theory, namely, an emphasis away from interactions occurring between sites to interactions occurring between conformational states (Monod et al., 1965). Allosteric proteins were then described by these authors as follows: (a) They are oligomeric in nature (i.e., composed of more than one subunit). (b) Each subunit possesses one (equivalent) binding site for ligand, thus, giving rise to cooperative interactions. (c) They can exist as an equilibrium mixture of two or more states in the absence of ligand, with the transition between states now being defined as the allosteric transition. (d) The transition between conformational states involves a conservation of molecular symmetry such that all subunits "flip" from one state to another in a concerted fashion. (e) Ligands that prefer binding to one state over another will "select" the preferred state and, thus, increase the proportion of proteins in that state. As a consequence, observed (macroscopic) ligand affinity will alter depending on the type and amount of conformational state that predominates.

It can be seen that this last definition of allosteric proteins is quite explicit. Its description of interactions between multiple subunits makes it immediately applicable to oligomeric proteins that display cooperative binding, e.g., ion channel-linked receptors. It should be noted that models dealing with receptor isomerization between different conformational states were published as early as the 1950 s to describe the postulated mechamation, thereby creating a bias toward that conformation. In terms of free energy, this mechanism is generally preferable to one of conformational induction, where the ligand actually creates the conformation through the binding process (Burgen, 1981; Kenakin, 1995a). It should be noted, however, that conformational selection and conformational induction most likely represent two extremes of a common mechanism used by proteins in changing the type and abundance of conformational state in the presence of ligand.

On the surface, the concept of receptor allosterism within the context of multiple conformational equilibria may seem somewhat removed from the concept of an interaction occurring between distinct binding sites on the one protein. For instance, multistate models allow allosterism to arise simply as a consequence of the transition between one orthosteric conformation to another, without necessarily postulating the existence of a second binding site in each conformational state. In contrast, the simple model of allosteric interaction between two sites does not explicitly consider the existence of multiple conformations of the protein on which the sites are situated. As will be discussed below, these two ideas are not mutually exclusive; rather they address different aspects of a protein's ability to undergo conformational changes. To avoid engendering further confusion, the remainder of this review will use the term "receptor isomerization" when describing the transition of receptors between multiple conformational states and "allosteric interaction" when describing a reciprocal interaction between multiple binding sites on the same protein.

3. Allosteric Interactions: Ternary Complex Models. Ion channels and ion channel-linked receptors are known to exist as oligomers; that is, they are composed of multiple protein subunits, and with an increased complexity in macromolecular structure comes an increased probability of multiple ligand binding sites. Allosteric interactions at ion channel-linked receptors, therefore, have been well documented and studied for almost half a century now. In contrast, GPCRs have, until recently, been considered traditionally to exist as monomers, and relatively fewer allo- 
Katz, 1957; Katz and Thesleff, 1957; Karlin, 1967; Colquhoun, 1973; Thron, 1973; Leff, 1995). These models described how selective affinity of ligands for specific receptor states (in the case of either open or shut ion channels) could bias the system toward the favored state. The second major idea in the GPCR field was that receptors could translocate within membranes and associate with other membrane-bound proteins (Cuatrecasas, 1974). Thus, any mechanism ascribed to a GPCR would need to explicitly invoke the presence of at least two binding sites on the same receptor protein, one for the orthosteric ligand and one for the G protein. This tripartite coupling mechanism represents the simplest scheme for an allosteric interaction occurring between distinct sites (as opposed to states) on a single receptor protein.

In general, the interaction between agonist binding and G protein coupling is positively cooperative in nature (Ehlert, 1985). This is logical, given the mechanisms that are thought to underlie signaling via GPCRs (Gilman, 1987; Bourne, 1997; Hamm, 1998). Agonist binding to the orthosteric site results in an alteration of receptor conformation that displays a higher affinity toward the G protein, thus favoring coupling. However, the binding of GTP to its site on the G protein results in a change of $G$ protein structure that is transmitted to the receptor's conformation as a negatively cooperative effect on agonist binding, thus promoting the uncoupling of the activated $G$ protein from the receptor and allowing signaling to proceed. These negatively cooperative effects of GTP on agonist binding underlie the so-called "GTP shift" that has often been used as a biochemical measure of agonist efficacy (Kenakin, 1997c; Christopoulos and El-Fakahany, 1999).

Figure 2 summarizes the evolution of GPCR models from simple operational schemes to the contemporary ternary complex mechanisms. The original TCM, as described by De Lean et al. (1980) allowed a ligand-bound activated receptor to form a $\mathrm{G}$ protein complex resulting in activation. This is a simple example of a receptor isomerization mechanism, where the binding of ligand A promotes a conformation of receptor that either signals in its own right (e.g., ion-channels; Fig. 2A, left) or couples to and activates a $\mathrm{G}$ protein (Fig. 2A, right). The
$\left(\mathrm{R}^{*}\right)$ and inactive $(\mathrm{R})$ receptor states, $K_{\mathrm{a}}$ is the equilibrium association constant of the ligand-receptor complex and $\alpha$ is referred to as a "cooperativity factor", i.e., it is a ratio of the affinity of the ligand for the active versus the inactive state of the receptor. Alternatively, it may be viewed as a measure of the ability of ligand-bound receptor to enrich the $R^{*}$ state. The use of cooperativity factors in closed equilibrium reaction schemes such as those shown in Fig. 2 serves to reduce the number of parameters required to describe a model while satisfying the principle of microscopic reversibility (Wyman and Allen, 1951; Weber, 1975; Wyman, 1975; Ehlert, 1985; Weiss et al., 1996a). This idea, also referred to as the concept of "free energy coupling" (Weber, 1972, 1975), states that the energy required to reach one species from another must be the same at equilibrium, irrespective of what path is chosen, hence, the use of the cooperativity factor $\alpha$.

When developing the original TCM, De Lean et al. (1980) also considered the possibility of a closed (cyclic) system operating in equilibrium, that is, they speculated about the existence of precoupled RG complexes in the absence of bound ligand (Fig. 2B, right). However, direct evidence for this phenomenon was lacking at the time and had to be inferred from the analysis of complex radioligand binding isotherms. Nevertheless, the proposal of a requisite ternary complex mechanism to account for the known behavior of GPCRs paved the way for further explorations into the properties of such a model (Wregget and De Lean, 1984; Ehlert, 1985). Importantly, the symmetry of the model allowed it to be equally applicable to situations where more than one type of drug molecule could occupy the receptor at the same time (Stockton et al., 1983; Ehlert, 1988). Observations made initially on studies of the actions of a series of hexamethonium derivatives and the neuromuscular blocking agent gallamine on muscarinic acetylcholine receptors had already suggested that such a mechanism may be operative (Lüllman et al., 1969; Clark and Mitchelson, 1976; Stockton et al., 1983). Thus, the simultaneous binding of an orthosteric ligand, A, and an allosteric ligand, B, to the receptor would be governed by the respective equilibrium association constants, $K_{\mathrm{a}}$ and $K_{\mathrm{b}}$, just like the binding of an orthosteric ligand and $\mathrm{G}$ 

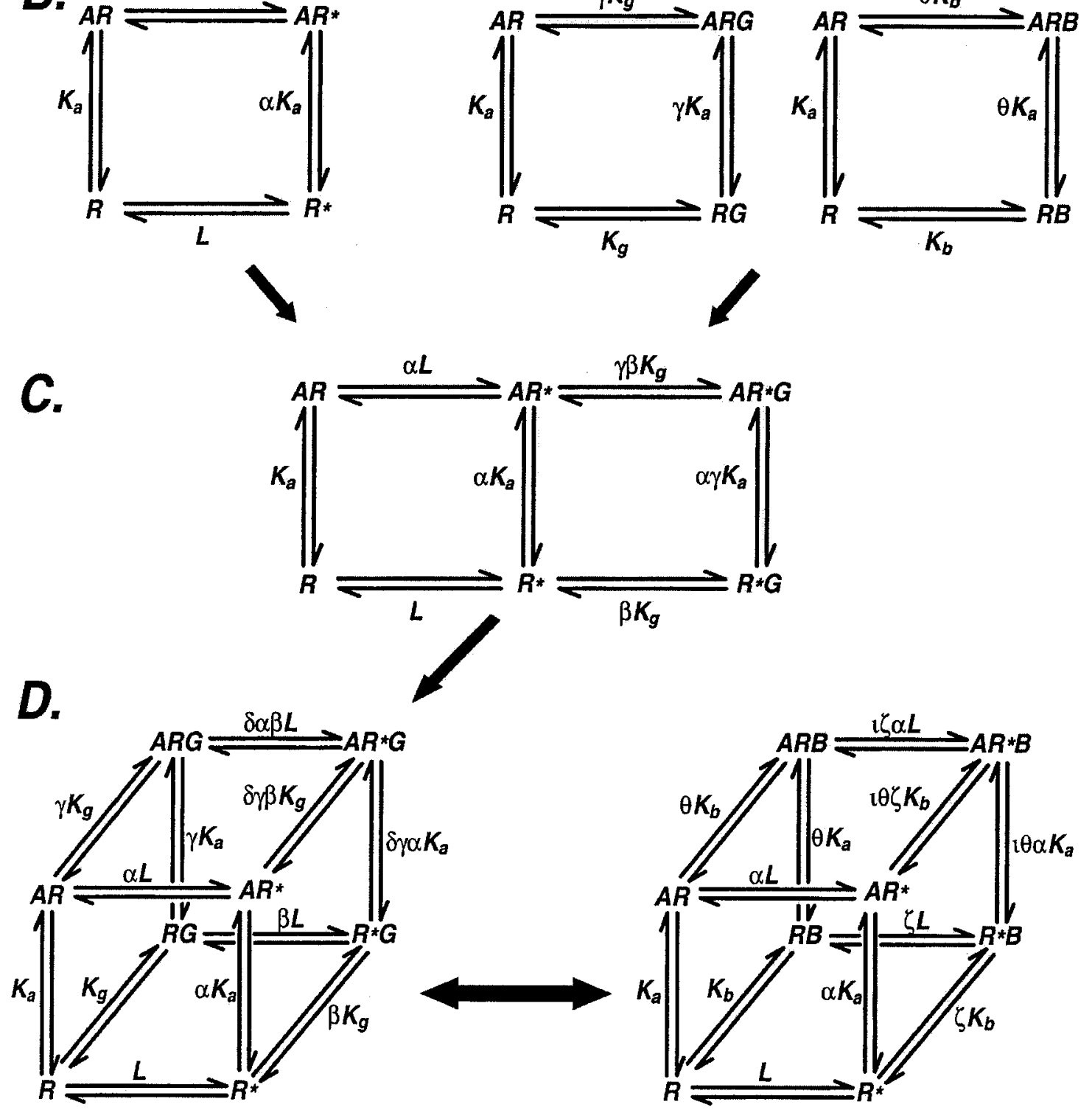

FIG 2. The evolution of allosteric receptor models for GPCRs. The earliest models were based on the assumption that the law of mass action dictates the binding of ligand $\mathrm{A}$ to the receptor, $\mathrm{R}$, according to the equilibrium association constant, $K_{\mathrm{a}}$, and then subsequently resulted in a response. This operational approach was then impacted upon by a progression of mechanistic insights. A, the agonist bound receptor can isomerize to produce a different state that can signal on its own (left) or translocate within the membrane to interact with a $G$ protein (right). B, the receptor, $R$, can spontaneously isomerize to an active state, $\mathrm{R}^{*}$, (left) or couple to a $\mathrm{G}$ protein, $\mathrm{G}$, or allosteric ligand, $\mathrm{B}$, (right) in the absence or presence of orthosteric ligand. Thermodynamic considerations dictate that the isomerization constant, L, and the equilibrium association constants, $K_{\mathrm{a}}, K_{\mathrm{b}}$, and $K_{\mathrm{g}}$, are modified to an extent governed by the cooperativity factors, $\alpha, \gamma$, or $\theta$, when the same interactions take place on an occupied receptor. C, the ETC model of Samama et al. (1993) combines the two-state model with the ternary complex model but only allows for the active receptor state to interact with G protein. D, the CTC model (left) of Weiss et al. (1996a, 1996b, 1996c) allows the inactive R state to interact with G protein and the active state. This model is formally identical with the allosteric two-state model (right) of Hall (2000), which describes the interaction of an allosteric modulator and orthosteric ligand on a receptor that can adopt active and inactive conformations. 
terpart. For example, if the receptor is bound to ligand, its affinity for $\mathrm{G}$ protein is $\gamma K_{\mathrm{g}}$ not $K_{\mathrm{g}}$. If it is bound to another ligand, $\mathrm{B}$, then its affinity for agonist is $\theta K_{\mathrm{a}}$ and not $K_{\mathrm{a}}$. This form of the TCM was the first explicit model of allosteric interactions occurring between topographically distinct binding sites applied to a GPCR, and it is still a useful, minimal model with which to assess and quantify experimental data (vide infra). It should be noted, however, that the TCM as an allosteric model of receptor-G protein interactions, on one hand, and receptor-modulator interactions, on the other, can lead to different predictions with respect to the binding curve of the orthosteric ligand. This is because G protein accessibility to receptors within the plane of the membrane can often be limiting, leading to shallow and/or biphasic orthosteric ligand binding curves due to G protein depletion (see Ehlert, 1985). In contrast, allosteric modulator drugs, like orthosteric ligands, are invariably present in vast excess relative to the concentration of receptor, and ligand depletion is, thus, much less likely to occur; the simple TCM does not predict biphasic or shallow binding curves in the absence of ligand depletion (vide infra).

The subsequent conclusive demonstration of constitutive GPCR activity by Costa and Herz (1989) indicated that receptors could couple to and activate $G$ proteins in the absence of ligand. This necessitated the modification of the original TCM described by De Lean et al. (1980), which did not have the capability of spontaneous formation of the $R^{*} \mathrm{G}$ species, into the extended ternary complex model (ETC model; Samama et al., 1993), as is shown in Fig. 2C. From this scheme, it can be seen that the amount of active-state receptor available for subsequent coupling to $\mathrm{G}$ protein is given by the isomerization constant $\mathrm{L}$. Therefore, increasing the relative stoichiometry of receptors versus $G$ protein leads to an elevated abundance of $R^{*} \mathrm{G}$, the species responsible for agonist independent response (constitutive receptor activity). For example, for a system containing 1000 receptors and a value for $L$ of 0.001 , there will be one single $R^{*}$ species. However, if the receptor number were to be increased by a factor of 1000 , then the number of receptors in the signaling $R^{*} \mathrm{G}$ form would be 1000 . By increasing the number of receptors present in the system, the number development of the more thermodynamically complete, albeit more complex, cubic ternary complex (CTC) model by Weiss et al. (1996a-c; Fig. 2D, left). Although the CTC model is formally more correct than the ETC model, this correctness comes at a price of carrying too many parameters to allow for useful estimation based on experimental observations. In turn, this can make the model less predictive. Therefore, in practical terms, it is worth considering whether the more complex CTC model is worth applying to experimental data instead of the ETC model. The critical issue is the need for the ARG complex, the nonsignaling ternary complex between ligand, receptor, and $G$ protein.

There are two approaches that can be used to try to determine which model, ETC or CTC, has greater utility in the receptor pharmacology of GPCR systems. One is the biochemical evaluation of the evidence for the existence of the inactive ARG complex. To date, there is a paucity of such evidence but it is not clear whether this is because of the apparent rarity of this species in biological systems or because of the lack of tools for detecting this species. There are isolated cases where experimental data are consistent with the existence of a nonsignaling ternary complex species. One example involves the inverse agonist ICI-174,864 ( $N, N$-diallyl-TyrAib-Aib-Phe-Leu-OH) acting at the $\mathrm{G}_{\mathrm{i} / \mathrm{o}}$-coupled $\delta$-opioid receptor expressed in HEK 293 cells (Chiu et al., 1996). Whereas the opioid agonist DPDPE mediated an inhibition of forskolin-stimulated cAMP accumulation, ICI174,864 caused a further stimulation of the cAMP response above the basal forskolin response, consistent with the inverse agonist properties previously ascribed to ICI-174,864 (Costa and Herz, 1989). However, pretreatment of the cells with pertussis toxin, which uncouples $\mathrm{G}_{\mathrm{i} / \mathrm{o}}$-proteins from their receptors, resulted in an abolition of both the agonistic effects of DPDPE and the inverse agonist effects of ICI-174,864. Although the former finding is consistent with the expectation that agonists require active receptor-G protein complexes, the latter finding with ICI-174,864 is inconsistent with the notion that inverse agonists prefer uncoupled receptor-G protein complexes to promote a reduction in constitutive receptor activity. One explanation for the pertussis toxin sensitivity of the ICI-174,864 effect is the 
and insulin-like growth factor 1 receptors (Bouaboula et al., 1997). The crossover inhibition was dependent on the presence of the $\mathrm{CB}_{1}$ receptor and did not occur with the non-GPCR, fibroblast growth-factor receptor. Crossover inhibition was also observed when Mas-7 (a mastoparan
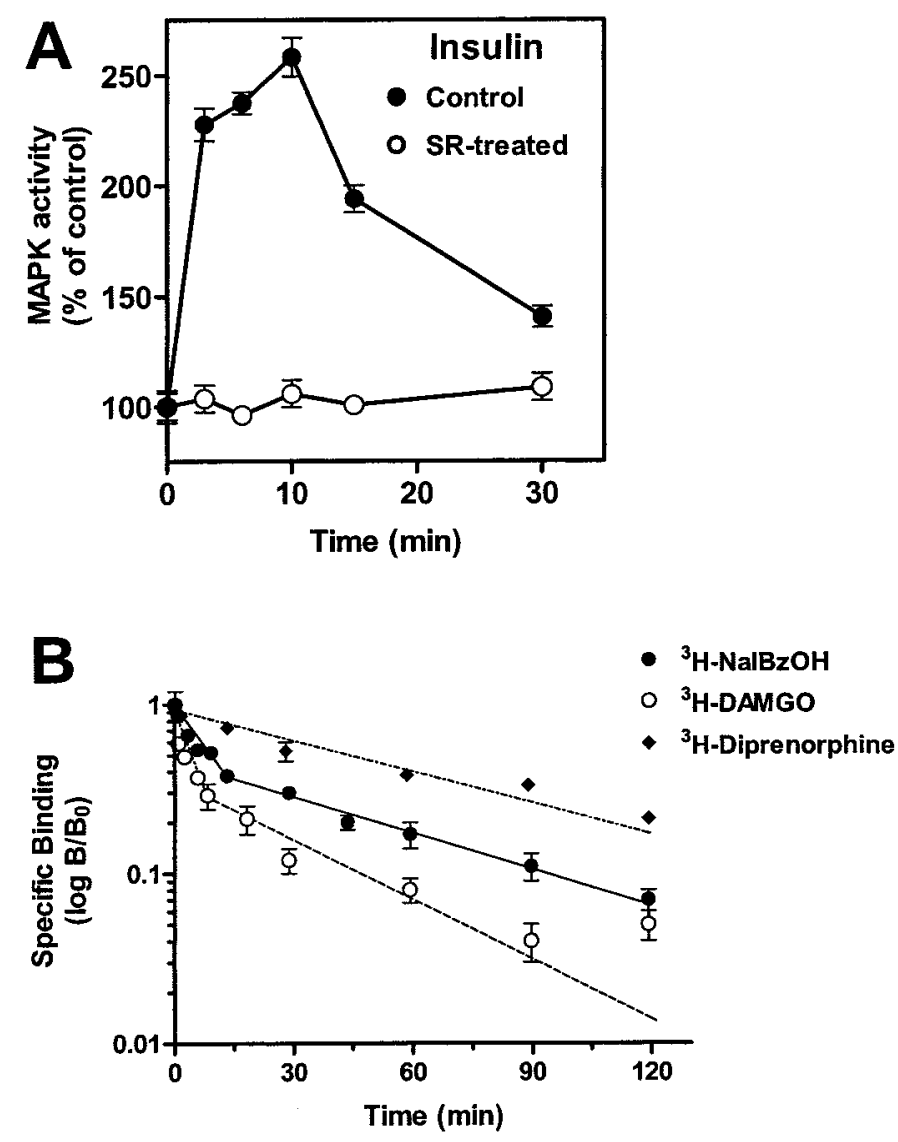

FIG 3. Biochemical evidence for a nonsignaling [ARG] ternary complex. A, interaction of the inverse agonist, SR141716A, with the cannabinoid $\mathrm{CB}_{1}$ receptor abolishes $\mathrm{G}_{\mathrm{i} / \mathrm{o}}$-dependent mitogen-activated protein kinase signaling mediated by the insulin receptor tyrosine kinase, possibly by sequestering $\mathrm{G}$ protein in an inactive ternary complex of inverseagonist, $\mathrm{CB}_{1}$ receptor, and $\mathrm{G}$ protein. Data taken from Bouaboula et al. (1997). B, dissociation kinetics of opioids in CHO cell membranes expressing the human $\mu$-opioid receptor. Unlike the antagonist $\left[{ }^{3} \mathrm{H}\right]$ diprenorphine, the antagonist $\left[{ }^{3} \mathrm{H}\right] \mathrm{NalBzOH}$ and the agonist $\left[{ }^{3} \mathrm{H}\right]$ DAMGO each displayed biphasic dissociation kinetics, indicative of two affinity states of the receptor. The biphasic binding was sensitive to guanine nucleotides, suggesting that both $\left[{ }^{3} \mathrm{H}\right]$ DAMGO and $\left[{ }^{3} \mathrm{H}\right] \mathrm{NalBzOH}$ were coupling to $\mathrm{G}$ proteins, but only the former agent was able to initiate a response. Data taken from Brown and Pasternak (1998). studies in the presence of the stable GTP analog Gp$\mathrm{p}(\mathrm{NH}) \mathrm{p}$. This indicated a low level of negative efficacy for this ligand at this receptor and also that $\mathrm{NalBzOH}$ has a preferential affinity for the inactive state of the receptor. In apparent contrast to this, $\left[{ }^{3} \mathrm{H}\right] \mathrm{NalBzOH}$ demonstrated biphasic kinetics indicative of two affinity states (Fig. 3B), consistent with an association of at least one state with G protein (Brown and Pasternak, 1998). An association with $\mathrm{G}$ protein (with no concomitant signaling) was indicated by the elimination of the high affinity state by $\operatorname{Gpp}(\mathrm{NH}) \mathrm{p}$. The lack of a similar effect by the $\mu$-opioid antagonist diprenorphine and the production of this same effect with pertussis toxin treatment indicated that the high-affinity component was a ligand-specific receptor complex associated with $\mathrm{G}_{\mathrm{i} / \mathrm{o}}$ protein.

Most recently, a study by Chen et al. (2000a) provided strong evidence for the potential of a mammalian GPCR to inhibit signaling in a dominant-negative manner by sequestering $\mathrm{G}$ protein $\alpha$-subunits in a nonsignaling ternary complex. Specifically, a point mutation in Phe303 in the sixth transmembrane domain of the $\alpha_{1 \mathrm{~b}}$-adrenoceptor resulted in a receptor that displayed enhanced agonist binding affinity relative to the wild type, but a loss in agonist-mediated signaling through the phosphoinositide (PI) pathway. Furthermore, the mutant receptor, but not the wild type, could be coimmunoprecipitated with $\mathrm{G} \alpha_{\mathrm{q}}$ in the absence of agonist, indicating a tight coupling of mutant receptor to $\mathrm{G}$ protein, and overexpression of $\mathrm{G} \alpha_{\mathrm{q}}$-subunits resulted in a rescue of the dominant negative activity of the mutant with respect to PI signaling. Taken together, these findings are compatible with the ability of the mutant $\alpha_{1 \mathrm{~b}}$-receptor to selectively sequester $\mathrm{G} \alpha_{\mathrm{q}}$-subunits in a conformation that promotes high agonist binding affinity but not signaling.

A second potential method of determining which model best fits a given experimental system is to examine the predictions of the models and compare those with experimental findings. For example, both the ETC and CTC models predict that increasing the amount of $\mathrm{G}$ protein available to the receptor will increase the amount of $R^{*} \mathrm{G}$ species and, subsequently, the amount of constitutive activity. The relationship between G pro- 
between constitutive activity and receptor number, expressed as a fraction of the maximal system response, is given by

$$
\frac{\text { basal }}{\max }=\frac{\frac{[\mathrm{R}]}{K_{\mathrm{G}}}(1+\delta \alpha \beta \mathrm{L})}{\delta \alpha\left[1+\frac{[\mathrm{R}]}{K_{\mathrm{G}}}(1+\beta \mathrm{L})\right]}
$$

If receptor concentration is not limiting (i.e., as $[R] \rightarrow \propto$ ), then the constitutive activity will reach an asymptotic value of

$$
\frac{\text { basal }}{\max }=\frac{1+\delta \alpha \beta \mathrm{L}}{\delta \alpha(1+\beta \mathrm{L})}
$$

For a high-efficacy agonist, $\delta \alpha \gg 1$ and the expression reduces to

$$
\frac{\text { basal }}{\max }=\frac{\beta \mathrm{L}}{1+\beta \mathrm{L}}
$$

Due to the possibility of producing a nonsignaling RG species, the CTC model predicts that the constitutive activity produced by addition of $G$ protein need not reach the system maximum.

It can be seen that the two models predict the same qualitative but differing quantitative responses. Unfortunately, although submaximal levels of constitutive activity have been observed with receptor transfection experiments in Xenopus laevis melanophores (Chen et al., $2000 \mathrm{~b}$ ), it is not possible to determine whether the $\mathrm{G}$ protein levels in these cells were limiting and, thus, prevented the production of system maximal response. Also, because cellular responses are amplified functions of $\left[\mathrm{R}^{*} \mathrm{G}\right]$, it is not possible to determine whether a full constitutive maximal response relates to a submaximal or fully maximal conversion of receptor species to $\mathrm{R}^{*} \mathrm{G}$.

It is presently unclear which of these models better predicts and describes experimental findings with GPCRs. On the practical side, the ETC model has fewer parameters, is simpler to use, and is, therefore, parsimonious. The CTC model is heuristic and more encompassing but has a greater number of nonestimatable ulation between two binding sites on a receptor that exists in both active and inactive states (see Fig. 2D, right). The properties of this "allosteric two-state model" were recently explored by Hall (2000), who compared it to the CTC model for agonist-G protein interaction. Although the equations derived from the model are formally identical with those of the G protein-based CTC model, there are important differences between the two models with respect to the effects of the cooperativity factors on receptor activation (Hall, 2000). This is because the allosteric two-state model (Fig. 2D, right) quantifies response as the production of activated receptor species $\left(\mathrm{R}^{*}, \mathrm{AR}^{*}, \mathrm{BR}^{*}\right.$, and $\left.\mathrm{AR} * \mathrm{~B}\right)$, as would be the case for ion channel-linked receptors. In contrast, the CTC model quantifies response as the production of activated receptor-G protein species (i.e., $R^{*} G, A R^{*} G$ ). Thus, the $\theta$ parameter in the allosteric two-state model only modifies orthosteric ligand affinity; the equivalent parameter in the CTC model, $\gamma$, modifies the ability of agonist to interact with $\mathrm{G}$ and, thus, affects response production and efficacy. As with the CTC model versus the ETC model, the applicability of the two-state allosteric model will depend on the observations to which it is applied and the systems in which it is tested. The allosteric two-state model would be most suitable, for instance, at ion channel-linked receptors, where the production of stimulus is equivalent to production of response. One interesting prediction of the model is the property of coagonism, whereby an allosteric modulator can modify orthosteric ligand intrinsic efficacy without itself possessing any efficacy; this is embodied in the parameter, $\iota$, in Fig. 2D. Coagonism is commonly observed for ligands acting at the NMDA receptor, for example (Corsi et al., 1996).

\section{B. Behavior of the Ternary Complex Model}

Allosteric interactions at GPCRs can be manifested in a variety of ways. A useful means of obtaining a picture of the possible repertoire of behaviors displayed by allosteric ligands is to simulate them using one of the allosteric ternary complex models introduced above and to compare the predications of the model with experimental observations. When choosing the most appropriate model for such an exercise, a trade-off needs to be made 
havior of the simple allosteric TCM is warranted.

As outlined previously, the simple allosteric TCM at GPCRs involves the concomitant binding of two ligands, $A$ and $B$, to the one receptor, $R$, to form a ternary complex, ARB. For illustrative purposes, Scheme 1 will be adopted.

Ligand A binds to the orthosteric site, whereas ligand $\mathrm{B}$, the allosteric modulator, binds to the allosteric site. The constants $K_{\mathrm{a}}$ and $K_{\mathrm{b}}$ denote the equilibrium association constants for the binding of $\mathrm{A}$ and $\mathrm{B}$, respectively, to their binding sites on the unoccupied receptor. In this regard, each of these bimolecular reactions is no different from the standard mass-action schemes applied to orthosteric binding. However, allosteric interactions are not only characterized by unconditional ligand affinity constants, but also by the cooperativity factor denoted here by the symbol $\alpha$. Values of $\alpha>1$ denote positive cooperativity, whereas $\alpha<1$ denotes negative cooperativity. Values of $\alpha$ approaching zero would be indistinguishable from competitive antagonism. In contrast, an $\alpha$ value equal to 1 denotes an allosteric interaction that results in unaltered ligand affinity at equilibrium. Allosteric interactions can still be discerned under nonequilibrium conditions, and this is discussed later (vide infra).

In addition to the well characterized allosteric effects between agonists and G proteins occurring at GPCRs, a growing number of studies are identifying additional allosteric sites located on specific GPCRs. The best stud-

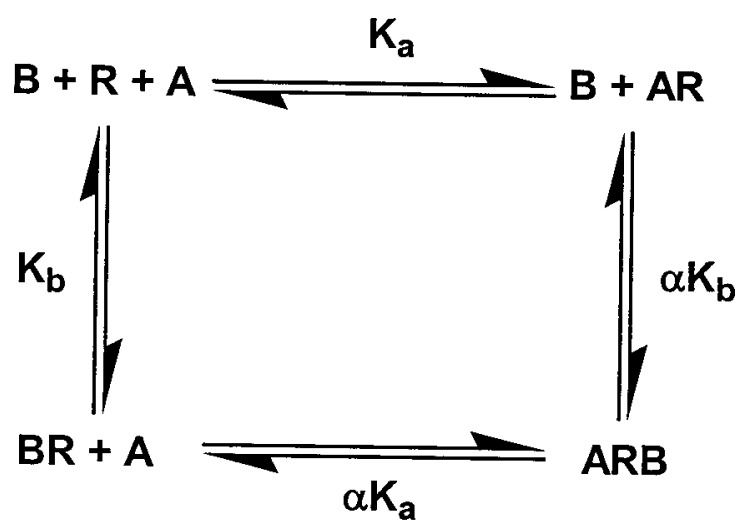

SCHEME 1
From the simple scheme described above, fractional receptor occupancy by the orthosteric ligand $\mathrm{A}\left(\rho_{\mathrm{A}}\right)$ is equal to $([\mathrm{AR}]+[\mathrm{ARB}] /[\mathrm{R}])$ and is expressed as

$$
\rho_{\mathrm{A}}=\frac{\frac{[\mathrm{A}]}{K_{\mathrm{A}}}}{\frac{[\mathrm{A}]}{K_{\mathrm{A}}}+\frac{\left(1+[\mathrm{B}] / K_{\mathrm{B}}\right)}{\left(1+\alpha[\mathrm{B}] / K_{\mathrm{B}}\right)}}
$$

where $K_{\mathrm{A}}$ and $K_{\mathrm{B}}$ denote the equilibrium dissociation constants of $\mathrm{A}$ and $\mathrm{B}$, respectively, at the free receptor. In the absence of allosteric modulator, the receptor occupancy of the orthosteric site is determined by the orthosteric ligand's equilibrium dissociation constant, $K_{\mathrm{A}}$. However, when an allosteric ligand is present, the occupancy of the orthosteric site will now be determined by the following composite parameter, $K_{\mathrm{App}}$

$$
K_{\mathrm{App}}=\frac{K_{\mathrm{A}}\left(1+[\mathrm{B}] / K_{\mathrm{B}}\right)}{\left(1+\alpha[\mathrm{B}] / K_{\mathrm{B}}\right)}
$$

If the interaction between $\mathrm{A}$ and $\mathrm{B}$ is positively cooperative ( $\alpha>1)$, then $K_{\mathrm{App}}<K_{\mathrm{A}}$ and the binding curve of ligand $\mathrm{A}$ at the modulator-occupied receptor will be shifted to the left relative to the binding curve of $A$ at the free receptor. In contrast, negative cooperativity between $\mathrm{A}$ and $\mathrm{B}(\alpha<1)$ will be manifested as a rightward displacement of the binding curve for A (i.e., $K_{\mathrm{App}}>K_{\mathrm{A}}$ ). Figure 4 illustrates these relationships for the binding of an orthosteric ligand in the presence of increasing concentrations of an allosteric modulator with an $\alpha$ value of either 0.1 (negative cooperativity) or 10 (positive cooperativity). This figure also illustrates an important aspect of allosteric interactions, namely that these types of interactions approach a limit, the extent of which is governed by the magnitude of $\alpha$. The closer the value of $\alpha$ is to 1 , the more readily the limit is approached with increasing concentrations of $\mathrm{B}$.

\section{The Molecular Nature of Allosterism at G Protein- Coupled Receptors}

The ability of orthosteric ligands, once bound, to modify the signaling properties of receptors has been defined as a measure of orthosteric ligand efficacy (Kenakin, 
Dopamine $\mathrm{D}_{2}$

Endothelin $\mathrm{ET}_{\mathrm{A}}$

$\mathrm{GABA}_{\mathrm{B}}$

Glutamate mGluR

Glutamate mGluR

Muscarinic $\mathrm{M}_{1}-\mathrm{M}_{5}$

Neurokinin $\mathrm{NK}_{1}$

Purine $\mathrm{P} 2{ }_{\mathrm{Y} 1}$

Serotonin 5- $\mathrm{HT}_{1 \mathrm{~B} / 1 \mathrm{D}}$

Serotonin $5-\mathrm{HT}_{2 \mathrm{~A}}$

Serotonin $5-\mathrm{HT}_{7}$
Amilorides, zinc

Aspirin, sodium salicylate

CGP7930; CGP13501

CPCCOEt, Ro 67-7476, Ro 01-6128; BAY36-7620

MPEP

Gallamine, alcuronium, brucine, dimethyl-W84

Heparin

$2,2^{\prime}$-pyridylsatogen tosylate

5 -HT moduline

Oleamide

Oleamide
Hoare and Strange, 1996; Schetz et al., 1999

Blandin et al., 2000; Talbodec et al., 2000

Urwyler et al., 2001

Litschig et al., 1999; Carroll et al., 2001; Knoflach et al., 2001

Pagano et al., 2000; Spooren et al., 2001

Clark and Mitchelson, 1976; Stockton et al., 1983; Knaus et al., 1991; Proska and Tucek, 1994; Lazareno and Birdsall, 1995; Traenkle et al., 1998

Knaus et al., 1991

Spedding et al., 1975; King et al., 1996

Fillion et al., 1996; Massot et al., 1998

Thomas et al., 1997

Thomas et al., 1997; Hedlund et al., 1999 1996a, 2002). The very nature of efficacy is intertwined with the ability of the orthosteric ligand to produce a conformation of the receptor that either promotes signaling (as is seen with agonists) or attenuates constitutive receptor signaling (as is observed with inverse agonists). Because the binding of an allosteric modulator to a distinct accessory site on the receptor causes its own alteration of receptor conformation, it is conceivable that the resulting conformation may influence orthosteric ligand efficacy, in addition to the effects on orthosteric ligand affinity described in the preceding section. Thus, although assays of receptor signaling are necessarily influenced by post-binding stimulus-response events, they nevertheless afford the opportunity to detect specific receptor conformations promoted by allosteric modulators that may not necessarily be evident in radioligand binding assays.

When considering the conformational space of GPCRs, it is often parsimonious to confine GPCR activity to two states (an inactive state that does not activate G proteins and an active state that does). However, there are no data to suggest that agonists simply enrich a single population of active receptor state to produce response. It is well established that proteins exist in numerous conformations or substates (Frauenfelder et al., 1988, 1991; Frauenfelder, 1995). Thermal energy causes fluctuation between these states with certain low-energy states being "favored" (Gerstein et al., 1994; Haltia and Freire, 1995). Although the ETC and CTC models are sometimes referred to as two-state models, this is a misnomer from the point of view of ligand activation. The two states $\mathrm{R}$ and $\mathrm{R}^{*}$ refer to the unliganded forms of the receptor, and upon binding of ligand, the factors $\alpha$ and $\gamma$ (and additionally $\delta$ for the CTC model) confer complete ligand specificity to the protein species. Under these circumstances, these models are infinite-state models because ligands could have unique values for $\alpha$, $\gamma$, and $\delta$ (Watson et al., 2000). This introduces the concept of $\mathrm{G}$ protein- and ligand-selective receptor active states.

1. G Protein-Specific Receptor Conformations. There are numerous lines of evidence to suggest that different agonists produce response through the formation of different receptor active states. The most compelling data are obtained from receptors that are pleiotropic with respect to the $G$ proteins with which they interact because these different $G$ proteins provide a means of differentiating signaling active states. From this standpoint, the pattern of activation of various stimulus-response pathways can be used to infer the existence of these states. This phenomenom is termed "stimulus trafficking", whereby agonists differ in the ability to stimulate separate stimulus-response pathways through a single receptor (Kenakin, 1995a, 1995b, 1997a).

It is known that different regions of the cytosolic loops of GPCRs activate different G proteins (Ikezu et al., 1992; Wade et al., 1999), and it would not be expected that different tertiary conformations of the receptor protein would expose these different regions in an identical manner. Therefore, if ligands produce different tertiary conformations, then these may be detected through the relative capabilities of the resulting species to activate different $G$ proteins. This should not be confused with differential activation of pathways through strength of 


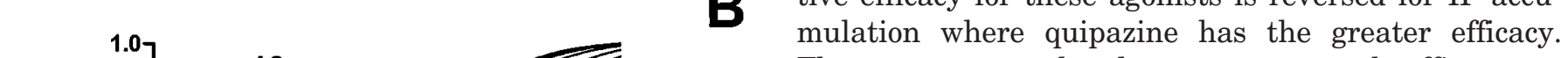

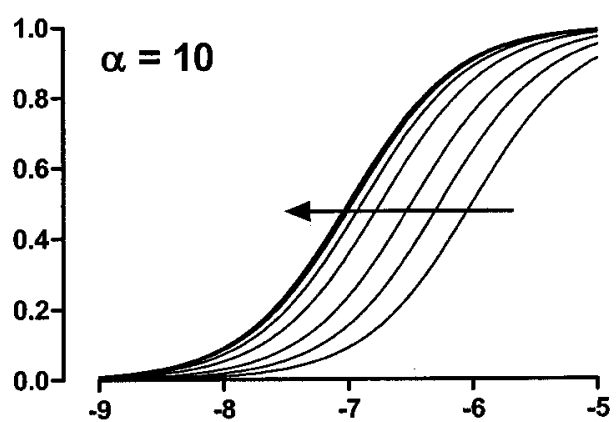

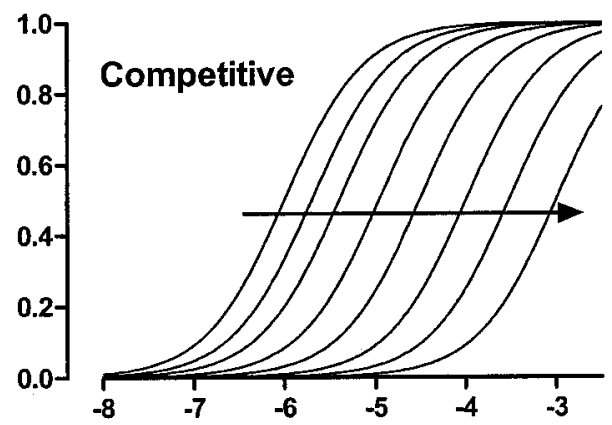

FIG 4. Effect of a negative allosteric modulator (A), positive allosteric modulator (B), or a competitive antagonist (C) on orthosteric ligandreceptor occupancy $\left(\rho_{\mathrm{A}}\right)$ based on the simple ternary complex model for allosteric interactions (eq. 5). For all the simulations, $\mathrm{p} K_{\mathrm{A}}=6$ and $\mathrm{p} K_{\mathrm{B}}=$ 9 . The modulator, B, modifies orthosteric ligand affinity to a limit determined by the cooperativity factor $(\alpha)$ that characterizes the interaction between allosteric and orthosteric sites. In these examples, ligand affinity is either maximally diminished (A) or enhanced (B) by a factor of 10 . In contrast, simple competitive interactions (C) are characterized by mutually exclusive binding of the two ligands for the same site and, thus, allow for a theoretically limitless dextral shift of orthosteric ligand occupancy.

stimulus. If a receptor couples to one pathway with great efficiency and to another one poorly, a strong agonist with high efficacy may activate both pathways, whereas a weaker agonist would activate only the most efficiently coupled pathway; this is not stimulus trafficking. To conclude true differences in receptor active state, a reversal of potency for the pathways or differences in the maximal activation of the pathways by the agonists must be demonstrated. This has been shown for some receptors. For example, the human $5-\mathrm{HT}_{2 \mathrm{C}}$ receptor is coupled to two separate response pathways in $\mathrm{CHO}$ cells, namely phospholipase $\mathrm{A}_{2}$-mediated arachadonic acid release and phospholipase C-mediated inositol
Thus, a receptor-related parameter, namely efficacy, reverses with the two agonists for the same receptor. Similarly, there is a reversal of the relative potency of substance $\mathrm{P}$ analogs on neurokinin NK-1 receptors described where substance $\mathrm{P}$ is 2.1 times more potent than the analog $\left[\mathrm{P}_{3}{ }^{\mathrm{E}}\right.$ met $\left.\left(\mathrm{O}_{2}\right)^{11}\right] \mathrm{SP}$ for producing cyclic AMP through NK-1 receptor activation, but is 0.11 times less potent than the analog for producing phosphoinositol hydrolysis through activation of the same receptor (Sagan et al., 1999). Reversals of efficacy also have been reported for pituitary adenylate cyclase-activating polypeptide receptors (Spengler et al., 1993), dopamine receptors (Meller et al., 1992), and Drosophila tyramine receptors (Robb et al., 1994). In general, these data cannot accommodate a mechanism whereby all of the agonists involved produce an identical active receptor state.

Specially designed recombinant GPCR systems (termed "stimulus-biased" assay systems; Watson et al., 2000) also can be used to detect stimulus trafficking. These systems consist of surrogate host cells for receptor transfection with identical cellular backgrounds except for the enrichment of a single $\mathrm{G} \alpha$-subunit. A study with human calcitonin receptor (type 2), a pleiotropic receptor that can interact with $\mathrm{G}_{\mathrm{s}}, \mathrm{G}_{\mathrm{q}}$, and $\mathrm{G}_{\mathrm{i}}$, (Horne et al., 1994), showed striking reversals in relative potencies of peptide calcitonin agonists. Specifically, after transfection of the receptors into wild-type HEK 293 cells and HEK cells stably transfected with enriched populations of $\mathrm{G} \alpha$-subunits, differences in relative agonist potencies were observed. For example, the relative potency of porcine calcitonin and rat amylin changed by a factor of 18 (from 4.6 to 84 ) when compared in wild-type and $\mathrm{G} \alpha_{\mathrm{s}^{-}}$ enriched cells. This suggests that porcine calcitonin produces a conformation more conducive to using $\mathrm{G}_{\mathrm{s}}$ than does amylin. In these studies, even the rank order of potency of the agonists changed in that the potency of rat calcitonin gene-related peptide (CGRP) was 0.3 times that of rat amylin in wild-type cells and three times greater than rat amylin in $\mathrm{G} \alpha_{\mathrm{s}}$-enriched host cells (Watson et al., 2000). Because the classification of receptors using agonist potency ratios and rank orders of potency is based on the tenet that the active state pro- 
stitutively active systems and inverse agonism in constitutively active ones. Such a pattern of response can be used as presumptive evidence that the agonist produces a receptor active state that is different (i.e., of lower efficacy) than the spontaneously formed active state, i.e., ligand selective agonism. Under these circumstances, protean agonism can be considered a looking glass into receptor states.

There are theoretical conditions under which protean agonism could occur. For example, in the CTC, a ligand could promote the $\mathrm{R}^{*}$ form of the receptor by having $\alpha>$ 1 but then produce a liganded form of the receptor active state of lower affinity than the unliganded form $(\gamma<1)$; the result would be a reversal of the positive to a negative agonism under conditions of constitutive activity. Importantly, there are also experimental examples of protean agonism. The $\beta$-adrenoceptor ligand dichloroisoproterenol has been shown to produce positive partial agonism in Sf9 cells transfected with $\beta_{2}$-adrenoceptors. When membranes were prepared from these same cells, the system demonstrated constitutive activity (due to removal of cellular GTP) and dichloroisoproterenol then became an inverse agonist. The same behavior was observed for the ligands labetolol and pindolol (Chidiac et al., 1994, 1996).

The kinetics of cyclic AMP formation have been used to detect agonist-selective receptor states. Thus, in the presence of limiting GTP concentrations, such kinetics indicate a differential rate of heterotrimer dissociation of $\mathrm{G}$ protein subunits with different $\beta$-adrenoceptor agonists (Krumins and Barber, 1997). Similarly, differences in the ability of $\beta$-adrenoceptor agonists to hydrolyze inosine versus guanosine triphosphate suggest the formation of ligand-specific receptor active states as well (Seifert et al., 1999).

Mutation studies also suggest that ligands stabilize different tertiary conformations of receptors. For example, mutations of dopamine $\mathrm{D}_{2}$ receptors produce agonist-specific abolition of $\mathrm{G}$ protein activation (Wiens et al., 1998). Desensitization of receptors by some agonists also suggests differential receptor active state formation. Whereas it would be expected that the ability of agonists to induce desensitization would parallel their ability to produce response (i.e., intrinsic efficacy), stud- ous deviation from a simple two-state model of receptor activation suggesting that different ligands produce uniquely different protein conformations (Onaran et al., 2000).

The major window of detection of allosteric effects historically has been receptor-mediated physiological response. Thus, ligands have been detected as allosteric modulators or enhancers on the basis of effects resulting in changes in tracer ligand affinity and/or tracer ligandinduced response. However, different receptor conformations are involved in receptor-mediated effects other than cellular signaling (Kenakin, 2002). Thus, conformations resulting in changes in receptor phosphorylation and/or receptor internalization also can be relevant to the therapeutic effect of allosteric ligands. For example, studies on receptor internalization suggest ligand-specific receptor conformations. Thus, the cholecystokinin receptor antagonist D-Tyr-Gly-[(Nle $\left.{ }^{28,31}, \mathrm{D}-\mathrm{Trp}^{30}\right)$ cholecystokinin-26-32]phenethyl ester is an antagonist on the receptor producing blockade of responses to cholecystokinin but produces profound acceleration of receptor internalization (Roettger et al., 1997). This indicates the formation of a unique conformation that does not signal to $G$ proteins but is more amenable to receptor phosphorylation and subsequent internalization. Similarly, whereas enkephalins and morphine both stimulate $\delta$ - and $\mu$-opioid receptors, enkephalins induce rapid receptor internalization while morphine does not (Keith et al., 1996).

2. Ligand-Specific Receptor Conformations. Although the preceding discussion of specific receptor conformations focused on the receptor-G protein interaction, it is evident that the entire surface of a GPCR may be viewed as a potential binding site, and any ligand binding to either the orthosteric or allosteric site(s) on a GPCR has the potential to alter receptor conformation such that the affinity and/or intrinsic efficacy of a ligand binding to the other site(s) on the GPCR will also change. This scheme is also compatible with the potential for multiple ligand-specific receptor conformations to be engendered depending on the binding site and extent of conformational change induced in the receptor protein. Thus, ligands that would be classed as allosteric modulators with respect to their effects on the endogenous orthosteric agonist for the receptor of interest should be placed in the same realm as other modifiers of receptor 
allosteric sites, orthosteric and $\mathrm{G}$ protein sites, and allosteric and G protein sites. Because efficacy at GPCRs is invariably related to the ability of the receptor to interact with its cognate $G$ protein(s), then efficacy at the molecular level can be impacted not only by the interaction between orthosteric ligand and $\mathrm{G}$ protein or orthosteric ligand and allosteric modulator (e.g., Section IIB), but also by the interaction of the allosteric modulator and the G protein. For instance, Fig. 5A shows the effects of the allosteric modulator alcuronium on PI hydrolysis in CHO cells transfected with the human $\mathrm{M}_{1}$ muscarinic acetylcholine receptor (Jakubik et al., 1996). Even in the absence of the muscarinic agonist carbachol, alcuronium was able to elicit a significant stimulatory effect on PI hydrolysis that was insensitive to antagonism of the orthosteric site by the classical muscarinic antagonist quinuclidinyl benzilate. The effect of alcuronium on PI hydrolysis was absent in cells that did not express the $\mathrm{M}_{1}$ muscarinic receptor. Thus, it can be concluded that alcuronium was promoting receptor-G protein coupling via an action at the allosteric site on $\mathrm{M}_{1}$ receptors. In a similar manner, the allosteric modulator gallamine was also found to activate the $M_{1}$, $\mathrm{M}_{2}$, and $\mathrm{M}_{4}$ muscarinic receptors in the absence of any other ligand (Jakubík et al., 1996), although it inhibits the binding of the endogenous muscarinic agonist acetylcholine at the same receptors (Lazareno and Birdsall, 1995). This latter finding is a striking example of ligand-specific receptor conformations, whereby gallamine (and alcuronium) can promote conformations that are positively cooperative for G protein coupling but negatively cooperative for agonist binding.

Allosteric ligand-mediated receptor-G protein interactions are not restricted to the muscarinic acetylcholine receptors. Figure 5B shows the effect of the allosteric modulator PD 81,723 on the saturation binding properties of the agonist $\left[{ }^{3} \mathrm{H}\right] N^{6}$-cyclohexyladenosine $\left(\left[{ }^{3} \mathrm{H}\right] \mathrm{CHA}\right)$ at the adenosine $\mathrm{A}_{1}$ receptor. In the absence of modulator, the radiolabeled agonist could only recognize approximately one-ninth of the total receptor population, as defined by the binding of the radiolabeled antagonist, 8-[dipropyl-2,3$\left.{ }^{3} \mathrm{H}(\mathrm{N})\right]$ cyclopentyl-1,3-dipropylxanthine, $\left[{ }^{3} \mathrm{H}\right] \mathrm{CHA}$ (Kollias-Baker et al., 1997). This finding indicated that the agonist $\left[{ }^{3} \mathrm{H}\right] \mathrm{CHA}$ was selectively labeling only highaffinity receptor-G protein complexes, rather than the en-

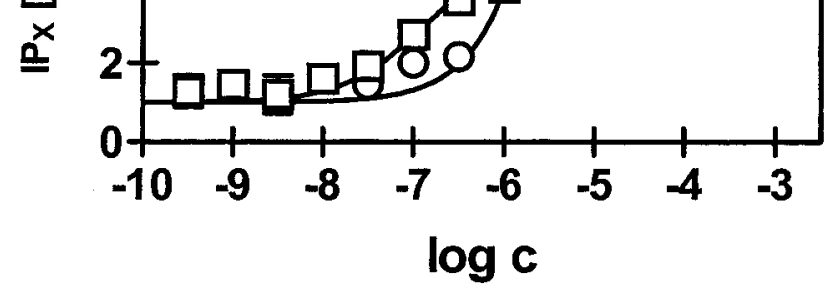

B

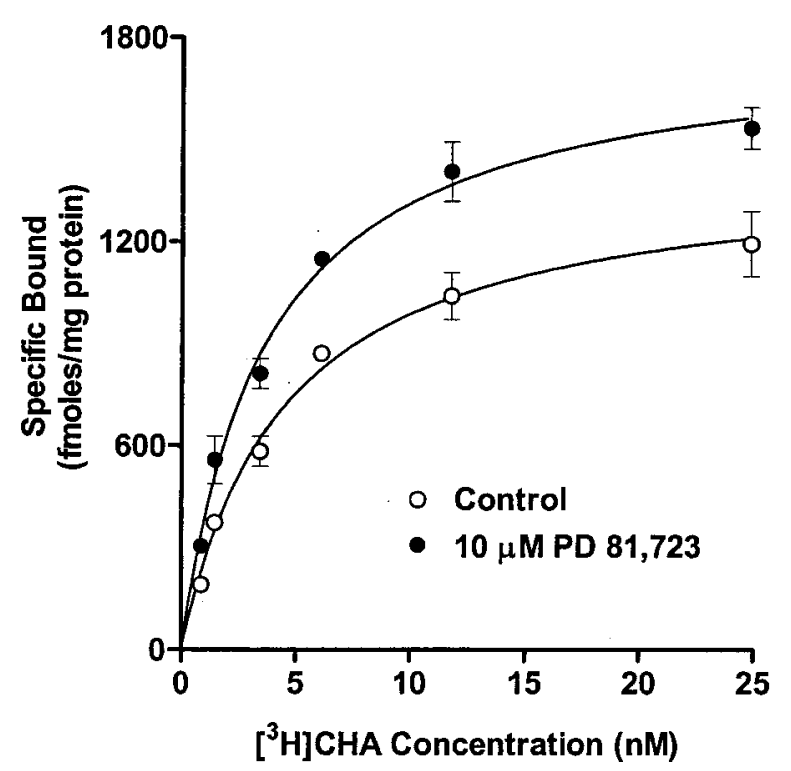

FIG 5. G protein-dependent effects of allosteric modulators. A, effects of the orthosteric agonist, carbachol $(\bigcirc)$, and allosteric modulator, alcuronium ( $\square$ ), on phosphoinositol production in CHO cells transfected with the human $\mathrm{M}_{1}$ muscarinic acetylcholine receptor. Data taken from Jakubík et al. (1996). B, effect of the allosteric modulator, PD 81,723, on the binding of the orthosteric agonist $\left[{ }^{3} \mathrm{H}\right] \mathrm{CHA}$ to adenosine $\mathrm{A}_{1}$ receptor-G protein complexes in $\mathrm{CHO}$ cells. Data taken from Kollias-Baker et al. (1997).

tire receptor pool. Interestingly, the addition of PD 81,723 resulted in a significant enhancement in the total density of binding sites recognized by $\left[{ }^{3} \mathrm{H}\right] \mathrm{CHA}$ with no change in the agonist $K_{\mathrm{D}}$ value. This finding is inconsistent with a direct allosteric effect of the modulator on agonist affinity, but is in accord with a positive allosteric effect on receptor-G protein coupling. In essence, it seemed as if PD 81,723 was able to "create" more binding sites by promot- 
fects by enhancing the affinity of the orthosteric ligand for its site on the receptor. (b) Allosteric agonists: These ligands exert their effects by promoting $\mathrm{G}$ protein coupling independent of any effects on orthosteric agonist binding. (c) Allosteric antagonists: These ligands can exert their effects by one or a combination of mechanisms; they can decrease the affinity of the receptor for its orthosteric agonist and/or decrease the affinity of the receptor for its $\mathrm{G}$ protein(s).

To be thermodynamically complete, any model of allosteric interactions between multiple ligands on the same GPCR must, thus, take into account the ability of the receptor to isomerize between multiple conformational states and to bind to $\mathrm{G}$ protein. At equilibrium, each conformational state is characterized by its own set of cooperativity factors. Even for the "simplest" case of two receptor conformations ( $R$ for inactive and $R^{*}$ for active) the resulting thermodynamic picture (Christopoulos et al., 1998) can become quite complicated; the model is shown in Fig. 6. Nevertheless, this quaternary complex model (QCM) of receptor allosterism reflects the fact that allosteric modulators of GPCRs possess a rich repertoire of behaviors that can extend beyond simple changes on orthosteric ligand binding affinities. In addition to the possible ternary complexes comprising the receptor, G protein, and either orthosteric or allosteric ligand, the model also allows for the quaternary complexes of orthosteric ligand, allosteric ligand, G protein, and receptor in both active (AR*BG) an inactive states (ARBG). Table 3 defines the constants and cooperativity factors that describe the model, whereas Table 4 lists the equations describing occupancy, potency, and response parameters of an orthosteric ligand based on the model. Table 5 shows the equations for $K_{\mathrm{App}}$, response and $\mathrm{EC}_{50}$ from the QCM under the special conditions of $[\mathrm{B}]=0$ or $[\mathrm{G}]=0$, where it can be seen that the model then becomes formally identical with the CTC model of Weiss et al. (1996a) or the allosteric two-state model of Hall (2000), respectively. Thus, both latter models are subsets of the quaternary complex model of allosterism at GPCRs.

Although a detailed examination of the properties of the QCM are beyond the scope of this review, one important aspect of the model is the ability to incorporate

\section{Detecting Allosteric Interactions}

Allosteric interactions can be quite complex and there are a number of pharmacological approaches that are best used in tandem to successfully detect and quantify such interactions at GPCRs. Allosteric phenomena can be detected using radioligand binding assays and functional tissue or cellular assays. Because many allosteric effects are often subtle and characterized by different degrees of cooperativity, screening assays will need to be optimized for detecting these particular effects, and this may entail using different conditions than would normally be used for screening orthosteric ligands.

\section{A. Assays of Radioligand Binding}

\section{Equilibrium Binding Assays. Radioligand binding} assays often provide the most direct means for visualizing allosteric behavior. For example, Fig. 7A shows the effects of the negative allosteric modulator, oleamide, on the saturation binding properties of $\left[{ }^{3} \mathrm{H}\right] 5-\mathrm{HT}$ at the $5-\mathrm{HT}_{7}$ receptor expressed in HeLa cells, whereas Fig. 7B shows the effect of the modulator gallamine on the saturation binding of $\left[{ }^{3} \mathrm{H}\right] N$-methylscopolamine at the $\mathrm{M}_{2}$ muscarinic receptor expressed in $\mathrm{CHO}$ cells. Although in each instance the modulator is able to shift the radioligand binding curves to the right, the allosteric nature of the interaction is revealed as progressively higher concentrations of antagonist fail to cause significant dextral displacements of the radioligand saturation curve. These observations are in direct contrast to what would be expected for a simple competitive interaction, where, theoretically, there would be no limit to the dextral displacement of the radioligand curve attainable in the presence of increasing antagonist concentrations. A common graphical method for assessing the relationship between radioligand saturation binding and antagonist concentration involves the determination of the affinity shift, that is, the ratio of radioligand affinity in the presence $\left(K_{\mathrm{App}}\right)$ to that obtained in the absence $\left(K_{\mathrm{A}}\right)$ of each concentration of antagonist. A plot of log (affinity shift -1 ) versus log [antagonist] should yield a straight line with a slope of 1 for a competitive interaction, but a curvilinear plot for an allosteric interaction. Such curves 


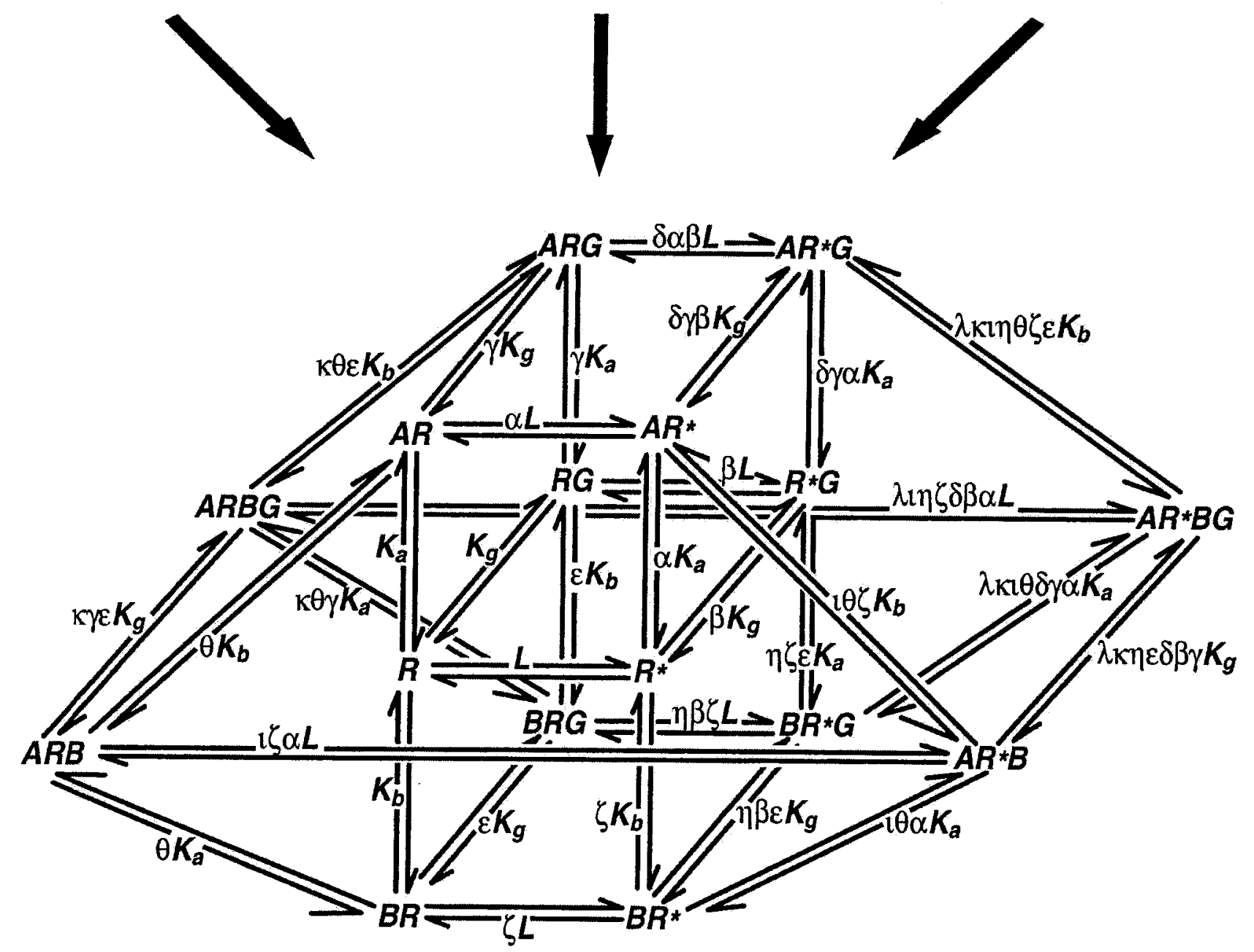

FIG 6. The quaternary complex model of allosteric interactions at GPCRs; a thermodynamically complete, extended model taking into account the concomitant binding of orthosteric ligand, A, allosteric ligand, B, and G protein, $\mathrm{G}$, on a receptor that can exist in two conformational states ( $\mathrm{R}$ and $\mathrm{R})$. The model parameters are defined in Table 3.

are evident in Fig. 7, C and D, which shows the affinity shift plots for the interaction between oleamide and $\left[{ }^{3} \mathrm{H}\right] 5$-HT or gallamine and $\left[{ }^{3} \mathrm{H}\right] N$-methylscopolamine, respectively.

2. Inhibition Binding Assays. Radioligand inhibition, or competition, binding assays are more commonly used for the routine screening of novel chemical entities than saturation binding assays, so it is quite likely that the first detection of an allosteric modulator may occur during this type of experiment. Of course, in the latter instance, the interaction cannot be called competitive; but for allosteric modulators with high degrees of negative cooperativity, the interaction may be mistaken as competitive if low degrees of radioligand occupancy are investigated. Because of this potential pitfall in interpreting inhibition binding experiments, it is useful to explore the meaning of the standard observed parameters in binding curves in terms of the simple allosteric 
Activation cooperativity of $[\mathrm{B}]$ for the unliganded receptor

Activation cooperativity between $[\mathrm{B}]$ and $[\mathrm{G}]$

Binding cooperativity between $[\mathrm{A}]$ and $[\mathrm{B}]$

Activation cooperativity between $[\mathrm{A}]$ and $[\mathrm{B}]$

Binding cooperativity between $[\mathrm{A}],[\mathrm{B}]$, and $[\mathrm{G}]$

Activation cooperativity between $[\mathrm{A}],[\mathrm{B}]$, and $[\mathrm{G}]$

model outlined above (section IIB). Thus, an inverse sigmoidal curve is predicted for an allosteric inhibition of a given amount of bound radioligand much like what is observed for a competitive antagonist. Considering only specifically bound radioligand, the signal $\left(\rho_{\mathrm{A}}\right)$ from a radioligand $[\mathrm{A}]$, in the presence of a given concentration of allosteric antagonist [B], is given by eq. 5 . Whereas a competitive ligand will decrease the bound ligand down to nonspecific binding levels, the maximal inhibition produced by an allosteric antagonist will depend upon the magnitude of the cooperativity factor, $\alpha$. The maximal scale of inhibition of specific radioligand binding is equal to

$$
\text { fractional maximal inhibition }=\frac{[\mathrm{A}]+K_{\mathrm{A}}}{[\mathrm{A}]+\frac{K_{\mathrm{A}}}{\alpha}}
$$

It can be seen from this expression that the maximum degree of antagonism of any given bound concentration of radioligand $\mathrm{A}$ is a function of $\alpha$. This is because the inhibition of a radioligand by either an allosteric ligand or a competitive (i.e., orthosteric) ligand follows the receptor occupancy of a single concentration of radioligand as the saturation binding curve to that ligand is shifted to the right by the nonradioactive ligand. This is shown in Fig. $8 \mathrm{~A}$, where the saturation curve to a radioligand is shifted to the right by a high concentration of allosteric ligand with $\alpha=0.2$. This results in a maximal shift to the right of 5-fold by the allosteric ligand. If receptor occupancy is viewed at a fixed radioligand concentration of approximately $1.5 \times$ $K_{\mathrm{A}}$ then the inhibition curve shown in the right panel of Fig. 8A is observed. It can be seen that the strength of the allosteric blockade (magnitude of $\alpha$ ), thus, determines the amount of maximal inhibition of the binding curve (see eq. 7.

The expected behavior of allosteric antagonists in inhibition binding assays outlined in the preceding paragraph the maximal inhibition of specific radioligand binding attainable by an allosteric antagonist will depend on the concentration of radioligand. Thus, it can be seen that if a radioligand concentration was chosen to be $0.01 \times K_{\mathrm{A}}$, then the antagonist shown in Fig. 8A would have taken the binding to near nonspecific binding levels. Also, if the negative cooperativity is high, for example $\alpha$ is less than 0.1 , then the dependence of the maximal displacement window on $\alpha$ becomes moot because the shift produced by the allosteric antagonist would bring the binding down to nonspecific binding levels as well (see Fig. 8B). Hence, whereas a maximal displacement above nonspecific binding levels can denote allosteric antagonism, a complete displacement to nonspecific binding levels does not necessarily implicate competitive antagonism and preclude allosteric blockade.

Another potential method to detect allosteric, as opposed to competitive, antagonism in radioligand binding studies is to examine the relationship between the amount of radioligand present in the assay (denoted $\left[\mathrm{A}^{*}\right]$ ) and the amount of antagonist required to reduce the specific binding produced by that radioligand to $50 \%$ of $\mathrm{B}_{0}$. For competitive antagonists, this can be calculated from the Gaddum (1936) equation for competitive antagonism. Thus, the receptor occupancy for a radioligand $\mathrm{A} *$ in the presence of a competitive antagonist $[\mathrm{B}]$ is given by

$$
\rho_{\mathrm{A}}=\frac{\frac{\left[\mathrm{A}^{*}\right]}{K_{\mathrm{A}}}}{\frac{\left[\mathrm{A}^{*}\right]}{K_{\mathrm{A}}}+\left(1+\frac{[\mathrm{B}]}{K_{\mathrm{B}}}\right)}
$$

where $K_{\mathrm{A}}$ and $K_{\mathrm{B}}$ are the equilibrium dissociation constants of the radioligand and competitive antagonist, respectively. From this equation, the concentration of antagonist required to reduce a defined level of specific radioligand binding to $50 \% \mathrm{~B}_{0}$ can be calculated as

$$
[\mathrm{B}] / K_{\mathrm{B}}=[\mathrm{A} *] / K_{\mathrm{A}}+1
$$

According to this relationship, therefore, the concentration of antagonist (expressed as a multiple of the $K_{\mathrm{B}}$ ) is linearly related to the concentration of radioligand present in the assay. This relationship, as defined for enzymes, is commonly referred to as the Cheng-Prusoff 


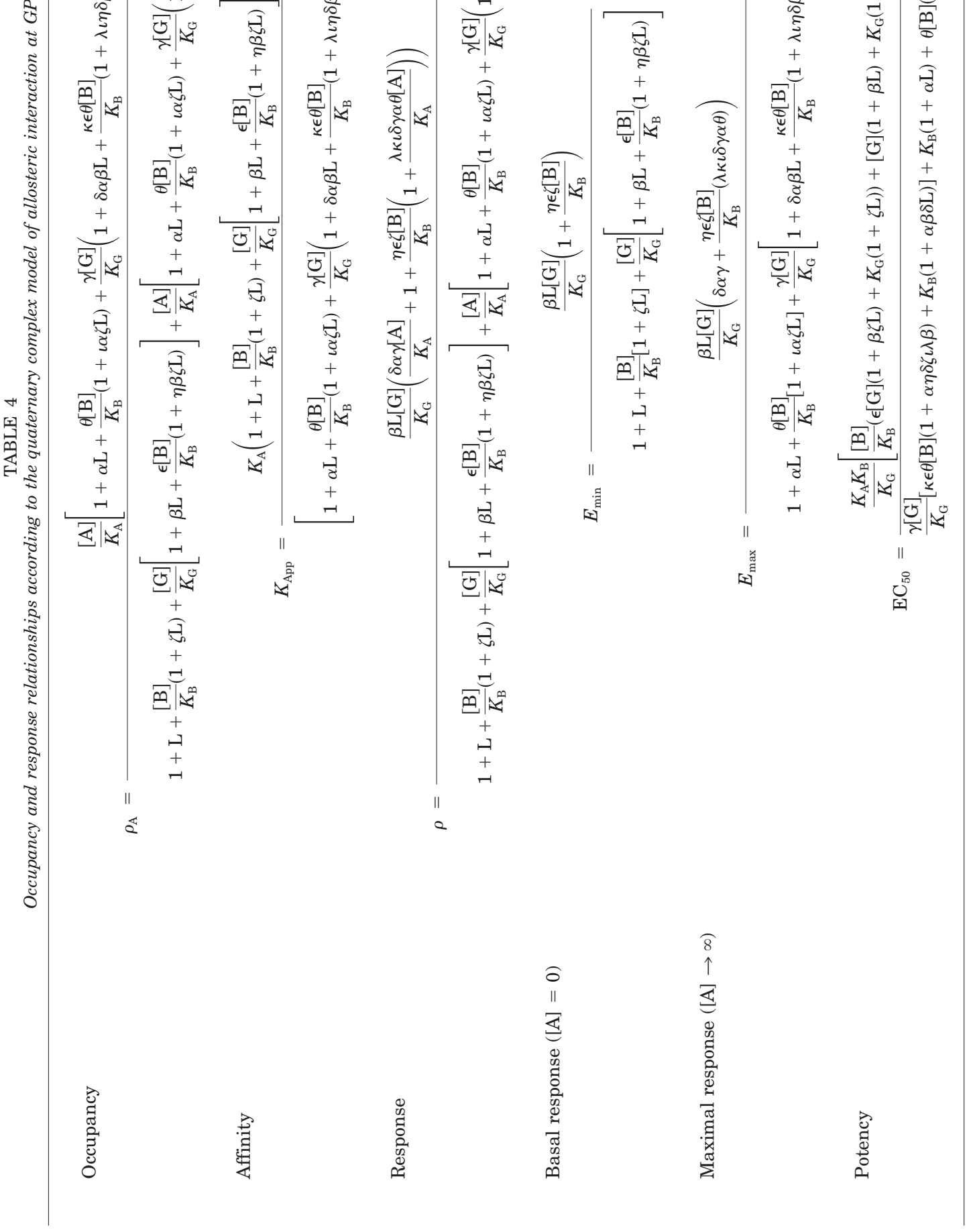




$$
\mathrm{EC}_{50}=\frac{K_{\mathrm{A}}\left[1+\mathrm{L}+\frac{[\mathrm{B}]}{K_{\mathrm{B}}}(1+\zeta \mathrm{L})\right]}{1+\alpha \mathrm{L}+\frac{\theta[\mathrm{B}]}{K_{\mathrm{B}}}(1+\alpha \zeta \mathrm{L} \mathrm{L})}
$$

${ }^{a}$ In the absence of $[\mathrm{G}]$, the expression for response is more accurately defined as the stimulus and is equal to $\left(\left[\mathrm{R}^{*}\right]+\left[\mathrm{AR}^{*}\right]+\left[\mathrm{BR}^{*}\right]+[\mathrm{AR} * \mathrm{~B}]\right) /[\mathrm{R}]_{\mathrm{T}}$.

(1973) relationship. A corresponding relationship for allosteric ligands can be also be derived

$$
\mathrm{IC}_{50}=K_{\mathrm{B}}\left[\frac{[\mathrm{A}]+K_{\mathrm{A}}}{\alpha[\mathrm{A}]+K_{\mathrm{A}}}\right]
$$

where $\mathrm{IC}_{50}$ denotes the concentration of allosteric antagonist producing 50\% inhibition of specific radioligand binding. It can be seen from this equation that if the concentration of radioligand is low (i.e., if $[\mathrm{A}] \ll K_{\mathrm{A}}$ ), then the $\mathrm{IC}_{50}$ will be approximately equal to the $K_{\mathrm{B}}$ (see also Ehlert, 1988). It can also be seen that this is not a linear relationship but rather a hyperbolic one. Thus, one way to potentially differentiate competitive and allosteric antagonism in radioligand binding assays is to compare the $\mathrm{IC}_{50}$ for blockade as a function of radioligand concentration. Figure $8 \mathrm{C}$ shows such a relationship for a competitive antagonist (linear dotted line) and a series of allosteric antagonists with $\alpha$ values ranging from 0.1 to 0.003 . It can be seen that the pronounced curvature of the relationship for the allosteric ligands differentiates them from the competitive ligand.

The variability of the extent and the direction of allosteric modulation of radioligand binding can be practically demonstrated by the effects of two different allosteric modulators of $\mathrm{M}_{2}$ muscarinic acetylcholine receptors on the same radioligand in the same membrane preparation. Figure 9A shows the interaction between the muscarinic receptor antagonist $\left[{ }^{3} \mathrm{H}\right] N$-methylscopolamine and the allosteric modulator gallamine, which is characterized by negative cooperativity. It can be seen that the use of a sub- $K_{\mathrm{A}}$ concentration of radioligand (which is quite common for these types of screening assays) results in an apparently complete inhibition of specific radioligand binding. Increasing the concentration of the radioligand to 10 times its $K_{\mathrm{A}}$, however, unmasks the limited ability of the negative allosteric modulator to inhibit specific binding. In contrast, the interaction between the same radioligand and the modulator, alcuronium, at the same receptor, is characterized by a marked positive cooperativity, clearly deviating from the predictions of simple competition (Fig. 9B). Findings such as these highlight another important aspect of allosteric interactions, that is, they are unique for each and every pair of interacting ligands involved. A positive allosteric modulator of one particular orthosteric ligand is not necessarily a positive modulator of another orthosteric ligand. Table 6 demonstrates this with examples of the interaction between alcuronium and a variety of orthosteric ligands at the $\mathrm{M}_{2}$ muscarinic acetylcholine receptor.

The preceding discussion suggests important practical considerations when screening for allosteric ligands. For instance, assays can generally use low concentrations of radioligand $\left(<K_{\mathrm{A}}\right)$ in the first instance, but these may then need to be supplemented with assays using a high radioligand concentration to demonstrate the limiting effects of cooperative interactions on the pattern of the resulting binding curve. Second, because the allosteric interaction is unique for each drug pair, it is logical that screening programs for allosteric ligands should include, at the very least, the endogenous hormone or neurotransmitter for the receptor of interest as part of the assay. Yet another important factor in radioligand binding experiments is the actual choice of radioligand. Agonist radioligands rely on the ability of the receptor to couple to $\mathrm{G}$ proteins and would be most useful in detecting allosteric modulators that are able to modify receptor-G protein coupling, whereas radiolabeled antagonists may not. In general, the design of radioligand binding assays to detect allosteric modulators should, 


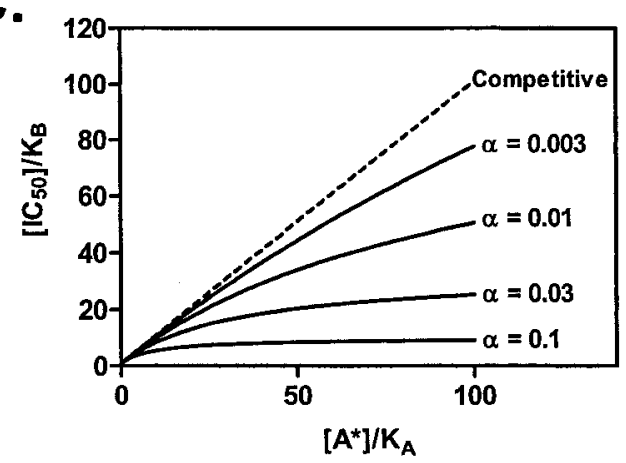

FIG 8. Inhibition of radioligand binding by allosteric antagonists. A, Saturation binding curve for a radioligand shifted to the right by a maximally effective concentration of allosteric antagonist with $\alpha=0.2$. The curve to the left of the panel shows the displacement of a defined concentration of radioligand by a range of concentrations of allosteric antagonist. Note how the displacement does not reduce the bound counts to nonspecific binding levels. B, same as A but for a more powerful allosteric antagonist $(\alpha=0.01)$. In this case, the displacement counts are reduced to nonspecific binding levels. C, the increase in the $\mathrm{IC}_{50}$ for antagonism (as a ratio of the $K_{\mathrm{B}}$ ) as a function of the amount of radioligand in the assay (as a ratio of $K_{\mathrm{A}}$ ). A linear relationship is predicted for a competitive ligand. For allosteric ligands, hyperbolic curves are generated.

teric site, subscript 2 refers to binding of $\mathrm{B}$ to the allosteric site, and the cooperativity factor, $\beta$, denotes the allosteric interaction between the two molecules of B on the receptor. From this model, the following equation can be derived describing the fractional receptor occupancy by $\mathrm{A}$ at equilibrium.

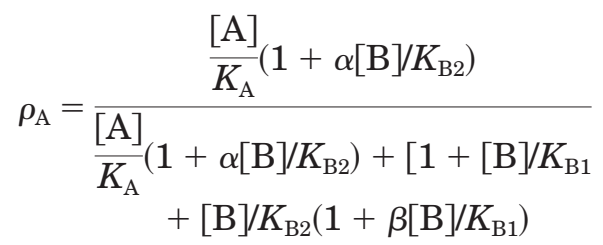

where $K_{\mathrm{A}}, K_{\mathrm{B} 1}$, and $K_{\mathrm{B} 2}$ denote equilibrium dissociation constants. eq. 11 was used to simulate the binding curves shown in Fig. 10, C and D. In Fig. 10C, the interaction between the two molecules of $\mathrm{B}$ is positively cooperative $(\beta>1)$, whereas the interaction between $\mathrm{B}$ and $\mathrm{A}$ is negatively cooperative $(\alpha<1)$. This yields a very steep inhibition curve (Hill slope of approximately 2 ), as was observed experimentally for the interaction between MIA and $\left[{ }^{3} \mathrm{H}\right]$ spiperone at the $\mathrm{D}_{2}$ receptor. In Fig. 10D, the interaction between $\mathrm{A}$ and $\mathrm{B}$ is positively cooperative $(\alpha>1)$, whereas the interaction between the two molecules of $\mathrm{B}$ is neutrally cooperative $(\beta=1)$, yielding the observed bell-shaped curve.
3. Nonequilibrium (Kinetic) Studies. The study of allosteric modulator effects on radioligand kinetic binding properties probably represents the most sensitive direct measurement of allosteric interactions at GPCRs. The rates of association and dissociation of a ligand from its binding site (be it orthosteric or allosteric) on a receptor are exponential processes. Importantly, the actual rate constants that govern the ligand association $\left(k_{\text {on }}\right)$ and dissociation $\left(k_{\text {off }}\right)$ can be determined experimentally from kinetic experiments that measure radioligand binding as a function of time, and are very sensitive indicators of the interaction of the ligand with a particular conformation of receptor. Hence, a change in receptor conformation induced by an allosteric agent would be expected to result in an alteration of orthosteric ligand association and/or dissociation characteristics. It is this alteration in orthosteric ligand kinetics that underlies the effects of allosteric modulators on orthosteric ligand affinity at equilibrium.

From the simple TCM, the association constant, $K_{\mathrm{a}}$, can be re-defined according to its respective kinetic rate constants. That is, $K_{\mathrm{a}}=k_{\text {onA }} / k_{\text {offA }}$, where $k_{\text {onA }}$ equals the association rate constant and $k_{\text {offA }}$ equals the dissociation rate constant of ligand A. In the simplest case (and, thus far, the most commonly observed experimental sit- 


\section{Log[Gallamine]}

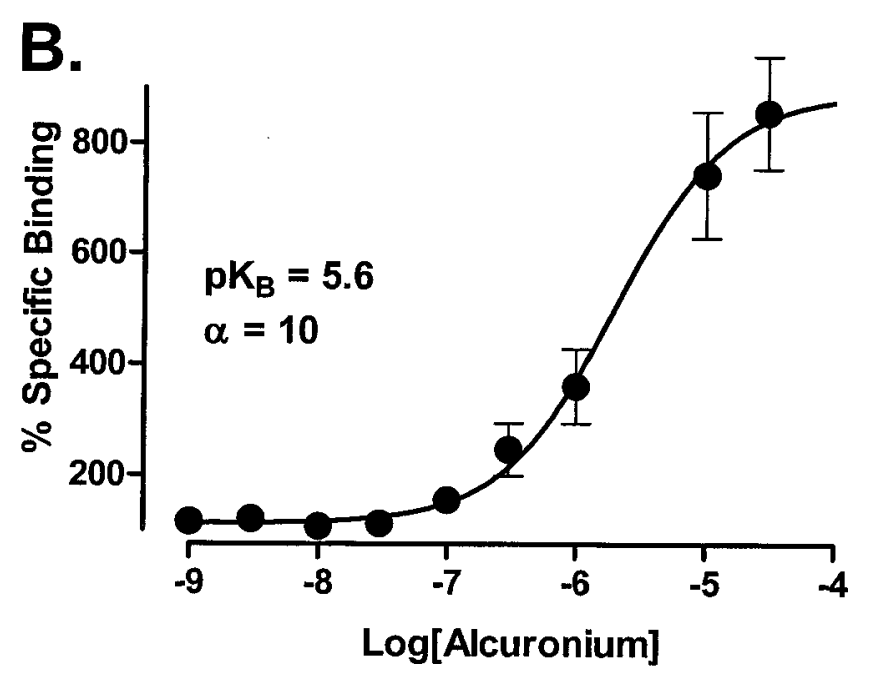

FIG 9. Effect of the allosteric modulators gallamine and alcuronium on the binding of the orthosteric antagonist, $\left[{ }^{3} \mathrm{H}\right] N$-methylscopolamine, at $M_{2}$ muscarinic acetylcholine receptors in guinea pig atrial membranes. $\mathrm{A}$, negative cooperativity between gallamine and two different concentrations of the radioligand: $0.1 \mathrm{nM}\left(\bigcirc ; 0.5 \times K_{\mathrm{A}}\right)$ and $2 \mathrm{nM}\left(-; 0 \times K_{\mathrm{A}}\right)$. B, positive cooperativity between alcuronium and $0.1 \mathrm{nM}$ radioligand. Also shown on the figure are the best estimates based on fitting the data to the allosteric model (eq. 5). Data taken from Christopoulos (2000a).

uation), the kinetics of the modulator are more rapid than those of the orthosteric ligand. Under these conditions, the rate of dissociation of an orthosteric ligand in the presence of an allosteric modulator may be derived as follows (Lazareno and Birdsall, 1995; Christopoulos, 2000b)

$$
\rho_{\text {At }}=\rho_{\mathrm{A}} \cdot \mathrm{e}^{-k_{\text {offobs }} t}
$$

where

$$
k_{\text {offobs }}=\frac{\alpha[\mathrm{B}] k_{\text {offAB }} / K_{\mathrm{B}}+k_{\text {offA }}}{1+\alpha[\mathrm{B}] / K_{\mathrm{B}}}
$$

In these two equations, $\rho_{\mathrm{At}}$ denotes the receptor occupancy by $[\mathrm{A}]$ at time $\mathrm{t}, \rho_{\mathrm{A}}$ denotes the receptor occupancy by [A] at equilibrium, $k_{\text {offobs }}$ denotes the experimentally observed dissociation rate constant for $[\mathrm{A}]$, and $k_{\text {offAB }}$ denotes the dissociation rate constant for $[\mathrm{A}]$ from the ternary complex $[\mathrm{ARB}]$. The remaining parameters are as defined previously. The association of an orthosteric ligand under similar conditions is derived as

$$
\rho_{\mathrm{At}}=\rho_{\mathrm{A}} \cdot\left(1-\mathrm{e}^{-k_{\text {onobs }} t}\right)
$$

where

$$
k_{\text {onobs }}=k_{\text {offobs }}\left[1+\frac{[\mathrm{A}]}{K_{\mathrm{App}}}\right]
$$

The parameter, $k_{\text {onobs }}$, denotes the apparent association rate constant of orthosteric ligand in the presence of allosteric modulator. $K_{\mathrm{App}}$ is defined in eq. 6 .

Allosteric modulators may increase or decrease the association and/or dissociation characteristics of the orthosteric ligand at its binding site on the receptor. Positive allosteric modulation can, thus, be manifested through an overall enhancement of orthosteric ligand association rate and/or a reduction in dissociation rate. To date, however, an enhancement of orthosteric ligand association rate has not been conclusively demonstrated for any allosteric modulators of GPCRs, although a recent study by Molderings et al. (2000) has suggested that agmatine is able to enhance the association rate and retard the dissociation rate of $\left[{ }^{3} \mathrm{H}\right]$ clonidine at the $\alpha_{2}$-adrenoceptor through an allosteric mechanism, thus, enhancing radioligand affinity at equilibrium. For negative allosteric modulators, their equilibrium effects on orthosteric ligand affinity can generally be mediated via slowing orthosteric ligand association and/or enhancing dissociation. Unfortunately, the former mechanism is experimentally difficult to distinguish from simple competitive inhibition because competition will also lead to an apparent reduction in the observed orthosteric ligand association rate. In contrast, dissociation kinetic experiments theoretically monitor only the disintegration characteristics of a preformed orthosteric ligand-receptor complex, and any changes in the observed dissociation rate are much more unambiguously attributed to 


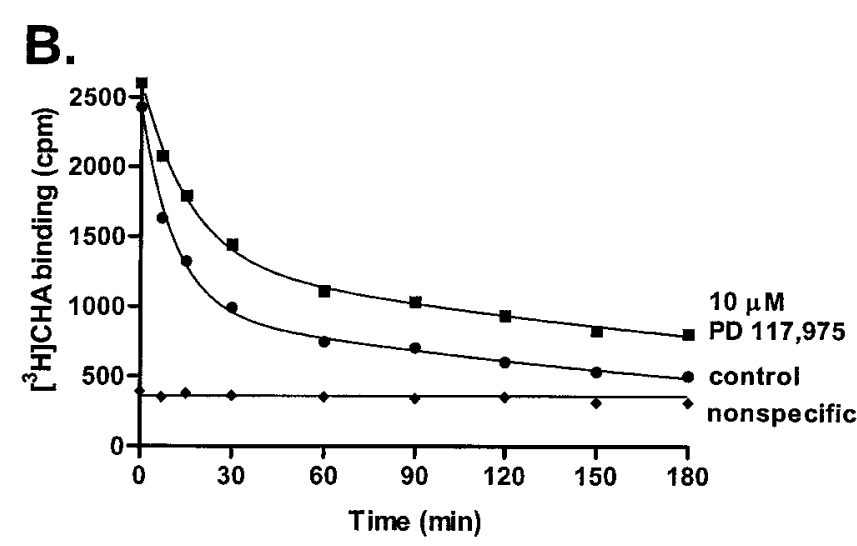

FIG 11. Effects of allosteric modulators on orthosteric ligand dissociation kinetics. A, enhancement of the dissociation rate of $\left[{ }^{3} \mathrm{H}\right]$ yohimbine from the human $\alpha_{2 \mathrm{~A}}$ receptor expressed in $\mathrm{CHO}$ cell membranes by the modulator EPA. Data taken from Leppik et al. (1998). B, slowing of the dissociation rate of $\left[{ }^{3} \mathrm{H}\right] \mathrm{CHA}$ from the adenosine $\mathrm{A}_{1}$ receptor in rat brain membranes by the modulator PD 117,975. Data taken from Bruns and Fergus (1990).

modulators of muscarinic acetylcholine receptors are known to retard the dissociation rate of orthosteric radioligands while still reducing equilibrium binding affinity (Ellis, 1997). This can most easily be reconciled in a mechanism where orthosteric ligand association is also slowed by the modulator to a greater extent than dissociation.

The quite profound effects that allosteric modulators can exert on orthosteric ligand kinetics can also lead to pitfalls in data analysis and interpretation. The most insidious effect is seen in binding experiments that are ostensibly conducted under standard "equilibrium" conditions but are, in fact, not at equilibrium due to the marked effects of the modulator on orthosteric ligand association and dissociation. This is most commonly observed with positive and neutrally cooperative ligands because their kinetic effects on the approach of the system to equilibrium occur over most concentrations of modulator that are tested, thus, increasing the likelihood of equilibrium not being achieved over the time course of a typical experiment. The consequences of this

\section{[Tetra-W84] (M)}

Fig 12. Neutral cooperativity between $\left[{ }^{3} \mathrm{H}\right] N$-methylscopolamine and the modulator, Tetra-W84 at the $\mathrm{M}_{2}$ muscarinic acetylcholine receptor. Increasing concentrations of modulator are able to decrease the rate of radioligand association and dissociation, thus, revealing the allosteric nature of the interaction (solid symbols). However, because the kinetics of the radioligand are influenced over similar concentration ranges and to similar extents, equilibrium binding studies show minimal effects on levels of radioligand binding (open circles). Data taken from Kostenis and Mohr (1996).

kinetic artifact can be modeled using eq. 14 and are shown in Fig. 13. Even after $64 \mathrm{~h}$, a positive allosteric modulator that is able to completely inhibit the dissociation of an orthosteric ligand from the ARB complex $\left(k_{\text {offAB }}=0\right)$ yields a bell-shaped binding curve. The effects of high concentrations of the modulator on the kinetics of the orthosteric ligand are so marked that equilibrium has not been achieved in the presence of the high modulator concentrations. Only after $2048 \mathrm{~h}$ (approximately 85 days) is equilibrium achieved. Experimentally, the easiest way of circumventing this problem is to prelabel the receptors with orthosteric radioligand before exposure to the allosteric agent (see Lazareno and

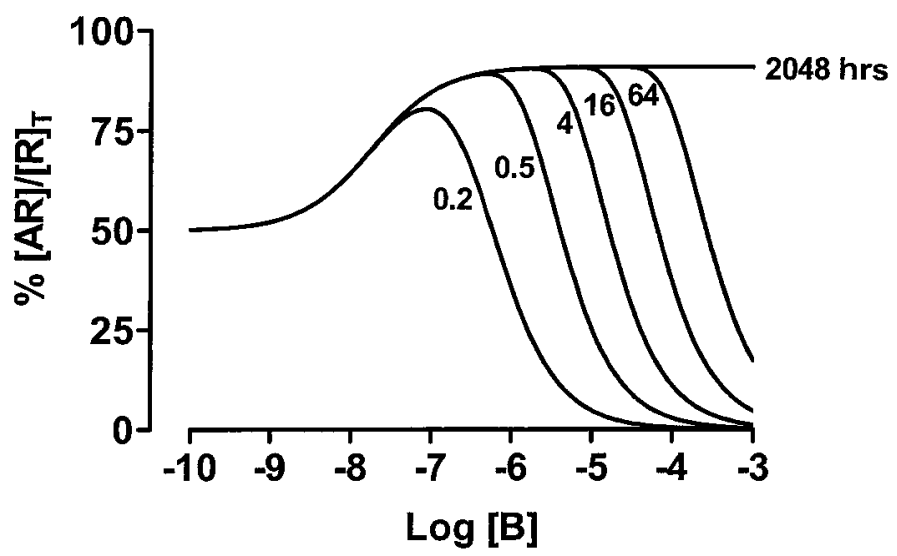

FIG 13. Allosteric modulation under nonequilibrium conditions. Orthosteric radioligand binding was simulated for a positive allosteric modulator $(\alpha=10)$ using eqs. 12 through 15 and the following parameters: $\mathrm{p} K_{\mathrm{A}}=\mathrm{p} K_{\mathrm{B}}=7, k_{\text {offA }}=0.5 \mathrm{~min}^{-1}, k_{\text {off AB }}=0 \mathrm{~min}^{-1}$, and $\log [\mathrm{A}]=-7$. The curves represent the concentration-occupancy relationship for the interaction at the different times (hours) shown in the figure. It is evident that allosteric modulators may slow the kinetics of the system to such an extent that equilibrium is unachievable during the time course of the experiment, thus, yielding complex binding curves. 
Although radioligand binding assays provide the most direct means for visualizing and quantifying allosteric interactions at GPCRs, functional assays of receptor activity can also be used. In fact, the earliest demonstrations of receptor allosterism relied on these types of assays. According to the simple TCM (Fig. 2), an allosteric modulator that affects orthosteric ligand affinity but not efficacy will displace the concentration-response curves of an orthosteric agonist in a parallel fashion with no change in basal response, maximal tissue response, or curve shape and slope. In the case of positive cooperativity, the ascription of an allosteric mechanism to the experimental data would be relatively straightforward, because the agonist curves would be displaced to the left of the control agonist curve. However, as is the case for radioligand binding assays, negative allosteric modulation may be misinterpreted as competitive antagonism, particularly for modulators with high degrees of negative cooperativity. An important key to the successful detection and quantification of negative allosteric modulation is to investigate the effects of as large a range of antagonist concentrations as is practicable. The classic approach to quantifying antagonism using this type of protocol is based on Schild analysis (Arunlakshana and Schild, 1959) and its variants.

1. Schild Analysis. Competitive antagonism follows a strict adherence to the model defined by Gaddum (1936, 1957) and quantified by Arunlakshana and Schild (1959). Thus, the effect of a competitive antagonist on the concetration-response curve to an agonist is strictly defined by the term $1+[\mathrm{B}] / K_{\mathrm{B}}$, where $[\mathrm{B}]$ is the concentration of antagonist and $K_{\mathrm{B}}$ the equilibrium dissociation constant of the receptor-antagonist complex. Under these circumstances, the dextral displacement produced (expressed as "CR", which is the equiactive concentration ratio of agonist concentrations measured in the presence and absence of antagonist) is related to $[\mathrm{B}]$ and $K_{\mathrm{B}}$ by the Schild equation (Arunlakshana and Schild, 1959).

$$
\log (\mathrm{CR}-1)=\log [\mathrm{B}]-\log K_{\mathrm{B}}
$$

The slope and linearity of the Schild regression become very useful criteria for the definition of competitive antagonism. Deviations from linearity or from a line with slope of unity can occur as a result of a number of with the maximal concentration-ratio attainable being determined by the cooperativity factor, $\alpha$. Figure 14A shows the antagonism by gallamine of the negative inotropic effects of acetylcholine at $\mathrm{M}_{2}$ muscarinic receptors in the guinea pig electrically stimulated left atrium. It can be seen that as the concentration of modulator is increased, the dextral displacement of the acetylcholine curves approaches a limit. The Schild regression of the same data are shown in Fig. 14B, where the deviation from a straight line is clearly evident. In fact, a linear regression through the data points yields an unsatisfactory fit with a slope factor of 0.65 . The appropriate fit of the allosteric model to the data can be obtained with the following equation (Ehlert, 1988).

$$
\log (\mathrm{CR}-1)=\log \left(\frac{[\mathrm{B}](1-\alpha)}{\alpha[\mathrm{B}]+K_{\mathrm{B}}}\right)
$$

As shown in Fig. 14B, eq. 17 allows an estimate to be obtained of the cooperativity factor and the dissociation constant of the modulator for the allosteric site.

Another prediction of the allosteric model directly related to the dependence of allosterism on the choice of orthosteric ligand (e.g., agonist) is the phenomenon of agonist-specific degrees of antagonism. This trait is also demonstrated by gallamine (Clark and Mitchelson, 1976; Kenakin and Boselli, 1989). Although gallamine produces dextral displacement of muscarinic agonist concentration-response curves in rat trachea, the resulting regressions are agonist-dependent (Fig. 14C), and some deviate from a slope of unity (Kenakin and Boselli, 1989). Agonist-dependent Schild regressions can also be obtained in systems with mixtures of receptors (Kenakin, 1982, 1992), but in those instances, the pattern is a set of parallel displaced Schild regressions with differing intercepts ( $\mathrm{pA}_{2}$ values). In contrast, allosteric antagonism would show the pattern in Fig. 14C, namely, little change in intercept with deviations occurring at higher concentration ratios (as saturation of the allosteric sites occurs).

2. Additivity of Concentration Ratios. As discussed previously, competitive antagonism defines a formal relationship between the concentration of the antagonist and its expected effects on agonist concentration-re- 


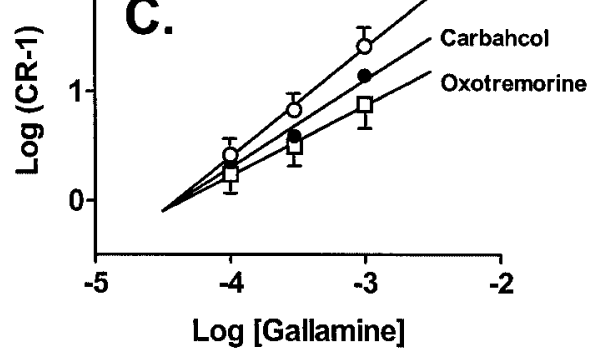

FIG 14. Schild analysis of allosteric interactions. A, effects of acetylcholine (ACh) on the electrically evoked contractions of the guinea pig left atrium in the absence $(\mathbf{\square})$ or presence of the allosteric modulator gallamine at the following concentrations: $10 \mu \mathrm{M}(\boldsymbol{\Delta}), 30 \mu \mathrm{M}(\boldsymbol{\nabla}), 100 \mu \mathrm{M}(\bullet), 300$ $\mu \mathrm{M}(\square)$, and $500 \mu \mathrm{M}(\bullet)$. All experiments were conducted in the presence of the cholinesterase inhibitor, diisopropylfluorophosphate. B, Schild plot of the data shown in A. The solid line (slope =1) denotes the behavior expected for a competitive antagonist, whereas the dashed line shows the best fit linear regression (and associated slope factor) through the points. The curve through the points and associated parameter estimates represent the fit of the allosteric model (eq. 17). Data taken from Christopoulos (2000a). C, agonist-dependence of functional allosterism. Schild regressions for gallamine as an antagonist of muscarinic agonist responses in rat trachea. Data taken from Kenakin and Boselli (1989).

sponse curves, i.e., a parallel dextral displacement with no diminution of curve maxima, and a magnitude of curve shift defined by the Schild equation. The addition of a second antagonist to a mixture of agonist and antagonist would simply produce re-equilibration of the three molecules with their respective contributions to receptor activity being defined by the ratio of their concentration and equilibrium dissociation constants (i.e., $\left[\mathrm{B}_{1}\right] / K_{\mathrm{B} 1}+\left[\mathrm{B}_{2}\right] / K_{\mathrm{B} 2}+\left[\mathrm{B}_{3}\right] / K_{\mathrm{B} 3} \ldots$ etc.). Thus, the measured effect of adding a second antagonist of known receptor potency into a system can be used to detect possible deviation from true competitivity by the two antagonists in terms of additive concentration ratios (Paton and Rang, 1965). Specifically, if two antagonists, $\mathrm{B}$ and $\mathrm{C}$, were combined and tested against an agonist, then their combined concentration-ratio $\left(\mathrm{CR}_{\mathrm{BC}}\right)$ would be given as follows for a competitive interaction.

$$
\mathrm{CR}_{\mathrm{BC}}=\mathrm{CR}_{\mathrm{B}}+\mathrm{CR}_{\mathrm{C}}-1
$$

where $\mathrm{CR}_{\mathrm{B}}$ and $\mathrm{CR}_{\mathrm{C}}$ denote the concentration ratios obtained for the agonist in the absence or presence of each respective antagonist alone. In contrast, if the antagonists were not mediating their inhibitory effects by a simple competitive mechanism through the orthosteric binding site, then $\mathrm{CR}_{\mathrm{BC}}$ would be a multiplicative, rather than additive, function of $\mathrm{CR}_{\mathrm{B}}$ and $\mathrm{CR}_{\mathrm{C}}$ (Paton and Rang, 1965). For the specific case of the allosteric TCM, the actual expression for the interaction between an agonist, a competitive antagonist (B) and an alloste- ric modulator $(\mathrm{C})$ is given as (Christopoulos and Mitchelson, 1994).

$$
\mathrm{CR}_{\mathrm{BC}}=\mathrm{CR}_{\mathrm{C}}\left[1+\left(\mathrm{CR}_{\mathrm{B}}-1\right)\left(\frac{\alpha^{\prime}[\mathrm{C}] / K_{\mathrm{C}}+1}{[\mathrm{C}] / K_{\mathrm{C}}+1}\right)\right]
$$

where $\alpha^{\prime}$ denotes the cooperativity factor for the interaction between the antagonist, B, and modulator, C. A direct consequence of the dependence of allosteric modulation on the ligand occupying the orthosteric site is that markedly greater-than-additive or less-than-additive combination concentration ratios may be observed, clearly deviating from the additivity predicted by simple competition. Figure 15A illustrates this with an example of the interaction between the muscarinic agonist carbachol, the orthosteric antagonist $N$-methylscopolamine, and the allosteric modulator alcuronium. The dashed line represents the expected shift of the carbachol curve in the presence of both $N$-methylscopolamine and alcuronium if the interaction between all ligands was competitive. This predicted shift was calculated from the individual shifts produced by either $N$-methylscoplamine or alcuronium alone. However, the actual observed shift lies much farther to the right of the predicted shift, an example of supra-additive antagonism. This finding is consistent with the known ability of alcuronium to allosterically potentiate the binding of $N$ methylscopolamine, while simultaneously reducing the binding of carbachol, thus, enhancing the overall antagonism observed. 
presence of both antagonists if all ligands were interacting in a competitive manner at the orthosteric site, based on eq. 18. B, effect of carbachol in the absence ( ) or presence $(\square)$ of the combination of the two allosteric modulators, $10 \mu \mathrm{M}$ alcuronium and $10 \mu \mathrm{M}$ heptane 1,7-bis-(dimethyl-3'pthalimidopropyl) ammonium bromide. The dashed line shows the expected location of the agonist curve in the presence of both antagonists if the inhibitors were interacting in a competitive manner at a common allosteric site, based on eq. 20. Data taken from Lanzafame et al. (1997).

Concentration-ratio analysis is not only restricted to the combination of orthosteric antagonists with allosteric modulators. The combination of two allosteric modulators against an agonist can also be studied using this approach. This is particularly useful in demonstrating whether two different allosteric modulators interact with the same allosteric site on a GPCR. In this instance, the appropriate equation is (Lanzafame et al., 1997).

$$
\mathrm{CR}_{\mathrm{BC}}=\frac{1+\frac{\alpha\left(\mathrm{CR}_{\mathrm{B}}-1\right)}{\alpha-\mathrm{CR}_{\mathrm{B}}}+\frac{\beta\left(\mathrm{CR}_{\mathrm{C}}-1\right)}{\beta-\mathrm{CR}_{\mathrm{C}}}}{1+\frac{\left(\mathrm{CR}_{\mathrm{B}}-1\right)}{\alpha-\mathrm{CR}_{\mathrm{B}}}+\frac{\left(\mathrm{CR}_{\mathrm{C}}-1\right)}{\beta-\mathrm{CR}_{\mathrm{C}}}}
$$

where $\mathrm{B}$ and $\mathrm{C}$ denote two different allosteric modulators, and $\alpha$ and $\beta$ denote their respective cooperativity factors for interaction with the agonist. Figure 15B illustrates the interaction between carbachol and the two modulators, alcuronium and heptane 1,7-bis-(dimethyl3 '-pthalimidopropyl) ammonium bromide, at atrial muscarinic receptors. The excellent agreement between the observed carbachol curve in the presence of both modulators and the predicted curve based on eq. 20 is in accordance with both modulators interacting with the same allosteric site on the $\mathrm{M}_{2}$ muscarinic receptor.

3. Pharmacological Resultant Analysis. Although the additivity-of-concentration-ratio approach described above is obviously useful in detecting allosterism, a potentially significant shortcoming of this procedure is the required tacit assumption that neither antagonist has a secondary property that modifies the system sensitivity. A powerful tool to measure the additive effects of antagonists that does not have this handicap is pharmacological "resultant analysis" (Black et al., 1986). This technique compares the effect of a "test" antagonist on the observed antagonism produced by a "reference" antago- therefore, deviations from these requirements may indicate allosterism in the actions of the test antagonist.

The response $\left(\mathrm{E}^{\prime}\right)$ to an agonist in the combined presence of a test antagonist [C] and reference antagonist [B] is given by

$$
\mathrm{E}^{\prime}=f\left(\frac{\left[\mathrm{A}^{\prime}\right]}{[\mathrm{A}]+K_{\mathrm{A}}\left[1+\frac{\left[\mathrm{B}^{\prime}\right]}{K_{\mathrm{B}}}+\frac{[\mathrm{C}]}{K_{\mathrm{C}}}\right]}\right)
$$

where $[\mathrm{A}]$ refers to the concentration of agonist in the absence of reference antagonist, $\left[\mathrm{A}^{\prime}\right]$ refers to the concentration of agonist in the presence of reference antagonist, [B'] refers to the concentration of reference antagonist in the presence of test antagonist ([C]), and $K_{\mathrm{A}}, K_{\mathrm{B}}$, and $K_{\mathrm{C}}$ refer to the respective equilibrium dissociation constants of the receptor and molecules A, B, and C. The response in the absence of reference antagonist (denoted as $\mathrm{E}$ ) is given by eq. 21 with $[\mathrm{C}]=0$. Comparison of equiactive concentrations $\left(\mathrm{E}=\mathrm{E}^{\prime}\right)$ with the reference antagonist present and not present is given by

$$
\frac{\left[\mathrm{A}^{\prime}\right]}{[\mathrm{A}]}=r=1+\frac{\left[\mathrm{B}^{\prime}\right]}{K_{\mathrm{B}}\left(1+\frac{[\mathrm{C}]}{K_{\mathrm{C}}}\right)}
$$

A ratio, $r$, can be defined for equiactive agonist doses in the absence of test antagonist by setting $[\mathrm{C}]=0$ in eq. 22. Comparing equal levels of antagonism (in essence measuring the dextral displacement of Schild regressions along the test antagonist axis at a constant level of antagonism) leads to the expression of equiactive (from the point of view of equal levels of antagonism) concentrations of the reference antagonist in the absence ([B]) and presence $\left(\left[\mathrm{B}^{\prime}\right]\right)$ of test antagonist.

$$
\frac{\left[\mathrm{B}^{\prime}\right]}{[\mathrm{B}]}-1=\phi=\frac{[\mathrm{C}]}{K_{\mathrm{C}}}
$$

The logarithmic metameter of eq. 23 is

$$
\log (\phi-1)=\log [\mathrm{C}]-\log K_{\mathrm{C}}
$$


model. However, the theoretical underpinnings of the procedure can readily be modified to incorporate an allosteric model (Christopoulos and Mitchelson, 1997), leading to the following variant of eq. 24 .

$$
\log (\alpha-1)=\frac{[\mathrm{C}](1-\alpha)}{K_{\mathrm{C}}+\alpha[\mathrm{C}]}
$$

Thus, the methodology behind pharmacological resultant analysis allows for both the detection of allosteric interactions between two antagonists in a functional tissue assay and for the derivation of quantitative parameters describing the interaction.

\section{Potential Pitfalls}

Because allosteric interactions are noncompetitive in nature, they can be manifested in a variety of ways and are usually first detected when the researcher notes a deviation of their experimental data from the expectations of simple (competitive) mass-action kinetics. However, similar findings may also be made due to other
Due to the dependence of allosteric phenomena on the nature of the ligand occupying the orthosteric site, radioligand binding assays can yield quite different results even if the same modulator is studied at the same receptor. As discussed previously, factors such as radioligand choice, concentration, and equilibration time can have profound effects on the detection, or lack thereof, of allosteric phenomena. Even the concentration of membrane-bound receptors can have a significant impact on the detection of allosterism in binding assays, particularly when dissociation kinetic assays are used. In particular, some discussion is warranted about the most significant kind of experimental artifact in kinetic assays that is related to receptor concentration, namely the phenomenon of binding at the "collisional limit".

When the density of receptors exceeds 5,000 to 10,000 sites per cell, the probability of a dissociated molecule of ligand diffusing away into the bulk medium according to simple bimolecular mass-action kinetics is significantly decreased to the point that re-binding to adjacent recep-

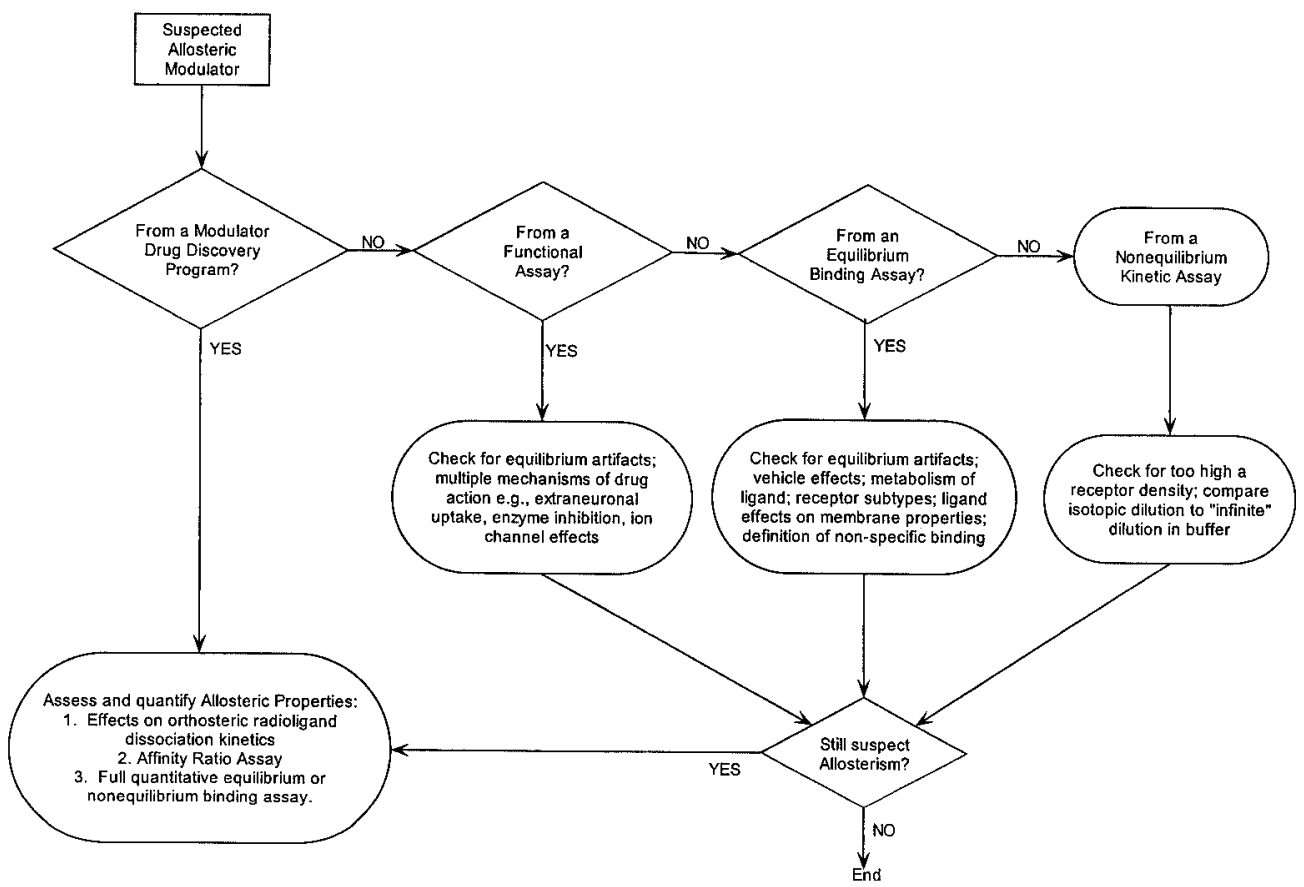

FIG 16. Flow chart strategy for dealing with compounds identified as potential allosteric modulators. Adapted from Christopoulos (2000b). 
instance, the dissociation rate will seem slower than in the latter, because the presence of a vast excess of unlabeled orthosteric ligand used for isotopic dilution will minimize the collision-limited re-binding of radioligand to the receptor. In general, claims of cooperative binding based on dissociation kinetic experiments using highly expressed or concentrated receptor preparations need to be viewed with caution due to the increased likelihood of collision-limited binding.

In terms of functional assays of allosterism, some methodological pitfalls that can mistakenly lead to claims of allosteric phenomena include inadequate equilibration times, heterogeneous receptor populations, or nonequilibrium steady states (Kenakin, 1997c). In particular, saturable agonist removal mechanisms (e.g., extraneuronal uptake and enzymatic breakdown) can have profound effects on agonist potency; a cancellation of these removal processes by a second ligand can enhance agonist potency and, thus, lead to the (false) claim of "positive allosteric modulation" by the second drug.

An even more insidious problem in the interpretation of allosteric phenomena from functional studies relates to the nature of the conformational change in receptor structure that the allosteric modulator produces. In addition to allosteric effects on orthosteric ligand affinity, the functional quantification of allosteric interactions using the ternary complex model is prone to the impact of possible allosteric effects on stimulus-response coupling. In the most obvious cases, this can be manifested as an observed response to the allosteric modulator in the absence of agonist. However, more subtle effects may not be detected, such as those where the modulator alters efficacy to affect the location of the concentrationresponse curve but not the maximal attainable agonist response or curve shape (Christopoulos, 2000a). As described previously by Ehlert (1988), the maximal concentration-ratio to which an allosteric antagonist's Schild regression asymptotes is given by the product of the cooperativity factor, $\alpha$, and the degree by which the efficacy of the receptor in the ternary complex, ARB, is altered by the modulator. Unless the modulator has no effect on signaling efficiency, the value of $\alpha$ may be erroneously determined from Schild analysis. drugs is inexorably linked to the magnitude of effect. For a long duration of effect, a high concentration of the competitive drug must be present to function as a depot. However, this high concentration will also produce a commensurately high magnitude of effect. In practice, there must always be a trade-off between the dose of competitive ligand that can be administered safely and the desired concentration reaching the receptor compartment. As a consequence, the desired steady-state of antagonism may not be achieved at the site of action due to the interplay between dosage regimen, safety profile, and pharmacokinetics. This codependence of kinetics and effects, however, is not relevant to allosteric drugs. In the latter instance, a very high concentration of allosteric ligand would serve as a depot for binding to the allosteric site but the maximal effect will be defined by the cooperativity factor for the ligand, namely the maximal degree of perturbation to the receptor produced by the allosteric ligand. As a consequence, allosteric modulators would be generally much safer in overdosage than orthosteric ligands, and they can be given in quite high doses if necessary to maintain adequate receptor concentrations without fear of overstimulating or overinhibiting receptor function.

A second advantage of positive allosteric modulators relates to their ability to selectively "tune" tissue responses in those organs where the endogenous agonist exerts its physiological effects (Birdsall et al., 1996). Because neurohumoral signaling involves the pulsatile release of hormones and variations in the activity of nerves that release neurotransmitters, an allosteric modulator would only be expected to exert its effects when endogenous agonist is present. For example, the actions of benzodiazepines, which potentiate the effects of the endogenous neurotransmitter $\gamma$-aminobutyric acid, depend only on the presence of the neurotransmitter for activity (Holzgrabe and Mohr, 1998). If nerve activity is reduced, an allosteric modulator would, thus, have minimal effects, despite its continued presence in the receptor compartment. This is not possible with orthosteric agonists, which will continuously modify receptor function as long as they are present. Thus, allosteric modulators can process the information gained from the 
neuronal function, with one consequence often being a decline in receptor-neurotransmitter responsiveness. Standard neurotransmitter replacement therapies target the orthosteric site; this is a specific example of concentration augmentation, where the concentration of agonist is increased to overcome the deficit associated with the neurodegenerative disorder. However, each individual neuron will have its own stimulus-response coupling profile that can differ from adjacent neurons, even though they each express the same receptor type. Thus, the augmentation approach can result in overstimulation of some neurons and understimulation of others. In contrast, the addition of an allosteric modulator that uniformly sensitizes the system by a given factor (i.e., $\alpha$ value) will result in response enhancement for the same concentration of endogenous neurotransmitter present at each neuron; no augmentation is required, and the resulting levels of neurotransmitter responsiveness can be corrected more closely toward normal levels.

Finally, allosteric ligands offer the possibility of "absolute subtype selectivity" in receptor action by one (or both) of two mechanisms. The first relates to the fact that allosteric sites are necessarily different from orthosteric sites, and it is, thus, quite conceivable that many receptors may show a greater divergence in sequence homology in the domains that define the allosteric site in contrast to the orthosteric site. In essence, the entire receptor surface (other than the orthosteric binding domain) becomes a potential binding site for an allosteric modulator. The likelihood of subtype-selectivity is, therefore, enhanced if drug discovery programs target receptor allosteric sites. The second mechanism for selectivity is related to cooperativity rather than affinity. Because the affinity of a modulator for its binding site is not correlated with the degree of cooperativity that exists between orthosteric and allosteric sites, a modulator may display the same affinity for each subtype of a receptor but still exert a selective effect by having different degrees of cooperativity at each subtype. Absolute subtype selectivity may, thus, be obtained where a modulator remains neutrally cooperative at all receptor subtypes except the one targeted for therapeutic purposes. Table 7 shows data obtained for the allosteric modula- acetylcholine. Although the affinity for the allosteric site at each receptor subtype was within a 5 -fold range of values for $\mathrm{N}$-chloromethylbrucine, the cooperativity factors were quite different. This compound was positively cooperative with acetylcholine at the $\mathrm{M}_{3}$ receptor, negatively cooperative at the $\mathrm{M}_{1}$ and $\mathrm{M}_{2}$ receptors, and effectively neutrally cooperative at the $\mathrm{M}_{4}$ receptor. Thus, some degree of absolute selectivity had been achieved.

It may of course be argued that the relative paucity of currently available allosteric modulators of GPCRs attests to the difficulty in actually realizing the theoretical advantages outlined in the preceding paragraphs. However, this paucity can also reflect the fact that most drug discovery to date has been biased toward orthosteric ligands (see section I). GPCRs react to an incredibly wide range of endogenous ligands, from small entities such as acetylcholine (muscarinic receptors) to large proteins such as stromal derived factor (SDF-CXCR4 chemokine receptors). The likelihood that allosteric conformational changes mediate the transfer of information between GPCRs and these ligands is, thus, quite high. In fact, it can also be argued that allosteric mechanisms are prevalent in the action of many small "drug-like" molecules (i.e., molecules of a low enough molecular weight amenable to absorption by the oral route of administration) that modify protein-protein interactions. For example, M-tropic HIV is known to form syncytia with cells (to produce subsequent viral infection) through the interaction of the viral coat protein gp120, the cellular single transmembrane protein CD4, and the chemokine GPCR CCR5. Mutational studies have shown that all four extracellular domains of the CCR5 receptor (blockade of which is not amenable to orthosteric interference by a small single structure), interact with viral coat protein to promote fusion (Rucker et al., 1996; Doms and Peiper, 1997; Doranz et al., 1997; Picard et al., 1997; Lee et al., 1999). Single-point mutations of CCR5 have been unsuccessful in preventing HIV-1 fusion, also indicating the involvement of multiple receptor domains in HIV-1 binding (Doranz et al., 1997). Experiments with chimeric CCR-5 have shown that the regions of the receptor that interact with the endogenous chemokine agonist MIP-1 $\alpha$ (macrophage inflammatory protein type 
779 (Baba et al., 1999). From these data it can be concluded that small molecules can effectively inhibit the interaction of large proteins through allosteric mechanisms and that this can be a viable avenue for therapeutic involvement.

The simplest hypothesis to explain how small structures can affect the binding of such huge protein domains is by the stabilization of receptor conformations that do not support viral entry. In terms of free energy, a mechanism of conformational selection (whereby a ligand selectively binds to a pre-existing receptor conformation thereby creating a bias toward that conformation) is preferable to a mechanism of conformational induction (where the ligand actually creates the conformation through binding). Differential affinities for different protein conformations will lead to enrichment of the species for which the ligand has the highest affinity. For example, assume a system of two receptor conformations $\mathrm{R}$ and $\mathrm{R}^{*}$ that coexist in the system according to an isomerization constant denoted L (Fig. 2). For a ligand with a differentially greater affinity for the $\mathrm{R}^{*}$ form, introduction of $[\mathrm{A}]$ into the system will result in an enrichment of the $R^{*}$ form. This can be shown by examining the amount of $R^{*}$ species (both as $R^{*}$ and $A R^{*}$ ) present in the system in the absence of ligand and in the presence of ligand. The equilibrium expression for ([R*] $\left.+\left[\mathrm{AR}^{*}\right]\right) /[\mathrm{R}]$, where $[\mathrm{R}]$ is the total receptor concentration given by the conservation equation $[R]=[R]+[A R]$ $+\left[\mathrm{R}^{*}\right]+\left[\mathrm{AR}^{*}\right]$, is

$$
\rho=\frac{\mathrm{L}\left(1+\frac{\alpha[\mathrm{A}]}{K_{\mathrm{A}}}\right)}{\frac{[\mathrm{A}]}{K_{\mathrm{A}}}(1+\alpha \mathrm{L})+1+\mathrm{L}}
$$

In the absence of agonist $([\mathrm{A}]=0), \rho_{0}=\mathrm{L} /(1+\mathrm{L})$, and in the presence of a maximal concentration of ligand (saturating the receptors; $[\mathrm{A}] \rightarrow \infty) \rho_{\infty}=(\alpha \mathrm{L}) /(1+\alpha \mathrm{L})$. The effect of the ligand presence on the ratio of $R$ to $R^{*}$ is given by $\rho_{\infty} / \rho_{0}$.

$$
\frac{\rho_{\infty}}{\rho_{0}}=\frac{\alpha(1+\mathrm{L})}{(1+\alpha \mathrm{L})}
$$

action of CCR5 with gp 120 viral coat protein. This, in turn, would allow TAK 779 to prevent HIV-1 infection.

An alternative hypothesis can be described in which the binding of the ligand actually deforms the receptor to cause the formation of a new receptor conformation (i.e., conformational induction; see Burgen, 1981). It should be noted that thermodynamically this is a much less acceptable mechanism than conformational selection where the conformation $R^{*}$ is already one of a library of conformations known to the receptor. However, it should also be pointed out that the enrichment of a rarely formed spontaneously formed conformation through conformational selection would be virtually indistinguishable as a mechanism from conformational induction (Kenakin, 1996b). In any case, the ever-expanding list of small drug molecules that interfere with large receptor-protein interactions suggests that clinically relevant allosteric modulators of GPCRs are viable and likely drug candidates; positive modulators of the extracellular calcium-sensing GPCR, for instance, are already in clinical trials (Conigrave et al., 2000a).

\section{Location of the Allosteric Site(s)}

\section{A. Locks and Keys}

In contrast to studies on ion channel-linked receptors, there is a relative paucity of detailed structural information regarding the amino acid composition of allosteric sites on various GPCRs. Part of the difficulty relates to the lack of sufficiently high-resolution crystallographic data of GPCR structure for molecular modeling purposes, although the recent publication of the X-ray crystal structure of rhodopsin at 2.8-Å resolution (Palczewski et al., 2000) may begin to redress this problem. Another difficulty is related to the fact that GPCRs display a remarkable diversity with respect to regions of the receptor protein that constitute the primary, orthosteric domain; there is no common orthosteric "lock" for agonist "keys" in GPCRs (Schwartz and Rosenkilde, 1996). Figure 17 illustrates some of the general modes of ligand binding for the three main classes of the GPCRs. Endogenous orthosteric agonists can bind within the transmembrane (TM) regions (e.g., class I bioamine receptors), bind to both TM and extracellular loop regions (e.g., class I neuropeptide recep- 
allosteric nature of the zinc effect on $\mathrm{D}_{1}$ and $\mathrm{D}_{2}$ receptors, where it can be seen that increasing concentrations of zinc progressively reduce antagonist binding affinity with no change in the $B_{\max }$ of the radioligand (Fig. 18, A and $\mathrm{C})$. Furthermore, the zinc-mediated reduction in radioligand affinity approaches a limit over the concentration ranges of modulator that were tested, thus, revealing the negatively cooperative nature of the interaction (Fig. 18, B and D). Importantly, recent studies on the $\mathrm{D}_{4}$ dopamine receptor have demonstrated that the effects of sodium, zinc, and the allosteric modulator MIA occur through distinct attachment points (Schetz and Sibley, 2001). Specifically, sodium was able to allosterically modulate the effects of zinc on antagonist binding, whereas neither zinc nor sodium interacted with MIA. However, a receptor mutation that modified the binding properties of MIA had no effect on zinc. Thus, in addition polyanionic compounds that are well known for sharing the common property of interacting with the predominantly cationic face of the amphipathic helical regions of the GPCR-G protein interface. In particular, the polysulfonic acid suramin has been extensively studied in radioligand binding and signal transduction assays. As well as acting as an orthosteric antagonist of purinergic receptors (Ralevic and Burnstock, 1998), suramin has been shown to uncouple opioid receptors (Butler et al., 1988), $\alpha_{2^{-}}$and $\beta_{2^{2}}$-adrenoceptors (Huang et al., 1990), and adenosine $A_{1}$ and dopamine $D_{2}$ receptors (Freissmuth et al., 1996) from their cognate G proteins. In addition, these effects are associated with an inhibition of agonist binding, whereas antagonist binding remains unaffected (Huang et al., 1990) or is enhanced (Freissmuth et al., 1996). Interestingly, the effects of suramin and a number of its analogs on orthosteric ligand bind-
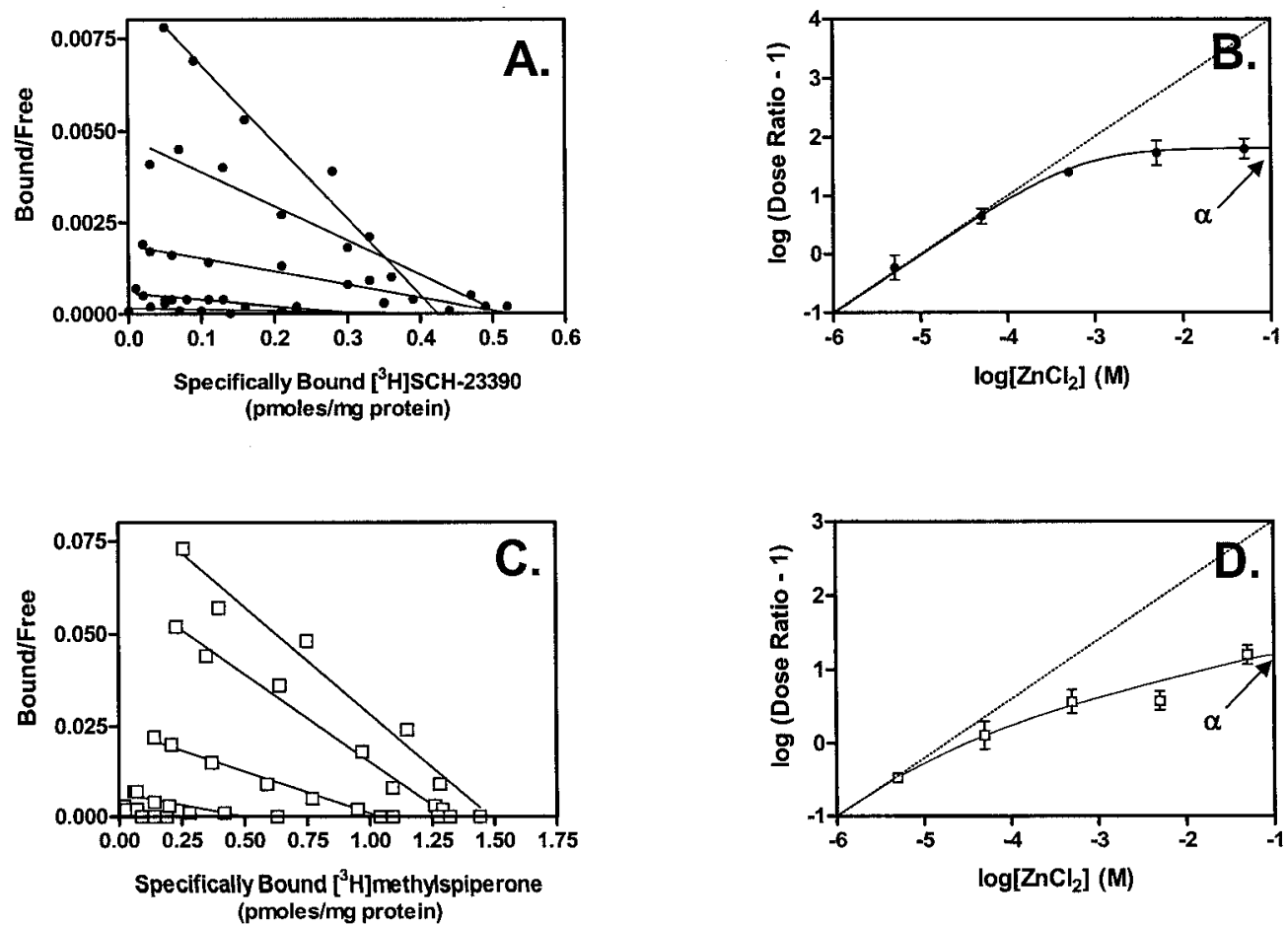

FIG 18. Saturation binding of $\left[{ }^{3} \mathrm{H}\right] \mathrm{SCH}-23390$ at the $\mathrm{D}_{1 \mathrm{~A}}$ dopamine receptor $(\mathrm{A})$ or $\left[{ }^{3} \mathrm{H}\right]$ methylspiperone at the $\mathrm{D}_{2}$ dopamine receptor $(\mathrm{C})$ in the absence or presence of increasing concentrations of $\mathrm{ZnCl}_{2}(5 \mu \mathrm{M}-50 \mathrm{mM})$. Data in $\mathrm{B}$ and $\mathrm{D}$ show the data in A and C, respectively, converted to Schild-type plots. Note the deviation from linearity at high zinc concentrations; the maximal dose-ratio is defined by the cooperativity factor, $\alpha$. Data taken from Schetz and Sibley (1997). 
receptors suggests that the interaction between these modulators and the receptor's orthosteric site, if it exists, must be neutrally cooperative in nature and only manifested indirectly through receptor-G protein coupling block. Furthermore, it is known that suramin can actually bind to a distinct site on $\mathrm{G}$ protein $\alpha$-subunits in the absence of any receptor coupling to modify nucleotide binding properties (Beindl et al., 1996). Thus, it is possible that the allosteric effects of polyanionic modulators such as suramin are mediated predominantly through their effects on $\mathrm{G}$ protein contact points.

\section{Extracellular Allosteric Sites}

In comparison with compounds that require access to an intracellular site of action, small molecule allosteric modulators that can target extracellular binding sites on a GPCR are particularly attractive targets in terms of drug discovery and therapeutics. Studies of extracellular binding domains of allosteric modulators have generally exploited receptor mutagenesis and/or the construction of receptor chimeras. It should be noted, however, that these approaches are most useful when undertaken in light of experimental evidence indicating the presence of a distinct allosteric binding site on the receptor that can be recognized by more than one type of allosteric modulator. This is not a trivial point, because many ligands have the ability to nonspecifically perturb receptor conformation, for instance through effects on the surrounding lipid bilayer, and, thus, be mistakenly labeled as "allosteric modulators".

To date, investigations on the localization of an extracellular allosteric site for small molecules and drugs at class I GPCRs have been predominantly focused on studies of the muscarinic acetylcholine receptor family. This is in no small part due to strong evidence in favor of a distinct and common allosteric site recognized by more than one type of modulator. For example, Fig. 19A shows the interaction between the allosteric modulators gallamine or TMB-8 and the modulator, obidoxime, at the $\mathrm{M}_{2}$ muscarinic acetylcholine receptor. Under the experimental conditions of the assay, gallamine allosterically enhances the observed dissociation rate of the orthosteric antagonist, $\left[{ }^{3} \mathrm{H}\right]$ quinuclidinyl benzilate $\left(\left[{ }^{3} \mathrm{H}\right] \mathrm{QNB}\right)$, TMB-8 reduces $\left[{ }^{3} \mathrm{H}\right] \mathrm{QNB}$ dissociation, whereas obi- log [gallamine or TMB-8 or obidoxime]

B.

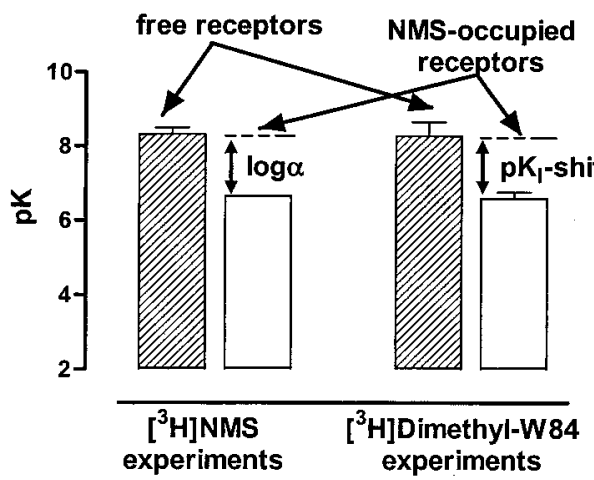

FIg 19. A, reversibility of the allosteric effects of gallamine or TMB-8 by obidoxime at the human $\mathrm{M}_{2}$ muscarinic acetylcholine receptor. Data are expressed as the ratio of the apparent $\left[{ }^{3} \mathrm{H}\right] \mathrm{QNB}$ dissociation rate in the presence $\left(k_{\mathrm{obs}}\right)$ and absence $\left(k_{0}\right)$ of allosteric modulator. Note that the accelearting effects of gallamine and the retarding effects of TMB-8 on radioligand dissociation are equally inhibited by obidoxime. The entire dataset was fitted to a model assuming competition between the three modulators for a common allosteric site. Data taken from Ellis and Seidenberg (2000). B, Binding properties of the modulator, gallamine, at the $\mathrm{M}_{2}$ muscarinic receptor as determined either indirectly, using $\left[{ }^{3} \mathrm{H}\right] \mathrm{NMS}$ to label the orthosteric site, or directly, using $\left[{ }^{3} \mathrm{H}\right]$ dimethyl-W84 to label the allosteric site. The ratio of gallamine affinities between the free and NMS-occupied receptor corresponds to the cooperativity factor, $\alpha$, in the simple allosteric ternary complex model when fitted to the $\left[{ }^{3} \mathrm{H}\right] N M S$ binding data. Labeling of the allosteric site with $\left[{ }^{3} \mathrm{H}\right]$ dimethylW84 to directly determine gallamine affinity at this site reveals an affinity shift ( $\mathrm{pK}_{\mathrm{I}}$ shift) of gallamine for the free versus the NMS-occupied receptor that is identical with the cooperativity factor determined from the $\left[{ }^{3} \mathrm{H}\right] \mathrm{NMS}$ experiments. The value of $\mathrm{pK}$ is defined as the negative logarithm of the apparent dissociation constant. Data taken from Tränkle et al. (1999).

doxime has a minimal effect. However, when the allosteric effects of gallamine or TMB-8 are monitored in the presence of obidoxime, a concentration-dependent reversal of these effects is noted. Importantly, the entire dataset could be fitted to a model assuming competition between all three modulators for a single allosteric site (Ellis and Seidenberg, 2000). Even more direct evidence for the presence of a specific allosteric site on muscarinic receptors has been facilitated by the synthesis of the 
equilibrium binding, dissociation kinetics, and functional bioassays have also yielded data with respect to a large range of muscarinic allosteric modulators that are in accord with interaction at a common site (for review, see Christopoulos et al., 1998). It should be noted that similar approaches have also been used, although to a more limited extent, to demonstrate the existence of a common allosteric site for multiple modulators on dopamine $\mathrm{D}_{2}$ receptors (Hoare and Strange, 1996), $\alpha_{1}$-adrenoceptors (Leppik et al., 2000), and $\alpha_{2}$-adrenoceptors (Leppik et al., 1998; Leppik and Birdsall, 2000).

The types of observations outlined above have provided impetus for detailed studies on the location of the muscarinic acetylcholine receptor allosteric site. In particular, gallamine has been used in almost all such studies as the prototypical muscarinic allosteric modulator, and experiments aimed at delineating the location of the allosteric site on muscarinic receptors have targeted residues thought to be involved in the binding of this modulator. The known abilities of gallamine to i) impede access to and egress from the orthosteric binding site (Birdsall et al., 1996), ii) protect the orthosteric site from chemical modifications (Jakubík and Tucek, 1994), and iii) rapidly produce allosteric effects in intact cells and whole tissues (Christopoulos et al., 1998) suggest that the allosteric site comprises extracellular contact points located above the orthosteric site, which is itself postulated to be located in the upper one-third of the inner transmembrane pore (Wess, 1993). In general, molecular biological approaches have either focused on regions conserved across the five muscarinic receptor subtypes or specifically focused on nonconserved residues; each of these approaches has its own advantages. For instance mutagenesis of conserved amino acids can yield information about allosteric site(s) common to all muscarinic receptors, whereas studies on nonconserved amino acids can provide insight into subtype-selective allosteric modulators.

In one of the earliest mutagenesis studies on muscarinic receptor allosteric sites, Lee et al. (1992) modified a series of conserved aspartate residues in the $M_{1}$ receptor and found that substitution of $\mathrm{Asp}^{71} \rightarrow \mathrm{Asn}$ decreased the affinity of gallamine for the receptor, and the magnitude of its cooperativity with $\left[{ }^{3} \mathrm{H}\right] \mathrm{NMS}$. Substituting play a role in gallamine's binding. More significantly, however, a mutation of the EDGE sequence $\left(\mathrm{Glu}^{172}\right.$ $\mathrm{Asp}^{173}$-Gly ${ }^{174}-\mathrm{Glu}^{175}$ ) in the second extracellular loop led to marked alterations in gallamine's ability to allosterically modulate $\left[{ }^{3} \mathrm{H}\right] \mathrm{NMS}$ binding (Leppik et al., 1994). This particular sequence of amino acids is unique to the $\mathrm{M}_{2}$ receptor, although it should be noted that every muscarinic receptor subtype, except for the $M_{1}$ receptor, has at least one acidic amino acid in the corresponding region (Ellis, 1997). Furthermore, substitution of the EDGE sequence into the second extracellular loop of the $M_{1}$ receptor conferred significantly higher affinity of gallamine for that receptor, thus, confirming that the allosteric site on muscarinic receptors requires specific extracellular contact points and is especially sensitive to acidic amino acids (Gnagey et al., 1999).

In a complementary series of studies, Ellis and colleagues have constructed a series of chimeric muscarinic receptors to probe the location of the allosteric site. Based on the large separation of gallamine's affinity between the $M_{2}$ receptor, on the one hand, and the $M_{5}$ or $\mathrm{M}_{3}$ receptors, on the other. Chimeric receptor constructs of $\mathrm{M}_{2} / \mathrm{M}_{5}$ and $\mathrm{M}_{2} / \mathrm{M}_{3}$ receptors identified broad regions of amino acids responsible for gallamine's allosteric properties (Ellis, 1997). A 31-amino acid stretch incorporating parts of the third extracellular loop and TMVI of the $\mathrm{M}_{2}$ receptor was necessary for gallamine's effects, which was in line with the observations of Matsui et al. (1995) because this stretch incorporated Trp ${ }^{400}$. However, the extension of these studies to the actions of other allosteric modulators, such as TMB-8, has subsequently identified additional epitopes as being important for allosteric potency, with a single threonine $\left(\mathrm{T}^{423}\right)$ residue at the $\mathrm{M}_{2}$ receptor playing a critical role in defining subtype selectivity for a number of muscarinic acetylcholine receptor modulators (Ellis and Seidenberg, 2000; Buller et al., 2002)

Taken together, the available data suggest that the allosteric binding site for many charged molecules on muscarinic acetylcholine receptors may be somewhere close to the orthosteric site, but at a more extracellular level. Because allosteric interactions are evident at all five subtypes, conserved residues such as $\operatorname{Tr}{ }^{101}, \operatorname{Trp}^{400}$, and possibly $\mathrm{Asp}^{71}$ (using the $\mathrm{M}_{1}$ receptor designation) 
al., 2000), has found general agreement with the preceding speculations (Birdsall et al., 2001). In particular, a region of conserved extracellular residues above TMs V to VII form a cleft that contains $\operatorname{Trp}^{400}, \mathrm{Ser}^{388}, \mathrm{Asp}^{393}$, and $\mathrm{Glu}^{397}$, acidic residues in the third extracellular loop important for gallamine binding (Gnagey et al., 1999). It is possible that this cleft forms an entrance to the orthosteric binding site and can explain the dramatic slowing effects many muscarinic allosteric modulators have on orthosteric ligand kinetics. Unfortunately, detailed structural information regarding the allosteric sites on class I GPCRs other than the muscarinic acetylcholine receptors is currently lacking.

1. Multiple Allosteric Sites. Not all of the data derived from studies on GPCR allosterism are compatible with the notion of a single extracellular allosteric site in addition to the orthosteric site. For instance, gallamine and tubocurarine exert biphasic effects on the dissociation of $\left[{ }^{3} \mathrm{H}\right] \mathrm{QNB}$ at $\mathrm{M}_{2}$ muscarinic receptors in low ionic strength media, first enhancing and then retarding radioligand dissociation depending on the concentration of modulator used (Ellis and Seidenberg, 1989; Ellis et al., 1991). These data are difficult to explain without postulating the existence of two separate allosteric sites that the modulators recognize with different affinities. Other examples include the green mamba venom "m1-toxin", which forms an almost irreversibly bound cap across the extracellular regions of the $\mathrm{M}_{1}$ muscarinic receptor by using multiple binding points (Max et al., 1993), and different attachment points have also been suggested for a series of hexamethonium derivatives (Bejeuhr et al., 1994) and unilaterally ring-substituted bispyridinium derivatives (Kostenis et al., 1996) on $\mathrm{M}_{2}$ muscarinic receptors. Significantly, the anticholinesterase tetrahydroaminacridine (THA) consistently results in inhibition curves with slopes steeper than unity for various orthosteric radioligands at muscarinic receptors (Flynn and Mash, 1989; Potter et al., 1989; Kiefer-Day et al., 1991; Mohr and Tränkle, 1994). The simplest scheme to accommodate these results would involve THA recognizing both the orthosteric and allosteric sites but only exerting positive cooperativity with respect to its own binding. Alternatively, THA may recognize two modulatory sites, each interacting positively co-operative with one an- terized by a significantly lower $\mathrm{pA}_{2}$ value, strongly suggestive of interaction at a different allosteric site. Unfortunately, one of the limitations of using ligands such as obidoxime is that its low affinity for the allosteric site(s) limits the concentration ranges over which it can be tested. More recent studies have identified the indolocarbazole, KT5720, as a relatively high-affinity allosteric modulator of $\mathrm{M}_{1}$ muscarinic receptors that shares obidoxime's ability of exerting minimal effects on orthosteric ligand dissociation kinetics while maintaining the ability to bind to an allosteric site (Lazareno et al., 2000). This important property has been used in combination experiments monitoring the interaction between KT5720 and $\left[{ }^{3} \mathrm{H}\right] \mathrm{NMS}$ in the absence or presence of acetylcholine and other allosteric modulators such as gallamine and brucine. Surprisingly, it was found that

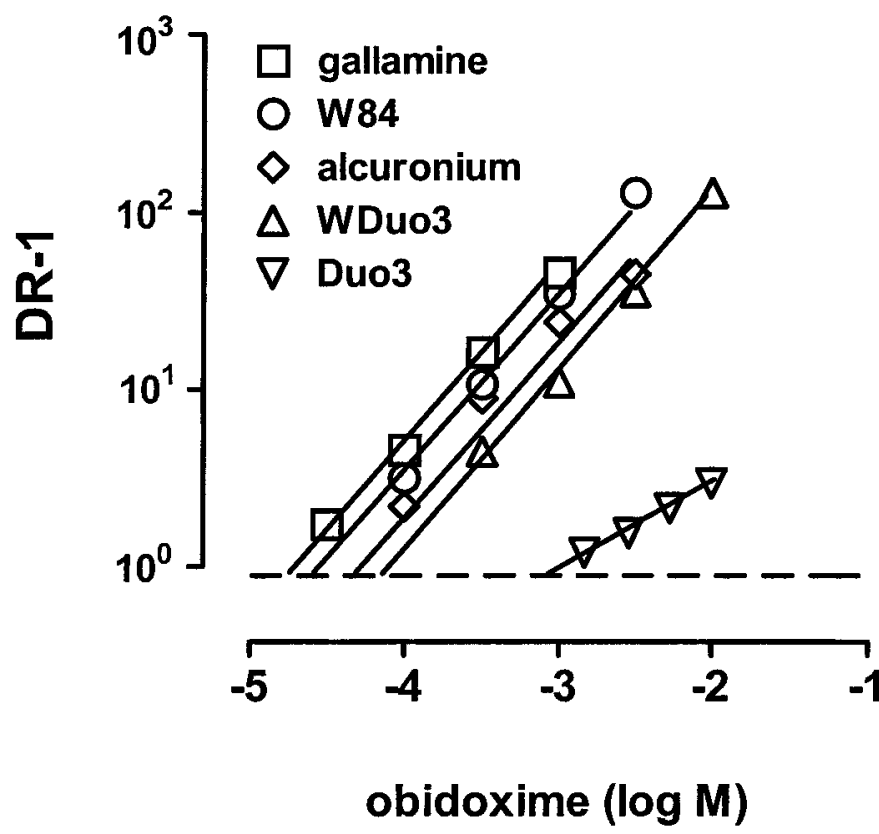

FIG 20. Schild plots of the interaction between the allosteric modulator, obidoxime, and other modulators at the $\mathrm{M}_{2}$ muscarinic acetylcholine receptor. Dose ratios (DR) were calculated as the concentration of indicated allosteric modulator producing half-maximal slowing of $\left[{ }^{3} \mathrm{H}\right] \mathrm{NMS}$ dissociation from the receptor in the absence to that obtained in the presence of increasing concentrations of obidoxime. The interaction between obidoxime and Duo3 is not consistent with binding to a common allosteric site recognized by the other modulators. Data taken from Tränkle and Mohr (1997). 
sion of the allosteric model to incorporate two binding sites for 5 -( $N, N$-hexamethylene)-amiloride on the $\alpha_{1}$-receptor can adequately accommodate the entire dataset.

Finally, it is possible that other highly conserved allosteric sites may be present on many GPCRs. Table 8 lists the inhibition binding parameters for the novel thiadiazole compound $N$-(2,3-diphenyl-1,1,4-thiadiazol5 - $(2 \mathrm{H})$-yildene)methenamine at a range of class I GPCRs. This compound inhibits the binding of both agonists and antagonists with low micromolar potency at these receptors in a reversible manner that is independent of receptor-G protein coupling (Fawzi et al., 2001). This is in contrast to other general modulators of GPCRs such as suramin (see above) that lose their allosteric properties in the absence of $\mathrm{G}$ proteins. Furthermore, the inhibition of orthosteric binding by $N$-(2,3-diphenyl1,1,4-thiadiazol-5-(2H)-yildene)methenamine is accompanied by a concentration-dependent reduction in radioligand $B_{\max }$ values, thus, suggesting a noncompetitive mode of binding. Overall, however, the presence of a distinct and conserved allosteric site for small molecules at a variety of class I GPCRs is still mostly speculative at the moment and remains to be further investigated.

\section{Endogenous Allosteric Modulators}

By definition, the orthosteric binding site on a GPCR comprises amino acids that form contacts with the endogenous agonist for that receptor; this site has, thus, specifically evolved to interact with an endogenous hormone or neurotransmitter. In contrast, allosteric bind-

TABLE 8

Inhibitory potency of the noncompetitive antagonist, SCH-202676, on the orthosteric binding of different Class I GPCRs

\begin{tabular}{llc}
\hline \multicolumn{1}{c}{ Receptor } & \multicolumn{1}{c}{ Radioligand } & $\mathrm{IC}_{50}$ \\
\hline & & $\mu M$ \\
$\delta$-Opioid & {$\left[{ }^{3} \mathrm{H}\right]$ Diprenorphine } & 0.3 \\
$\kappa$-Opioid & {$\left[{ }^{3} \mathrm{H}\right]$ Diprenorphine } & 1.7 \\
$\mu$-Opioid & {$\left[{ }^{3} \mathrm{H}\right]$ Diprenorphine } & 1.8 \\
$\mathrm{M}_{1}$ muscarinic & {$\left[{ }^{3} \mathrm{H}\right] N$-methylscopolamine } & 0.4 \\
$\mathrm{M}_{2}$ muscarinic & {$\left[{ }^{3} \mathrm{H}\right] N$-methylscopolamine } & 0.4 \\
$\alpha_{2 \mathrm{~A}}$-Adrenergic & {$\left[{ }^{3} \mathrm{H}\right]$ Yohimbine } & 0.5 \\
$\beta_{1}$-Adrenergic & {$\left[{ }^{125} \mathrm{I}\right]$ Iodocyanopindolol } & 1.2 \\
$\mathrm{D}_{1}$ dopamine & {$\left[{ }^{3} \mathrm{H}\right]$ SCH-23390 } & 0.1 \\
$\mathrm{D}_{2}$ dopamine & {$\left[{ }^{3} \mathrm{H}\right]$ Methylspiperone } & 0.1 \\
\hline
\end{tabular}

Adapted from Fawzi et al., 2001. distinct allosteric binding site for neuroactive steroids such as pregnanolone (Gasior et al., 1999). Thus, it is possible that some GPCRs may also normally interact with endogenous allosteric modulators under physiological or perhaps pathophysiological conditions.

One candidate for an endogenous allosteric modulator of GPCR function is the tetrapeptide LSAL, termed " 5 HT-moduline". This substance was originally isolated from rat brain and has been shown to interact with the $5 \mathrm{HT}_{1 \mathrm{~B}}$ autoreceptor with high affinity. In contrast, it does not have appreciable affinity for a variety of other 5HT and non-5HT receptors (Fillion et al., 1996; Massot et al., 1996). Interestingly, the interaction between 5-HT-moduline and either 5HT agonists or antagonists is noncompetitive and antagonistic in nature. In radioligand binding assays, 5-HT-moduline causes a reduction in the maximal attainable level of orthosteric binding and in assays of receptor function, it causes a reduction in maximal agonist responsiveness (Fillion et al., 1996; Massot et al., 1996). Importantly, this peptide demonstrates a regional distribution similar to that of $5 \mathrm{HT}_{1 \mathrm{~B}}$ receptors, is released from nerve terminals in a $\mathrm{Ca}^{2+}$ - and $\mathrm{K}^{+}$-dependent manner and is rapidly degraded by enzymatic breakdown (Massot et al., 1996; Cloez-Tayarani et al., 1997). Taken together, these criteria suggest a true neuromodulatory role for 5-HTmoduline, and a physiological role in stress conditions has also been postulated (Massot et al., 1998).

Other endogenous substances have been identified as possible allosteric modulators of muscarinic acetylcholine receptors. For example, Heron and Schimerlik (1984) suggested the presence of a nondialyzable, protease-sensitive factor in atria that reversibly affected the association kinetics of $\left[{ }^{3} \mathrm{H}\right] \mathrm{QNB}$. Another substance, termed "endogenous soluble factor", was isolated from embryonic chick heart by Creazzo and Hartzell (1985) and found to decrease $\left[{ }^{3} \mathrm{H}\right] \mathrm{QNB}$ binding in a noncompetitive manner. The authors suggested a possible role in agonist-induced desensitization and receptor down-regulation. Diaz-Arrastia et al. (1985) identified a low-molecular weight peptide, $\mathrm{P}_{2} \mathrm{~F}$, in calf thymus that also antagonized $\left[{ }^{3} \mathrm{H}\right] \mathrm{QNB}$ noncompetitively. Various researchers have identified other endogenous protein modulators of muscarinic receptors (Maslinski et al., 1988; 
function can be found in a variety of cardiac neuromyopathies characterized by the production of receptor autoantibodies. For instance, the chronic stage of the parasite-transmitted Chagas' disease, one of the most common determinants of congestive heart failure in the world, involves the endogenous generation of antibodies that interact with and persistently activate $\beta$-adrenergic and muscarinic acetylcholine receptors (Leiros et al., 1997). Previous studies with antibodies raised against specific GPCRs have identified the second extracellular loop of these receptors as a site of antibody binding that also leads to receptor activation (AbdAlla et al., 1996; Mijares et al., 1996, 2000). In the case of peptide receptors, such as the bradykinin $\mathrm{B}_{2}$ receptor, the antibody contact points in the extracellular loop may constitute part of the orthosteric site (AbdAlla et al., 1996). However, for antibodies raised against the class I bioamine receptors, this is unlikely (Tucek, 1997). Hence, the activation and subsequent desensitization of $\beta$-adrenergic and muscarinic acetylcholine receptors mediated by endogenously produced Chagasic autoantibodies (Leiros et al., 1997) may be mediated by an allosteric mechanism.

Perhaps not surprisingly, most candidate endogenous allosteric modulators of GPCRs identified thus far are peptides. However, this is not always the case. Oleamide is an amidated lipid found in cerebrospinal fluid that plays an important role in sleep regulation (Boger et al., 1998). However, this substance also has distinct effects on $5 \mathrm{HT}_{2}$ and $5 \mathrm{HT}_{7}$ receptors that are due to interaction with an allosteric site. For instance, at the $5 \mathrm{HT}_{2 \mathrm{~A}}$ receptor, oleamide potentiates agonist-mediated PI hydrolysis, whereas at the $5 \mathrm{HT}_{7}$ receptor, it is able to modify receptor signaling even in the absence of agonist; importantly, this latter effect of oleamide is resistant to antagonism by the orthosteric antagonist clozapine (Thomas et al., 1997). The allosteric binding properties of oleamide at the $5 \mathrm{HT}_{7}$ receptor have also been demonstrated in radioligand binding assays (Hedlund et al., 1999), thus, identifying this agent as a novel neuromodulator of GPCR function.

With the possible exception of the muscarinic acetylcholine receptors (see preceding section) and some of the class III GPCRs, the overall lack of specific structural information about the allosteric pharmacophore(s) of interactions between protein partners are transient, perhaps serving a catalytic role, whereas other times they involve the formation of more stable and longerlasting multimeric complexes. In all instances, however, the formation of a bond between two proteins causes a conformational change that can ultimately determine the functional consequence of the interaction. If the resulting multimeric complex displays altered properties with respect to its subsequent interactions with other ligands or proteins, then the potential exists for allosteric interactions to occur between the various binding sites on the complex.

By their very nature, GPCRs participate in a requisite coupling to other membrane components, most notably G proteins, to transduce the stimulus imparted to the receptor by an agonist to the cell. As discussed earlier, this interaction is characterized by allosteric effects transmitted between binding sites on either protein. From the perspective of the GPCR, the orthosteric site is the agonist binding site, whereas for the G protein, the orthosteric site may be defined as the guanine nucleotide binding site on the $\mathrm{G} \alpha$-subunit. The binding interface between the two proteins constitutes the allosteric site. Although this description ignores the additional allosteric effect that can occur as a consequence of $\mathrm{G}$ protein $\beta \gamma$-subunit binding (Onaran et al., 1993), it is nevertheless sufficient to illustrate the best studied example of GPCR complexing. Beyond the G protein paradigm, however, GPCRs have generally been considered to behave as monomeric proteins with respect to their interactions with orthosteric ligands. Even the examples of allosterism illustrated in the preceding sections are all instances of where more than one binding site is located on the receptor monomer, and allosteric behavior arises as a consequence of interactions between these sites. More recently, the classic picture of GPCRs as monomers has been reevaluated due to the realization that they can form complexes with proteins other than $G$ proteins. The most compelling evidence comes from the increasing number of studies demonstrating the ability of GPCR monomers to combine and form dimers, or even higher order oligomers, but studies are now expanding the list of "accessory proteins" that may act as partners with GPCRs in an array of signaling complexes. In all of 
protein types, thus, leading to a diverse array of receptor subtypes (Galzi and Changeux, 1994). Each of these instances can lead to cooperative behavior if more than one molecule of the orthosteric ligand is able to bind to the multimeric receptor complex.

Indirect evidence has also been available for cooperative binding of orthosteric ligands at GPCRs for quite some time. For instance, radioligand binding assays at the $\beta_{2}$-adrenoceptor (Limbird et al., 1975), the muscarinic receptors (Mattera et al., 1985; Lee et al., 1986; Potter et al., 1988, 1991; Henis et al., 1989; Wregget and Wells, 1995; Chidiac et al., 1997), and the histamine receptor (Steinberg et al., 1985a, 1985b, 1985c; Sinkins et al., 1993; Sinkins and Wells, 1993) have often described orthosteric binding properties that could not be readily reconciled either with simple mass-action monomeric receptor behavior or within the framework of a simple ternary complex model between orthosteric ligand, receptor, and G protein. For example, Fig. 21A shows the binding of the orthosteric agonist oxotremorine-M against the antagonist $\left[{ }^{3} \mathrm{H}\right] \mathrm{AF}-\mathrm{DX} 384$ at native $\mathrm{M}_{2}$ muscarinic receptors. In the presence of $\mathrm{G}$ protein coupling, the competition curve is inhibitory (circles), although it is characterized by a biphasicity that suggests multiple affinity states. Interestingly, when the nonhydrolyzable GTP analog $\mathrm{Gpp}(\mathrm{NH}) \mathrm{p}$ is included in the assay to uncouple receptor-G protein complexes, a distinctly bell-shaped binding curve (squares) is obtained for the agonist-antagonist interaction, characterized by an initial element of positive cooperativity. Given that both ligands recognize the orthosteric site of the muscarinic receptor, this pattern cannot be reconciled with the simple TCM of allosteric interaction described earlier, nor with the ternary complex model of orthosteric ligand-receptor-G protein. This behavior can be rationalized, however, if it is assumed that GPCRs can exist as dimers within the cell membrane. A simple model of receptor dimerization is illustrated in Scheme 3 , where $\mathrm{R}$ represents a dimerized receptor (e.g., R-R), A and $\mathrm{B}$ represent orthosteric ligands that can bind to either or both orthosteric sites on the dimer, and $K_{\mathrm{a}}$ and $K_{\mathrm{b}}$ denote the equilibrium association constants for binding of either ligand to a vacant dimer. The symbol $\alpha$ denotes the cooperativity factor for the binding of a
LOG [OXOTREMORINE-M]

B.

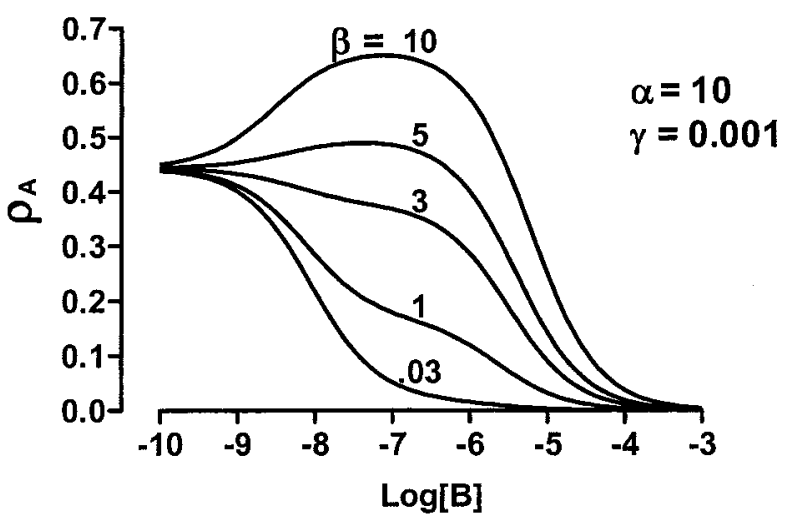

FIg 21. A, interaction between the orthosteric agonist, oxotremorine-M, and the orthosteric antagonist, $\left[{ }^{3} \mathrm{H}\right] \mathrm{AF}-\mathrm{DX} 384$, at the $\mathrm{M}_{2}$ muscarinic acetylcholine receptor copurified with $\mathrm{G}$ proteins from porcine sarcolemmal membranes. The data were obtained in the absence $(\bigcirc)$ or presence $(\square)$ of the nonhydrolyzable GTP analog, Gpp(NH)p. Curves through the data represent the best fit based on a model of receptor oligomerization. Data taken from Wregget and Wells (1995). B, predicted behavior of a dimeric receptor system. Effects of orthosteric ligand B on the binding of orthosteric ligand A according to eq. 29 with the following parameter values $\mathrm{p} K_{\mathrm{A}}=9, \mathrm{p} K_{\mathrm{B}}=8$, and $\log [\mathrm{A}]=-7$. The cooperativity factors shown in the figure represent the interaction between two molecules of A $(\alpha)$, two molecules of B $(\gamma)$, and a molecule each of A and B $(\beta)$ on the receptor dimer.

second equivalent of ligand $\mathrm{A}$ to a dimer that is already occupied by a molecule of $\mathrm{A}$, the symbol $\beta$ denotes the cooperativity factor for the binding of a molecule of ligand $\mathrm{B}$ to a dimer that is already occupied by a molecule of $\mathrm{A}$, whereas the symbol $\gamma$ denotes the cooperativity factor for the binding of a second equivalent of ligand $B$ to a dimer that is already occupied by a molecule of $\mathrm{B}$. The receptor conservation equation for this scheme is as follows.

$$
\begin{aligned}
{[\mathrm{R}]_{\mathrm{T}} } & =[\mathrm{R}]+2[\mathrm{AR}]+2[\mathrm{BR}]+2[\mathrm{ARB}]+[\mathrm{ARA}] \\
& +[\mathrm{BRB}]
\end{aligned}
$$


colleagues (Hebert et al., 1996, 1998), who used a strategy of differential epitope tagging to demonstrate that the $\beta_{2}$-adrenoceptor responds to agonist binding by forming receptor homodimers. Importantly, a peptide derived from TM domain VI of the $\beta_{2}$-adrenoceptor was able to inhibit both dimer formation and isoproterenolmediated adenylyl cyclase activity. This finding provided structural evidence for the TM VI interface as being an important determinant of $\beta_{2}$-adrenoceptor homodimerization and suggesting a requisite role of the dimerization process in $\beta_{2}$-receptor activation. Although originally identified in cellular membrane fragments, $\beta_{2}$-adrenoceptor homodimerization has subsequently been demonstrated in vivo in intact cells (Angers et al., 2000, 2001).

From these findings, it may be concluded that GPCR

Figure 21B illustrates a series of binding curves simulated according to eq. 29. The only difference between the curves is the degree of cooperativity $(\beta)$ between $\mathrm{A}$ and $\mathrm{B}$ on the receptor dimer, yet this is sufficient to accommodate a wide range of binding profiles including multiple affinity states and bell-shaped curves.

From the preceding discussion, it is apparent that even the simplest scenario of a receptor dimer provides scope for a bewildering array of allosteric interactions occurring between orthosteric binding sites. Despite the potential for allosteric effects arising from cooperative binding at GPCR oligomers, however, the frequency of such phenomena and their functional relevance are currently unclear. Certainly, more direct biochemical and/or structural evidence of GPCR dimerization is now becoming available, having been obtained from photoaffinity labeling experiments, receptor cross-linking studies, mutagenesis experiments, and the construction of receptor chimeras (for references, see Hebert and Bouvier, 1998). The latter studies, in particular, have provided an impetus for much of the more recent work on GPCR dimerization. For instance, Wess and colleagues (Maggio et al., 1993a,b), constructed a series of $\alpha_{2}$-adrenoceptor/ $/ \mathrm{M}_{3}$ muscarinic receptor chimeras that contained the first 5 transmembrane domains of one receptor type linked to the last two of the other type of receptor and then studied their properties in a recombinant expression system. When transfected alone, neither chimera showed significant ligand binding activity. homodimerization could represent a generalized paradigm of receptor activation. However, the $\delta$-opioid receptor has been found to display quite a different dimerization profile in response to agonist stimulation (Cvejic and Devi, 1997). Specifically, the effect of the agonist was found to be a promotion of receptor monomers and a decrease in receptor dimers. This agonist-mediated monomerization precedes agonist-mediated internalization of the receptors, thus, suggesting a role for $\delta$-opioid receptor dimers in modulating the internalization process. Interestingly, studies of bradykinin $\mathrm{B}_{2}$ receptor dimers have found that dimer formation is required both for agonist-mediated receptor activation and desensitization (AbdAlla et al., 1999).

Given the current paucity of detailed studies on the functional consequences of GPCR dimerization, it is quite likely that further studies will identify a number of roles for the dimerization process that will be dependent on both the nature of the dimerization mechanism and the cellular background in which this mechanism is operative. For example, the sensitivity of muscarinic $\mathrm{M}_{3}$ (Zeng and Wess, 1999) and $\kappa$-opioid (Jordan and Devi, 1999) receptor homodimers to reducing agents suggests a role for the disulfide bonds of the extracellular receptor loops in the mechanism of receptor dimerization. In contrast, other GPCRs, including the bradykinin $\mathrm{B}_{2}$ receptor, the metabotropic glutamate receptor, and the extracellular calcium-sensing receptor rely on their 
model postulates that GPCR homodimers can form by "swapping" TM regions V and VI. The advantages of dimer formation using this mechanism are that it is energetically favorable, using the same type of bonding forces that maintain the structure of a standard GPCR monomer, and that it can minimize the effects of lossof-function mutations. A number of studies of "functional receptor rescue" have demonstrated how mutated receptors that cannot signal are able to do so when they undergo a dimerization with another equivalent of receptor (see Gouldson et al., 1998, 2000).

GPCR dimerization does not necessarily have to be restricted to the formation of homodimers. Some receptors may need to form heterodimers to function properly. The first discovery of this phenomenon was in relation to the metabotropic $\mathrm{GABA}_{\mathrm{B}}$ receptor. Although cloning studies had identified two distinct monomeric receptor subtypes, termed the $\mathrm{GABA}_{\mathrm{B}} \mathrm{R} 1$ and $\mathrm{GABA}_{\mathrm{B}} \mathrm{R} 2$ receptors (see Marshall et al., 1999), appropriate functional responses corresponding to native receptor properties could only be obtained when these two subtypes were coexpressed in the same cell (Jones et al., 1998; Kaupmann et al., 1998; White et al., 1998). Subsequent studies have identified the $\mathrm{GABA}_{\mathrm{B}}$ heterodimer as a tightly associated C-terminal "coiled-coil" structure that is most likely preformed in the endoplasmic reticulum and, therefore, does not need to be induced by agonist binding (Marshall et al., 1999). Another recently identified example of GPCR heterodimerization involves the combination of $\delta$ - and $\kappa$-opioid receptors (Jordan and Devi, $1999)$. In contrast to $\delta$-opioid homodimers, $\kappa$ - $\delta$-heterodimers display a minimal tendency to monomerize in the presence of agonist. This suggests a role of heterodimerization in modulating receptor function. The $\kappa-\delta$ heterodimers also display profound differences in their ability to bind $\delta$ - or $\kappa$-selective ligands. Table 9 shows some examples of the binding properties of selective opioid ligands to the $\delta$-, $\kappa$-, or $\kappa$ - $\delta$-receptor complexes. What is most striking is the enhancement of apparent ligand affinity at the heterodimer when measured in the presence of another ligand, suggesting positive cooperativity in the mode of agonist binding to the heterodimer. Similarly, angiotensin $\mathrm{AT}_{1}$ receptor and bradykinin $\mathrm{B}_{2}$ receptor heterodimers display signifi- ison to each receptor when it is individually expressed (Fig. 22; see AbdAlla et al., 2000). Importantly, the altered pharmacological responsiveness of the $\mathrm{AT}_{1}-\mathrm{B}_{2}$ heterodimer has recently been linked to the hypertension that characterizes the condition of pre-eclampsia, which is often observed in pregnant women (AbdAlla et al., 2001). This is a striking example of a disease that is mediated, at least in part, as a consequence of increased GPCR heterodimer formation.

As with the ion channel-linked receptors, therefore, it seems that heterodimerization of GPCRs may represent an important mechanism for generating receptor subtypes with a pharmacological profile that is distinct from that of either monomer alone. In this latter instance, the resulting, "new" pharmacological profile most likely reflects the extent of allosteric interaction between multiple orthosteric sites within a receptor oligomer. However, the true extent of this phenomenon is far from known and the field of GPCR oligomerization is rapidly expanding. Further detailed discussion is beyond the scope of this review; Table 10 summarizes studies conducted on ligand regulation of GPCR oligomerization and/or altered receptor pharmacology as a consequence of GPCR oligomerization.

\section{B. Accessory Proteins}

In classical receptor theory, a basic tenet is the belief that the receptor is the minimal unit required for the production of drug response. Thus, operationally, a ligand combines with a receptor and produces a physiological response. Implicit in this scheme is the fact that

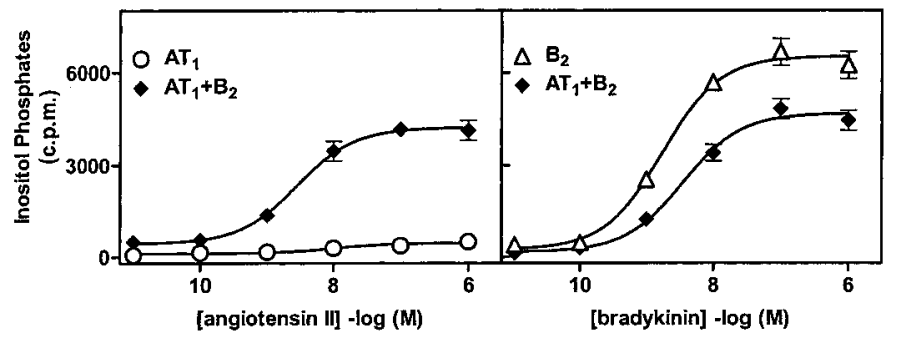

FIG 22. Generation of inositol phosphaptes by angiotensin-II (left panel) or bradykinin (right panel) in HEK 293 cells transfected individually (open symbols) or cotransfected (solid symbols) with the $\mathrm{AT}_{1}$ and $\mathrm{B}_{2}$ receptors. Receptor cotransfection generates a novel pharmacological profile for either agonist. Data taken from AbdAlla et al. (2000). 


\author{
$\delta$-Opioid \\ Dopamine $\mathrm{D}_{1}$ \\ Muscarinic $\mathrm{M}_{2}$ \\ Muscarinic $\mathrm{M}_{3}$ \\ Vasopressin $\mathrm{V}_{2}$ \\ $\kappa+\delta$ opioid $^{a}$ \\ Regulation by ligands not determined \\ $\alpha_{2}$-adrenoceptor \\ $\mathrm{AT}_{1}$ angiotensin \\ $\beta_{1}$-adrenoreceptor \\ $\beta_{2}$-adrenoceptor \\ Bradykinin $\mathrm{B}_{2}$ \\ $\delta$-Opioid \\ $\mathrm{D}_{2}$ receptor \\ $\mathrm{D}_{3}$ receptor \\ Glucagon receptor \\ $\mathrm{GnRH}$ \\ Histamine \\ Muscarinic \\ Muscarinic $\mathrm{M}_{1}$ \\ Muscarinic $\mathrm{M}_{2}$ \\ Muscarinic $\mathrm{M}_{3}$ \\ mGluR1 \\ $\mathrm{V}_{2}$ vasopressin \\ $5-\mathrm{HT}_{1 \mathrm{~B}}+5-\mathrm{HT}_{1 \mathrm{D}}$ \\ $\mathrm{AT}_{1}$ angiotensin + bradykinin $\mathrm{B}_{2}{ }^{a}$ \\ Adenosine $\mathrm{A}_{1}+\mathrm{P}_{2} \mathrm{Y}_{1}{ }^{a}$ \\ $\beta_{2}+\delta$-opioid ${ }^{a}$ \\ $\mathrm{GABA}_{\mathrm{B}} \mathrm{R} 1+\mathrm{R} 2^{a}$ \\ $\mu+\delta$-opioid ${ }^{a}$ \\ mGluR1 $\alpha+$ adenosine $\mathrm{A}_{1}{ }^{a}$ \\ cVey et al., 2001 \\ George et al., 1998 \\ Park et al., 2001 \\ Zeng and Wess, 1999 \\ Schulz et al., 2000 \\ Jordan and Devi, 1999 \\ Maggio et al., 1993a \\ Monnot et al., 1996 \\ Fowler et al., 1999 \\ Limbird et al., 1975; Venter and Fraser, 1983 \\ Pizard et al., 1998 \\ Polastron et al., 1994 \\ Ng et al., 1996; Zawarynski et al., 1998; Scarselli et al., 2000; Armstrong and Strange, \\ 2001; Lee et al., 2000 \\ Nimchinsky et al., 1997; Karpa et al., 2000 \\ Herberg et al., 1984 \\ Grosse et al., 1997 \\ Sinkins et al., 1993; Sinkins and Wells, 1993 \\ Hedlund et al., 1982; Avissar et al., 1983 \\ Potter et al., 1988 \\ Mattera et al., 1985; Boyer et al., 1986; Potter et al., 1991; Wregget and Wells, 1995; \\ Chidiac et al., 1997 \\ Maggio et al., 1993b \\ Ray and Hauschild, 2000 \\ Zhu and Wess, 1998 \\ Ng et al., 1993; Xie et al., 1999 \\ AbdAlla et al., 2000 \\ Yoshioka et al., 2001 \\ Jordan et al., 2001 \\ Kaupmann et al., 1998; White et al., 1998; Kuner et al., 1999 \\ Vaught et al., 1982; George et al., 2000; Gomes et al., 2000 \\ Ciruela et al., 2001
}

${ }^{a}$ Heterodimer displays novel pharmacological properties compared with the individually expressed receptors.

the receptor and ligand form a unique system that is portable to all physiological arenas. In fact, this is the basis of receptor pharmacology because it defines the various quantitative correspondences between ligand and effect and the relative activity of ligands, which then allows drug discovery to be carried out in surrogate systems and extrapolated to therapy in humans. This concept is now being tested as recombinant systems became widely used in experimental pharmacology. In these experiments, receptor cDNA is transfected into foreign host cells, and the resulting system, namely the receptor expressed into the membrane of the host, is used as a surrogate mimic of the receptor in its natural environment. In general, the majority of studies confirm this portability of receptor. However, careful observation of the expected behavior of some receptors expressed in some recombinant systems has uncovered anomalies that do not conform to the idea that a receptor is always a stand-alone entity that can be inserted into any cellular background and be expected to produce physiologically accurate behavior. These studies have provided evidence that GPCRs are active participants in proteinprotein interactions that can often occur independently or in conjunction with the receptor coupling to its $G$ protein(s) or to other receptors.

One such example has been found with $\alpha_{2 \mathrm{~A} / \mathrm{D}}$-adrenoceptors, which are known to couple to $\mathrm{G}_{\mathrm{i} / \mathrm{o}}$ proteins in NIH-3T3 and PC-12 cells. The signal can be eliminated by treatment with pertussis toxin and reconstituted by addition of $G$ protein. It was noted in these studies that the efficiency of receptor activation differed in various surrogate cell hosts. Specifically, the reconstitution was 3- to 9-fold greater in PC-12 cells (over NIH-3T3 cells), and it was observed that this effect was independent of the level of receptor expression (Nanoff et al., 1995; Sato et al., 1995). A heat-sensitive macromolecule could be 


\section{$\mathrm{G}$ proteins.}

Another class of monoamine agonist GPCRs known to interact with accessory proteins are the dopamine receptors. Dopamine $\mathrm{D}_{1}$ receptors preferentially signal through $\mathrm{G}_{\mathrm{s}}$ proteins to stimulate cAMP accumulation. Recently, a single transmembrane-spanning protein, termed "calcyon", has been shown to physically associate with $D_{1}$ receptors in neurons and potentiate their ability to stimulate intracellular calcium release, a typically $\mathrm{G}_{\mathrm{q} / 11}$-coupled response (Lezcano et al., 2000). Interestingly, calcyon does not seem to affect $\mathrm{D}_{1}$ receptor affinity toward dopamine agonists, which is characterized by both high- and low-affinity components, but significantly enhances the proportion of the high-affinity state (Lidow et al., 2001). This finding suggests a complex allosteric interaction involving at least three proteins, calcyon, the $\mathrm{D}_{1}$ receptor, and its interacting $\mathrm{G}$ protein(s). In addition, dopamine $\mathrm{D}_{2}$ and $\mathrm{D}_{3}$ receptors associate with the cytoskeletal protein filamin-A, which has been suggested to be required for proper cell surface expression of these receptors in neurons, and linking them to downstream signaling pathways (Lin et al., 2001).

There are a number of other factors proposed to affect the interaction between receptors and $G$ proteins. For example, stimulation of the chemokine $\mathrm{CCR} 2 \mathrm{~B}$ receptor by the monocyte chemotactic protein 1 promotes the rapid association of the receptor with the Janus kinase 2/STAT3 protein pathway. Furthermore, it has been postulated that the association of the CCR2B receptor with its cognate $G_{i}$ protein requires the allosteric effects induced in the receptor by both monocyte chemotactic protein 1 binding and Janus kinase 2 association (Mellado et al., 1998). In addition, the cytoskeletal protein tubulin has been shown to affect the activation state of $\mathrm{G}$ proteins (Wang et al., 1990; Roychowdhury et al., 1993; Popova et al., 1994), and, similarly, the protein neuromedulin also facilitates receptor-G protein interaction, possibly by accelerating the binding of cyclic nucleotides to G protein (Masure et al., 1986; Strittmatter et al., 1990, 1991, 1993). Similar effects are produced by the wasp venom mastoparan (Higashijima et al., 1988), the $\beta$-amyloid precursor protein (Okamoto et al., 1995), and compound 48/80 (Mousli et al., 1990). Regulators of $\mathrm{G}$ protein signaling proteins are also known to interfere factors would not be relevant to the classification of receptors and drugs or the determination of drug related selectivity in recombinant systems, even though many of the interactions may involve allosteric modulation of protein-protein interactions.

In contrast, there are cofactors that seem to be directly involved in receptor phenotypic behavior toward agonists and/or G proteins. The question then arises: which accessory proteins affect the specific ligand/receptor activity profiles of ligands thought to be the exclusive property of ligand-receptor relationships? Furthermore, if such accessory proteins do change the phenotype of receptors with respect to the ligands with which they interact, then by what manner do they do so? One idea relates to the geometric configuration of receptor systems in membranes. For example, it can be conceived that the organization of $\mathrm{G}$ protein with receptors in microdomains may cause predisposition of receptors that are pleiotropic with respect to $\mathrm{G}$ protein activation toward a subset $G$ proteins in certain cell types. Receptors and $\mathrm{G}$ proteins are organized in multimeric complexes that form microdomains (Neubig, 1994). The combination of such organization with ligand selective receptor active states could affect agonist profiles for receptors in different cellular hosts. For example, a family of proteins localized to some of these microdomains, called caveolins, cause enrichment of these microdomains with G proteins (Li et al., 1995; Scherer et al., 1995, 1996). It is not yet known whether this results in agonist-dependent selective receptor coupling to G proteins.

A particularly well characterized case where an accessory protein clearly changes the phenotype of the receptor is with a family of single transmembrane proteins required for the transport and ligand specificity termed receptor activity modifying proteins (RAMPs). There are three RAMPs ubiquitously distributed among tissues and sharing approximately a 31\% homology. Studies have shown that RAMP1 associates with the calcitonin receptor-like receptor CRLR and produces a high-affinity CGRP receptor (McLatchie et al., 1998). RAMP1 also seems to be important in controlling the translocation of CRLR to the cell surface. Unlike RAMP1, the combination of CRLR with RAMP2 or RAMP3 does not produce 
with human calcitonin receptors produces a decrease in the potency of human calcitonin and an increase in the potency of rat amylin (Armour et al., 1999). A striking reversal of relative potency of the agonists human calcitonin and rat amylin is observed with cotransfection of RAMP3 (Fig. 23A). This effect is consistent with a RAMP3-induced change in calcitonin receptor coupling to $\mathrm{G}$ protein. However, RAMP3 also confers a change in the potency of the peptide calcitonin antagonist AC66 for antagonism of amylin, but not human calcitonin responses (see Fig. 23, B and C). These data suggest that RAMP3 associates with the receptor to change its behavior to both agonists and antagonists (Armour et al., 1999). A study by Christopoulos et al. (1999) indicates that cotransfection of RAMP1 and RAMP3 produces an increase in specific amylin binding in COS-7 cells trans-
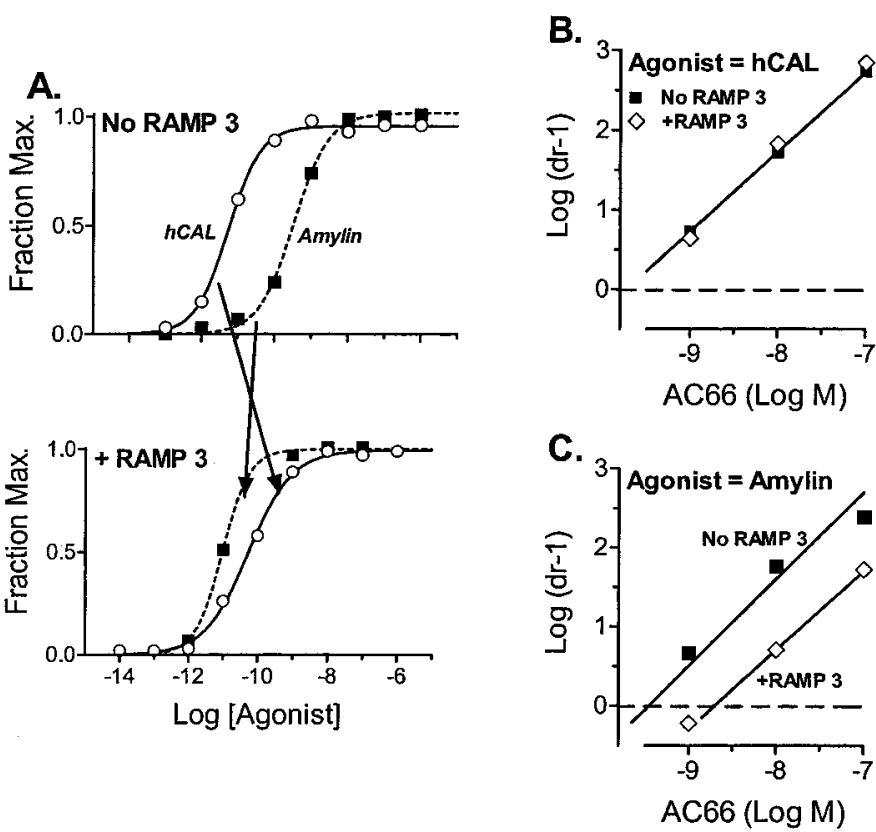

FIG 23. Effects of RAMP3 cotransfection on the effects of agonists (A) and the antagonist AC66 (B and C) for X. laevis melanophores transiently expressing human calcitonin receptors. A, the relative potency of rat amylin and human calcitonin changes by a factor of 16 with a change in the rank order of agonist potency with cotransfection of RAMP3. B, Schild regressions for AC66. There is no change in the antagonism of responses to human calcitonin with cotransfection of RAMP3. However, a 10-fold loss of potency of AC66 for amylin antagonism was observed (C). Redrawn from Armour et al. (1999). proteins are required to unmask the pharmacology of specific orphan receptors for which the gene product has been identified but the endogenous activating ligand has not.

Some other additions to the list of GPCR coupling partners promise to quash the concept of the receptor-G protein signaling hierarchy altogether. These novel coupling partners encompass an ever-growing array of proteins containing specific amino acid modules that allow them to bind to complementary modules in other proteins and, thus, lead to the assembly of multimeric signaling complexes. One important family of targeting proteins are the "PDZ domain-containing" proteins. These possess a GLGF sequence and a conserved arginine that can self-aggregate and/or interact with other proteins containing a $-\mathrm{S} / \mathrm{TxV}$ motif or a $\mathrm{F} / \mathrm{Y}-\mathrm{x}-\mathrm{F} / \mathrm{V} / \mathrm{A}$ motif. The PDZ proteins derive their name from the three cell-organizing proteins in which this association was first noted, the postsynaptic density-95 protein, the Drosophila disks large protein, and the Zona occludens protein. Although already known to play a crucial role in coupling to the NMDA ion channel-linked receptors and targeting them to postsynaptic densities in neurons, PDZ domain-containing proteins are now known to interact directly with GPCRs as well. For example, the somatostatin receptor subtype 2 couples to a PDZ domain-containing protein called SSTRIP, which then targets the receptors to their appropriate site of action (Zitzer et al., 1999). In addition, all three subtypes of $5 \mathrm{HT}_{2}$ receptor contain PDZ consensus motifs in their extreme C-terminal tails, and this motif has been implicated in the coupling of these receptors to neuronal NOS and a novel, multi-PDZ-domain protein termed MUPP1 (Ullmer et al., 1998; Manivet et al., 2000; Becamel et al., 2001). The $\beta_{2}$-adrenoceptor and the $\mathrm{P} 22_{\mathrm{Y} 1}$ purinoceptor also couple to a PDZ domain-containing protein known as $\mathrm{Na}^{+} / \mathrm{H}^{+}$exchange regulatory factor and are able to regulate its function completely independent of their ability to couple to G proteins (Hall et al., 1998a, 1998b). Similarly, the $\beta_{1}$-adrenoceptor couples to the postsynaptic density-95 protein via a similar PDZ interaction $(\mathrm{Hu}$ et al., 1996, 2000).

Finally, GPCRs that contain polyproline-rich regions, such as those found in the third intracellular loop of the 
to agonist-independent constitutive receptor activity and also revealed that the direct intracellular association of different Homer proteins was sufficient to promote or silence this receptor activation (Ango et al., 2001). In this instance, an allosteric conformational change induced via intracellular GPCR-protein interactions were shown to elicit agonist-independent signaling that displayed different temporal patterns to agonistmediated signaling; this can have significant implications for events such as synaptic plasticity.

Findings such as these highlight the bewildering array of GPCR-accessory protein interactions, but it should be noted that many of these may prove to use allosteric mechanisms in subserving their physiological roles. For instance, in certain neurons, a family of laminin-secreted proteins termed "netrins" controls axon elongation. The receptor originally proposed to bind netrin-1, the DCC protein, does not interact directly with the netrin. Rather, the DCC protein associates with one region of the adenosine $A_{2 b}$ receptor while the netrin- 1 protein associates with another region that is topographically distinct from the adenosine-binding site. Together, this novel "ternary complex" mediates many of the effects on axonal outgrowth ascribed to the netrins (Corset et al., 2000) and suggests a novel role for $\mathrm{A}_{2 \mathrm{~b}}$ receptors in the nervous system, beyond neurotransmission, that is predicated by an allosteric interaction.

\section{Conclusions}

Allosteric interactions can be manifested in a variety of ways, but they all involve the transmission of a conformational change across the surface of a GPCR such that the subsequent ability of that receptor to bind other ligands and/or proteins is modified. Thus, allosteric mechanisms allow for profound alterations in cellular homeostasis in response to often subtle receptor binding events. This review has focused on allosterism between multiple sites within the same GPCR and interactions between GPCRs and other proteins. Although the consequences of allosteric interactions involving these receptors can vary dramatically, the study and quantification of these phenomena often involve similar approaches that can provide a remarkable insight into

\section{References}

Abbott AJ and Nelsestuen GL (1988) The collisional limit: an important consideration for membrane-associated enzymes and receptors. FASEB J 2:2858-2866.

AbdAlla S, Lother H, el Massiery A, and Quitterer U (2001) Increased AT1 heterodimers mediate enhanced angiotensin II responsiveness. Nat Med 7:10031009.

AbdAlla S, Lother H, and Quitterer U (2000) $\mathrm{AT}_{1}$-receptor heterodimers show enhanced G-protein activation and altered receptor sequestration. Nature (Lond) 407:94-98.

AbdAlla S, Quitterer U, Grigoriev S, Maidhof A, Haasemann M, Jarnagin K, and Muller-Esterl W (1996) Extracellular domains of the bradykinin $\mathrm{B}_{2}$ receptor involved in ligand binding and agonist sensing defined by anti-peptide antibodies. $J$ Biol Chem 271:1748-1755.

AbdAlla S, Zaki E, Lother H, and Quitterer U (1999) Involvement of the amino terminus of the $\mathrm{B}_{2}$ receptor in agonist-induced receptor dimerization. J Biol Chem 274:26079-26084.

Ackers GK, Doyle MI, Myers D, and Daugherty MA (1992) Molecular code for cooperativity in hemoglobin. Science (Wash DC) 255:54-63.

Angers S, Salahpour A, and Bouvier M (2001) Biochemical and biophysical demonstration of GPCR oligomerization in mammalian cells. Life Sci 68:2243-2250.

Angers S, Salahpour A, Joly E, Hilairet S, Chelsky D, Dennis M, and Bouvier M (2000) Detection of $\beta_{2}$-adrenergic receptor dimerization in living cells using bioluminescence resonance energy transfer (BRET). Proc Natl Acad Sci USA 97:36843689 .

Ango F, Prezeau L, Muller T, Tu JC, Xiao B, Worley PF, Pin JP, Bockaert J, and Fagni L (2001) Agonist-independent activation of metabotropic glutamate receptors by the intracellular protein Homer. Nature (Lond) 411:962-965.

Ariëns EJ, van Rossum JM, and Simonis AM (1956) A theoretical basis of molecular pharmacology. Part II: interactions of one or two compounds with two interdependent receptor systems. Arzneim-Forsch 6:611-621.

Armour SL, Foord S, Kenakin T, and Chen WJ (1999) Pharmacological characterization of receptor-activity-modifying proteins (RAMPs) and the human calcitonin receptor. J Pharmacol Toxicol Methods 42:217-224.

Armstrong D and Strange PG (2001) Dopamine $\mathrm{D}_{2}$ receptor dimer formation. Evidence from ligand binding. J Biol Chem 276:22621-22629.

Arunlakshana O and Schild HO (1959) Some quantitative uses of drug antagonists. Br J Pharmacol 14:48-57.

Avissar S, Amitai G, and Sokolovsky M (1983) Oligomeric structure of muscarinic receptors is shown by photoaffinity labeling: subunit assembly may explain highand low-affinity agonist states. Proc Natl Acad Sci USA 80:156-159.

Baba M, Nishimura O, Kanzaki N, Okamoto M, Sawada H, Iizawa Y, Shiraishi M, Aramaki Y, Okonogi K, Ogawa Y, et al. (1999) A small-molecule, nonpeptide CCR5 antagonist with highly potent and selective anti-HIV-1 activity. Proc Natl Acad Sci USA 96:5698-5703.

Becamel C, Figge A, Polia S, Dumuis A, Peles E, Bockaert J, Lubbert H and Ullmer C (2001) Interaction of serotonin 5-hydroxytryptamine type 2C receptors with PDZ10 of the multi-PDZ domain protein MUPP1. J Biol Chem 276:12974-12982.

Beindl W, Mitterauer T, Hohenegger M, Ijzerman AP, Nanoff C, and Freissmuth M (1996) Inhibition of receptor/G protein coupling by suramin analogs. Mol Pharmacol 50:415-423.

Bejeuhr G, Blaschke G, Holzgrabe U, MohR K, Surig U, and Terfloth G. (1994) A stable and highly potent hexamethonium derivative which modulates muscarinic receptors allosterically in guinea-pig hearts. J Pharm Pharmacol 46:108-112.

Berg KA, Maayani S, Goldfarb J, Scaramellini C, Leff P, and Clarke WP (1998) Effector pathway-dependent relative efficacy at serotonin type $2 \mathrm{~A}$ and $2 \mathrm{C}$ receptors: evidence for agonist-directed trafficking of receptor stimulus. Mol Pharmacol 54:94-104.

Berman DM and Gilman AG (1998) Mammalian RGS proteins: barbarians at the gate. J Biol Chem 273:1269-1272.

Bhattacharya S and Linden J (1995) The allosteric enhancer, PD 81,723, stabilizes human $\mathrm{A}_{1}$ adenosine receptor coupling to $\mathrm{G}$ proteins. Biochim Biophys Acta 1265: $15-21$.

Birdsall NJ, Lazareno S, and Matsui H (1996) Allosteric regulation of muscarinic receptors. Prog Brain Res 109:147-151.

Birdsall NJ, Lazareno S, Popham A, and Saldanha J (2001) Multiple allosteric sites on muscarinic receptors. Life Sci 68:2517-2524.

Black JW, Gerskowitch VP, Leff P, and Shankley NP (1986) Analysis of competitive antagonism when this property occurs as part of a pharmacological resultant. $\mathrm{Br} J$ Pharmacol 89:547-555. 
for central canabinoid receptor inhibits mitogen-activated protein kinase activa-
tion stimulated by insulin or insulin-like growth factor 1 . Evidence for a new model of receptor/ligand interactions. J Biol Chem 272:22330-22339.

Bourne HR (1997) How receptors talk to trimeric G proteins. Curr Opin Cell Biol 9:134-142.

Boyer JL, Martinez-Carcamo, Monroy-Sanchez JA, Posadas C, and Garcia-Sainz JA (1986) Guanine nucleotide-induced positive cooperativity in muscariniccholinergic antagonist binding. Biochem Biophys Res Commun 134:172-177.

Brown GP, and Pasternak GW (1998) $\left[{ }^{3} \mathrm{H}\right]$ Naloxone benzoylhydrazone binding in MOR-1-transfected Chinese hamster ovary cells: evidence for G-protein-dependent antagonist binding. J Pharmacol Exp Ther 286:376-381.

Bruns RF and Fergus JH (1990) Allosteric enhancement of adenosine A1 receptor binding and function by 2-amino-3-benzoylthiophenes. Mol Pharmacol 38:939949.

Buller S, Zlotos DP, Mohr K, and Ellis J (2002) Allosteric site on muscarinic acetylcholine receptors: a single amino acid in transmembrane region 7 is critical to the subtype selectivities of caracurine $\mathrm{V}$ derivatives and alkane-bisaamonium ligands. Mol Pharmacol 61:160-168.

Burgen ASV (1981) Conformational changes and drug action. Fed Proc 40:27232728.

Butler SJ, Kelly EC, McKenzie FR, Guild SB, Wakelam MJ, and Milligan G (1988) Differential effects of suramin on the coupling of receptors to individual species of pertussis-toxin-sensitive guanine-nucleotide-binding proteins. Biochem $J$ 251: 201-205.

Carroll FY, Stolle A, Beart PM, Voerst A, Brabet I, Mauler F, Joly C, Antonicek H, Bockaert J, Muller T, et al. (2001) BAY36-7620: a potent noncompetitive mGlu1 receptor antagonist with inverse agonist activity. Mol Pharmacol 59:965-973.

Chen G, Way J, Armour S, Watson C, Queen K, Jayawickreme CK, Chen WJ, and Kenakin T (2000b) Use of constitutive G protein-coupled receptor activity for drug discovery. Mol Pharmacol 57:125-134.

Chen S, Lin F, Xu M, Hwa J, and Graham RM (2000a) Dominant-negative activity of an $\alpha_{1 \mathrm{~B}}$-adrenergic receptor signal-inactivating point mutation. EMBO J 19: $4265-4271$.

Cheng Y-C and Prusoff WH (1973) Relationship between the inhibition constant $\left(\mathrm{K}_{\mathrm{I}}\right)$ and the concentration of inhibitor which causes $50 \%$ inhibition $\left(\mathrm{I}_{50}\right)$ of an enzymatic reaction. Biochem Pharmacol 22:3099-3108.

Chidiac P, Green MA, Pawagi AB, and Wells JW (1997) Cardiac muscarinc receptors: cooperativity as the basis for multiple states of affinity. Biochemistry 36:73617379 .

Chidiac P, Hebert TE, Valiquette M, Dennis M, and Bouvier M (1994) Inverse agonist activity of $\beta$-adrenergic antagonists. Mol Pharmacol 45:490-499.

Chidiac P, Nouet S, and Bouvier M (1996) Agonist-induced modulation of inverse agonist eficacy at the $\beta_{2}$-adrenergic receptor. Mol Pharmacol 50:662-669.

Chiu TT, Yung LY, and Wong YH (1996) Inverse agonistic effect of ICI-174,864 on the cloned $\delta$-opioid receptor: role of $\mathrm{G}$ protein and adenylyl cyclase activation. $M o l$ Pharmacol 50:1651-1657.

Christopoulos A (2000a) Overview of receptor allosterism, in Current Protocols in Pharmacology (Enna SJ ed) pp 1.21.21-1.21.45, Wiley and Sons, New York.

Christopoulos A (2000b) Quantification of allosteric interactions at G proteincoupled receptors using radioligand binding assays, in Current Protocols in Pharmacology (Enna SJ ed) pp 1.22.21-1.22.40, Wiley and Sons, New York.

Christopoulos A (2002) Allosteric binding sites on cell-surface receptors: novel targets for drug discovery. Nat Rev Drug Discov 1:198-210.

Christopoulos A and El-Fakahany EE (1999) Qualitative and quantitative assessment of relative agonist efficacy. Biochem Pharmacol 58:735-748.

Christopoulos A, Lanzafame A and Mitchelson F (1998) Allosteric interactions at muscarinic cholinoceptors. Clin Exp Pharmacol Physiol 25:184-194.

Christopoulos A and Mitchelson F (1994) Assessment of the allosteric interactions of the bisquaternary heptane-1,7-bis(dimethyl-3'-pthalimidopropyl)ammonium bromide at $\mathrm{M}_{1}$ and $\mathrm{M}_{2}$ muscarine receptors. Mol Pharmacol 46:105-114.

Christopoulos A and Mitchelson F (1997) Application of an allosteric ternary complex model to the technique of pharmacological resultant analysis. J Pharm Pharmacol 49:781-786.

Christopoulos G, Perry KJ, Morfis M, Tilakaratne N, Gao Y, Fraser NJ, Main MJ, Foord SM, and Sexton PM (1999) Multiple amylin receptors arise from receptor activity-modifying protein interaction with the calcitonin receptor gene product. Mol Pharmacol 56:235-242.

Ciruela F, Escriche M, Burgueno J, Angulo E, Casado V, Soloviev MM, Canela EI, Mallol J, Chan WY, Lluis C, et al. (2001) Metabotropic glutamate $1 \alpha$ and adenosine A1 receptors assemble into functionally interacting complexes. J Biol Chem 276: 18345-18351.

nigrave AD, Quinn SJ, and Brown EM (2000a) Cooperative multi-modal sensing Pharmacol Sci 21:401-407.

Conigrave AD, Quinn SJ, and Brown EM (2000b) L-Amino acid sensing by the extracellular $\mathrm{Ca}^{2+}$-sensing receptor. Proc Natl Acad Sci USA 97:4814-4819.

Cornea A, Janovick JA, Maya-Nunez G and Conn PM (2001) Gonadotropin-releasing hormone receptor microaggregation. Rate monitored by fluorescence resonance energy transfer. J Biol Chem 276:2153-2158.

Corset V, Nguyen-Ba-Charvet KT, Forcet C, Moyse E, Chedotal A, and Mehlen P (2000) Netrin-1-mediated axon outgrowth and cAMP production requires interaction with adenosine A2b receptor. Nature (Lond) 407:747-750.

Corsi M, Fina P, and Trist DG (1996) Co-agonism in drug-receptor interaction: illustrated by the NMDA receptor. Trends Pharmacol Sci 17:220-222.

Costa T and Herz A (1989) Antagonists with negative intrinsic activity at $\delta$ opioid receptors coupled to GTP-binding proteins. Proc Natl Acad Sci USA 86:7321-7325.

Cox MA, Jenh CH, Gonsiorek W, Fine J, Narula SK, Zavodny PJ and Hipkin RW (2001) Human interferon-inducible $10-\mathrm{kDa}$ protein and human interferoninducible $\mathrm{T}$ cell alpha chemoattractant are allotopic ligands for human CXCR3 differential binding to receptor states. Mol Pharmacol 59:707-715.

Creazzo TL and Hartzell HC (1985) Reduction of muscarinic acetylcholine receptor number and affinity by an endogenous substance. $J$ Neurochem 45:710-718.

Cuatrecasas P (1974) Membrane receptors. Annu Rev Biochem 43:169-214.

Cvejic S and Devi LA (1997) Dimerization of the $\delta$ opioid receptor: implication for a role in receptor internalization. J Biol Chem 272:26959-26964.

del Castillo J and Katz B (1957) Interaction at end-plate receptors between different choline derivatives. Proc $R$ Soc Lond B Biol Sci 146:369-381.

De Lean A, Stadel JM, and Lefkowitz RJ (1980) A ternary complex model explains the agonist-specific binding properties of the adenylate cyclase-coupled $\beta$-adrenergic receptor. J Biol Chem 255:7108-7117.

De Vries L, Zheng B, Fischer T, Elenko E, and Farquhar MG (2000) The regulator of G protein signaling family. Annu Rev Pharmacol Toxicol 40:235-271.

Diaz-Arrastia R, Ashizawa T, and Appel SH (1985) Endogenous inhibitor of ligand binding to the muscarinic acetylcholine receptor. J Neurochem 44:622-628.

Doms RW, and Peiper SC (1997) Unwelcomed guests with master keys: how HIV uses chemokine receptors for cellular entry. Virology 235:179-190.

Doranz BJ, Lu ZH, Rucker J, Zhang TY, Sharron M, Cen YH, Wang ZX, Guo HH, Du JG, Accavitti MA, et al. (1997) Two distinct CCR5 domains can mediate coreceptor usage by human immunodeficiency virus type 1. J Virol 71:6305-6314

Ehlert FJ (1985) The relationship between muscarinic receptor occupancy and adenylate cyclase inhibition in the rabbit myocardium. Mol Pharmacol 28:410-421.

Ehlert FJ (1988) Estimation of the affinities of allosteric ligands using radioligand binding and pharmacological null methods. Mol Pharmacol 33:187-194.

Ellis J (1997) Allosteric binding sites on muscarinic receptors. Drug Dev Res 40:193204

Ellis J, Huyler J, and Brann MR (1991) Allosteric regulation of cloned m1-m5 muscarinic receptor subtypes. Biochem Pharmacol 42:1927-1932.

Ellis J and Seidenberg M (1989) Gallamine exerts biphasic allosteric effects at muscarinic receptors. Mol Pharmacol 35:173-176.

Ellis J and Seidenberg M (2000) Interactions of alcuronium, TMB-8, and other allosteric ligands with muscarinic acetylcholine receptors: studies with chimeric receptors. Mol Pharmacol 58:1451-1460.

Evans BN, Rosenblatt MI, Mnayer LO, Oliver KR, and Dickerson IM (2000) CGRPRCP, a novel protein required for signal transduction at calcitonin gene-related peptide and adrenomedullin receptors. J Biol Chem 275:31438-31443.

Fang YI, Iijima M, Ogawa M, Suzuki T, and Momose K (1993) Reduction in the numbers of muscarinic receptors by an endogenous protein. Biochem Pharmacol 46:637-641.

Fawzi AB, Macdonald D, Benbow LL, Smith-Torhan A, Zhang H, Weig BC, Ho G, Tulshian D, Linder ME, and Graziano MP (2001) SCH-202676: an allosteric modulator of both agonist and antagonist binding to $\mathrm{G}$ protein-coupled receptors. Mol Pharmacol 59:30-37.

Fillion G, Rousselle JC, Massot O, Zifa E, Fillion MP, and Prudhomme N (1996) A new peptide, 5-HT-moduline, isolated and purified from mammalian brain specifically interacts with 5-HT1B/1D receptors. Behav Brain Res 73:313-317.

Flynn DD and Mash DC (1989) Multiple in vitro interactions with and differential in vivo regulation of muscarinic receptor subtypes by tetrahydroaminoacridine. J Pharmacol Exp Ther 250:573-581.

Foord SM and Marshall FH (1999) RAMPs: accessory proteins for seven transmem brane domain receptors. Trends Pharmacol Sci 20:184-187.

Fowler CJ, Vedin V, and Sjoberg E (1999) Evidence for cooperative binding of 
Frey WH II, Emory CR, Wiebenga ME, Saxena S, Cardelli D, Ala TA, and Tollefson GD (1994) Inhibitor of antagonist binding to the muscarinic receptor is elevated in Alzheimer's brain. Brain Res 655:153-160.

Frey WH II, Najarian MM, Kumar KS, Emory CR, Menning PM, Frank JC, Johnson M, and Ala TA (1996) Endogenous Alzheimer's brain factor and oxidized glutathione inhibit agonist binding to the muscarinic receptor. Brain Res 714:87-94.

Fryer AD and El-Fakahany EE (1989) An endogenous factor induces heterogeneity of binding sites of selective muscarinic receptor antagonists in rat heart. Membr Biochem 8:127-132.

Gaddum JH (1936) The quantitative effects of antagonistic drugs. J Physiol (Lond) 89:7P-9P.

Gaddum JH (1957) Theories of drug antagonism. Pharmacol Rev 9:211-218.

Galzi J-L and Changeux J-P (1994) Neurotransmitter-gated ion channels as unconventional allosteric proteins. Curr Op Struct Biol 4:554-565.

Galzi J-L, Revah F, Bessis A, and Changeux JP (1991) Functional architecture of the nicotinic acetylcholine receptor: from electric organ to brain. Annu Rev Pharmacol 31:37-72.

Gao $\mathrm{Z}$ and Ijzerman AP (2000) Allosteric modulation of $\mathrm{A}_{2 \mathrm{~A}}$ adenosine receptors by amiloride analogues and sodium ions. Biochem Pharmacol 60:669-676.

Gao ZG, Van Muijlwijk-Koezen JE, Chen A, Muller CE, Ijzerman AP, and Jacobson KA (2001) Allosteric modulation of $\mathrm{A}_{3}$ adenosine receptors by a series of 3-(2pyridinyl)isoquinoline derivatives. Mol Pharmacol 60:1057-1063.

Gasior M, Carter RB, and Witkin JM (1999) Neuroactive steroids: potential therapeutic use in neurological and psychiatric disorders. Trends Pharmacol Sci 20: 107-112.

Gasparini F, Lingenhohl K, Stoehr N, Flor PJ, Heinrich M, Vranesic I, Biollaz M, Allgeier H, Heckendorn R, Urwyler S, et al. (1999) 2-Methyl-6-(phenylethynyl)pyridine (MPEP), a potent, selective and systemically active mGlu5 receptor antagonist. Neuropharmacology 38:1493-1503.

George SR, Fan T, Xie Z, Tse R, Tam V, Varghese G, and O’Dowd BF (2000) Oligomerization of $\mu$ - and $\delta$-opioid receptors. Generation of novel functional properties. J Biol Chem 275:26128-26135.

George SR, Lee SP, Varghese G, Zeman PR, Seeman P, Ng GYK, and O'Dowd BF (1998) A transmembrane domain-derived peptide inhibits D1 dopamine receptor function without affecting receptor oligomerization. J Biol Chem 273:3024430248.

Gerstein M, Lesk AM, and Chothia C (1994) Structural mechanisms for domain movements in proteins. Biochemistry 33:6739-6749

Gether U, Lin S, and Kobilka BK (1995) Fluorescent labeling of purified $\beta_{2}$ adrenergic receptor. Evidence for ligand-specific conformational changes. J Biol Chem 270:28268-28275.

Gilman AG (1987) G proteins: transducers of receptor-generated signals. Annu Rev Biochem 56:615-649.

Gines S, Hillion J, Torvinen M, Le Crom S, Casado V, Canela EI, Rondin S, Lew JY, Watson S, Zoli M, et al. (2000) Dopamine D1, and adenosine A1 receptors form functionally interacting heteromeric complexes. Proc Natl Acad Sci USA 97:86068611.

Gnagey AL, Seidenberg M, and Ellis J (1999) Site-directed mutagenesis reveals two epitopes involved in the subtype selectivity of the allosteric interactions of gallamine at muscarinic acetylcholine receptors. Mol Pharmacol 56:1245-1253.

Gomes I, Jordan BA, Gupta A, Trapaidze N, Nagy V, and Devi LA (2000) Heterodimerization of micro and delta opioid receptors: a role in opiate synergy. $J$ Neurosci 20:RC110.

Gouldson PR, Higgs C, Smith RE, Dean MK, Gkoutos GV, and Reynolds CA (2000) Dimerization and domain swapping in G-protein-coupled receptors: a computational study. Neuropsychopharmacology 23:S60-S77.

Gouldson PR, Snell CR, Bywater RP, Higgs C, and Reynolds CA (1998) Domain swapping in G-protein coupled receptor dimers. Protein Eng 11:1181-1193.

Grosse R, Schoneberg T, Schultz G, and Gudermann T (1997) Inhibition of gonadotropin-releasing hormone receptor signaling by expression of a splice variant of the human receptor. Mol Endocrinol 11:1305-1318.

Gurdal H, Bond RM, Johnson MD, Friedman E, and Onaran HO (1996) An efficacydependent effect of cardiac overexpression of $\beta_{2}$-adrenoceptor on ligand affinity in transgenic mice. Mol Pharmacol 52:187-194.

Hall DA (2000) Modeling the functional effects of allosteric modulators at pharmacological receptors: an extension of the two-state model of receptor activation. $\mathrm{Mol}$ Pharmacol 58:1412-1423.

Hall RA, Ostedgaard LS, Premont RT, Blitzer JT, Rahman N, Welsh MJ, and Lefkowitz RJ (1998a) A C-terminal motif found in the $\beta_{2}$-adrenergic receptor, $\mathrm{P} 2 \mathrm{Y} 1$ receptor and cystic fibrosis transmembrane conductance regulator deter- to the muscarinic receptor. Naunyn-Schmied Arch Pharmacol 320:3-13.

edlund PB, Carson MJ, Sutcliffe JG, and Thomas EA (1999) Allosteric regulation by oleamide of the binding properties of 5-hydroxytryptamine ${ }_{7}$ receptors. Biochem Pharmacol 58:1807-1813.

Hejnova L, Tucek S, and El-Fakahany EE (1995) Positive and negative allosteric interactions on muscarinic receptors. Eur $J$ Pharmacol 291:427-430.

Henis YI, Kloog Y, and Sokolovsky M (1989) Allosteric interactions of muscarinic receptors and their regulation by other membrane proteins, in The Muscarinic Receptors (Brown JH ed) pp 377-418, Humana Press, Clifton, NJ.

Herberg JT, Codina J, Rich KA, Rojas FJ, and Iyengar R (1984) The hepatic glucagon receptor. Solubilization, characterization, and development of an affinity adsorption assay for the soluble receptor. J Biol Chem 259:9285-9294.

Heron GS and Schimerlik MI (1984) Protein composition of the atrial muscarinic acetylcholine receptor partially purified by wheat germ agglutinin affinity chromatography. Arch Biochem Biophys 230:533-542.

Higashijima T, Uzu S, Nakajima T, and Ross EM (1988) Mastoparan, a peptide toxin from wasp venom, mimics receptors by activating GTP-binding regulatory proteins (G proteins). J Biol Chem 263:6491-6494.

Hill AV (1910) The possible effects of the aggregation of the molecules of haemoglobin on its dissociation curves. J Physiol 40:iv-vii.

Hirschberg BT and Schimerlick MI (1994) A kinetic model for oxotremorine M binding to recombinant porcine $\mathrm{m} 2$ muscarinic receptors expressed in Chinese hamster ovary cells. J Biol Chem 269:26127-26135.

Hoare SRJ and Strange PG (1996) Regulation of $\mathrm{D}_{2}$ dopamine receptors by amiloride and amiloride analogs. Mol Pharmacol 50:1295-1308.

Holzgrabe U and Mohr K (1998) Allosteric modulators of ligand binding to muscarinic acetylcholine receptors. Drug Disc Today 3:214-222.

Horne WC, Shyu J-F, Chakraborty M, and Baron R (1994) Signal transduction by calcitonin: multiple ligands, receptors and signaling pathways. Trends Endocrinol Metab 5:395-401.

Horstman DA, Brandon S, Wilson AL, Guyer CA, Cragoe EJ Jr, and Limbird LE (1990) An aspartate conserved among G-protein receptors confers allosteric regulation of $\alpha_{2}$-adrenergic receptors by sodium. J Biol Chem 265:21590-21595.

Howard OM, Korte T, Tarasova NI, Grimm M, Turpin JA, Rice WG, Michejda CJ, Blumenthal R, and Oppenheim JJ (1998a) Small molecule inhibitor of HIV-1 cell fusion blocks chemokine receptor-mediated function. J Leukoc Biol 64:6-13.

Howard OM, Oppenheim JJ, Hollingshead MG, Covey JM, Bigelow J, McCormack JJ, Buckheit RW Jr, Clanton DJ, Turpin JA, and Rice WG (1998b) Inhibition of in vitro and in vivo HIV replication by a distamycin analogue that interferes with chemokine receptor function: a candidate for chemotherapeutic and microbicidal application. J Med Chem 41:2184-2193.

Howard OM, Shirakawa AK, Turpin JA, Maynard A, Tobin GJ, Carrington M, Oppenheim JJ, and Dean M (1999) Naturally occurring CCR5 extracellular and transmembrane domain variants affect HIV-1 Co-receptor and ligand binding function. $J$ Biol Chem 274:16228-16234.

Hu J, Castets F, Guevara JL, and Van Eldik LJ (1996) S100 $\beta$ stimulates inducible nitric oxide synthase activity and mRNA levels in rat cortical astrocytes. $J$ Biol Chem 271:2543-2547.

$\mathrm{Hu} \mathrm{J}$ and El-Fakahany EE (1993) Allosteric interaction of dynorphin and myelin basic protein with muscarinic receptors. Pharmacology 47:351-359.

Hu J, Wang SZ, Forray C, and El-Fakahany EE (1992) Complex allosteric modulation of cardiac muscarinic receptors by protamine: potential model for putative endogenous ligands. Mol Pharmacol 42:311-321.

Hu LA, Tang Y, Miller WE, Cong M, Lau AG, Lefkowitz RJ, and Hall RA (2000) $\beta_{1}$-adrenergic receptor association with PSD-95. Inhibition of receptor internalization and facilitation of $\beta_{1}$-adrenergic receptor interaction with $N$-methyl-Daspartate receptors. J Biol Chem 275:38659-38666.

Huang RR, Dehaven RN, Cheung AH, Diehl RE, Dixon RA, and Strader CD (1990) Identification of allosteric antagonists of receptor-guanine nucleotide-binding protein interactions. Mol Pharmacol 37:304-310.

Hunt TW, Fields TA, Casey PJ, and Peralta EG (1996) RGS10 is a selective activator of G $\alpha$ i GTPase activity. Nature (Lond) 383:175-177.

Ikezu T, Okamoto T, Ogata E, and Nishimoto I (1992) Amino acids 356-372 constitute a $\mathrm{G}_{\mathrm{i}}$-activator sequence of the $\alpha_{2}$-adrenergic receptor and have a Phe substitute in the G protein-activator sequence motif. FEBS Lett 311:29-32.

Jacoby DB, Gleich GJ, and Fryer AD (1993) Human eosinophil major basic protein is an endogenous allosteric antagonist at the inhibitory muscarinic $\mathrm{M}_{2}$ receptor. $J$ Clin Invest 91:1314-1318.

Jakubík J, Bacakova L, El-Fakahany EE, and Tucek S (1997) Positive cooperativity 
causes mislocalization of D3 receptors. Mol Pharmacol 58:677-683.

Katz B and Thesleff S (1957) A study of the "desensitization" produced by acetylcholine at the motor end-plate. J Physiol (Lond) 138:63-80.

Kaupmann K, Malitschek B, Schuler V, Heid J, Froestl W, Beck P, Mosbacher J, Bischoff S, Kulik A, Shigemoto R, et al. (1998) GABA $_{\mathrm{B}}$-receptor subtypes assemble into functional heteromeric complexes. Nature (Lond) 396:683-687.

Keith DE, Murray SR, Zaki PA, Chu PC, Lissin DV, Kang L, Evans CJ, and von Zastrow M (1996) Morphine activates opioid receptors without causing their rapid internalization. J Biol Chem 271:19021-19024.

Kenakin T (1982) The Schild regression in the process of receptor classification. Can $J$ Physiol Pharmacol 60:249-265.

Kenakin T (1992) Tissue response as a functional discriminator of receptor heterogeneity: effects of mixed receptor populations on Schild regressions. Mol Pharmacol 41:699-707.

Kenakin T (1995a) Agonist-receptor efficacy I: mechanisms of efficacy and receptor promiscuity. Trends Pharmacol Sci 16:188-192.

Kenakin T (1995b) Agonist-receptor efficacy II: agonist trafficking of receptor signals. Trends Pharmacol Sci 16:232-238.

Kenakin T (1995c) Pharmacological Proteus. Trends Pharmacol Sci 16:256-258.

Kenakin T (1996a) The classification of seven transmembrane receptors in recombinant expression systems. Pharmacol Rev 48:413-463.

Kenakin T (1996b) Receptor conformational induction versus selection: all part of the same energy landscape. Trends Pharmacol Sci 17:190-191.

Kenakin T (1997a) Agonist-specific receptor conformations. Trends Pharmacol Sci 18:416-417.

Kenakin T (1997b) Protean agonists. Keys to receptor active states. Ann N Y Acad Sci 812:116-125.

Kenakin T (1997c) Pharmacologic Analysis of Drug-Receptor Interaction, LippincottRaven, Philadelphia, PA.

Kenakin T (2002) Efficacy at G-protein-coupled receptors. Nat Rev Drug Discov 1:103-110.

Kenakin T and Boselli C (1989) Pharmacologic discrimination between receptor heterogeneity and allosteric interaction: resultant analysis of gallamine and pirenzepine antagonism of muscarinic response in rat trachea. $J$ Pharmacol Exp Ther 250:944-952.

Kiefer-Day JS, Campbell HE, Towles J, and El-Fakahany EE (1991) Muscarinic subtype selectivity of tetrahydroaminoacridine: possible relationship to its capricious efficacy. Eur J Pharmacol 203:421-423.

King BF, Dacquet C, Ziganshin AU, Weetman DF, Burnstock G, Vanhoutte PM, and Spedding M (1996) Potentiation by 2,2'-pyridylisatogen tosylate of ATP-responses at a recombinant P2Y1 purinoceptor. Br J Pharmacol 117:1111-1118.

Knaus GA, Knaus HG, and Saria A (1991) Complex allosteric interaction of heparin with neurokinin-1 receptors. Eur J Pharmacol 207:267-270.

Knoflach F, Mutel V, Jolidon S, Kew JN, Malherbe P, Vieira E, Wichmann J, and Kemp JA (2001) Positive allosteric modulators of metabotropic glutamate 1 receptor: characterization, mechanism of action, and binding site. Proc Natl Acad Sci USA 23:13402-13407.

Kollias-Baker CA, Ruble J, Jacobson M, Harrison JK, Ozeck M, Shryock JC, and Belardinelli L (1997) Agonist-independent effect of an allosteric enhancer of the A1 adenosine receptor in CHO cells stably expressing the recombinant human A1 receptor. J Pharmacol Exp Ther 281:761-768.

Kostenis E, Botero Cid HM, Holzgrabe Y, and Mohr K (1996) Evidence for a multiple binding mode of bispyridinium-type allosteric modulators of muscarinic receptors. Eur J Pharmacol 314:385-392.

Kostenis E and Mohr K (1996) Composite action of allosteric modulators on ligand binding. Trends Pharmacol Sci 17:443-444.

Kourounakis A, Visser C, de Goote M, and Ijzerman AP (2001) Differential effects of the allosteric enhancer (2-amino-4,5-dimethyl-trienyl) [3-(trifluoromethyl) pheynl] methanone (PD81,723) on agonist and antagonist binding and function at the human wild-type and a mutant (T277A) adenosine A1 receptor. Biochem Pharmacol 61:137-144.

Kroeger KM, Hanyaloglu AC, Seeber RM, Miles LE, and Eidne KA (2001) Constitutive and agonist-dependent homo-oligomerization of the thyrotropin-releasing hormone receptor. Detection in living cells using bioluminescence resonance energy transfer. J Biol Chem 276:12736-12743.

Krumins AM and Barber R (1997) The stability of the agonist $\beta_{2}$-adrenergic receptor- $\mathrm{G}_{\mathrm{S}}$ complex: evidence for agonist-specific states. 52:144-154.

Kuner R, Kohr G, Grunewald S, Eisenhardt G, Bach A, and Kornau HC (1999) Role of heteromer formation in $\mathrm{GABA}_{\mathrm{B}}$ receptor function. Science (Wash DC) 283:7477. ylcholine receptor. Biochem Pharmacol 42:199-205.

ee NH, Hu J, and El-Fakahany EE (1992) Modulation by certain conserved aspartate residues of the allosteric interaction of gallamine at the $\mathrm{m} 1$ muscarinic receptor. $J$ Pharmacol Exp Ther 262:312-316.

Lee SP, O’Dowd BF, Ng GY, Varghese G, Akil H, Mansour A, Nguyen T, and George SR (2000) Inhibition of cell surface expression by mutant receptors demonstrates that $\mathrm{D}_{2}$ dopamine receptors exist as oligomers in the cell. Mol Pharmacol 58:120 128 .

Lee TW, Sole MJ, and Wells JW (1986) Assessment of a ternary model for the binding of agonists to neurohumoral receptors. Biochemistry 25:7009-7020.

Leff P (1995) The two-state model of receptor activation. Trends Pharmacol Sci 16:89-97.

Leiros CP, Sterin-Borda L, Borda ES, Goin JC, and Hosey MM (1997) Desensitization and sequestration of human $\mathrm{m} 2$ muscarinic acetylcholine receptors by autoantibodies from patients with Chagas' disease. J Biol Chem 272:12989-12993.

Leppik RA and Birdsall NJ (2000) Agonist binding and function at the human $\alpha_{2 \mathrm{~A}}$-adrenoceptor: allosteric modulation by amilorides. Mol Pharmacol 58:10911099 .

Leppik RA, Lazareno S, Mynett A, and Birdsall NJ (1998) Characterization of the allosteric interactions between antagonists and amiloride analogues at the human $\alpha_{2 \mathrm{~A}}$-adrenergic receptor. Mol Pharmacol 53:916-925.

Leppik RA, Miller RC, Eck M and Paquet JL (1994) Role of acidic amino acids in the allosteric modulation by gallamine of antagonist binding at the $\mathrm{m} 2$ muscarinic acetylcholine receptor. Mol Pharmacol 45:983-990.

Leppik RA, Mynett A, Lazareno S, and Birdsall NJ (2000) Allosteric interactions between the antagonist prazosin and amiloride analogs at the human $\alpha_{1 \mathrm{~A}^{-}}$ adrenergic receptor. Mol Pharmacol 57:436-445.

Leuthauser K, Gujer R, Aldecoa A, McKinney RA, Muff R, Fischer JA, and Born W (2000) Receptor-activity-modifying protein 1 forms heterodimers with two Gprotein-coupled receptors to define ligand recognition. Biochem $J$ 351:347-351.

Lezcano N, Mrzljak L, Eubanks S, Levenson R, Goldman-Rakic P, and Bergson C (2000) Dual signaling regulated by calcyon, a $\mathrm{D}_{1}$ dopamine receptor interacting protein. Science (Wash DC) 287:1660-1664.

Li S, Okamoto T, Chun M, Sargiacomo M, Casanova JE, Hansen SH, Nishimoto I, and Lisanti MP (1995) Evidence for a regulated interaction between heterotrimeric G proteins and caveolin. J Biol Chem 270:15693-15701.

Lidow MS, Roberts A, Zhang L, Koh P, Lezcano N, and Bergson C (2001) Receptor crosstalk protein, calcyon, regulates affinity state of dopamine $\mathrm{D}_{1}$ receptors. Eur $J$ Pharmacol 427:187-193.

Limbird LE, De Meyts P, and Lefkowitz RJ (1975) $\beta$-adrenergic receptors: evidence for negative cooperativity. Biochem Biophys Res Comm 64:1160-1168.

Lin R, Karpa K, Kabbani N, Goldman-Rakic P, and Levenson R (2001) Dopamine D and $D_{3}$ receptors are linked to the actin cytoskeleton via interaction with filamin A. Proc Natl Acad Sci USA 98:5258-5263.

Litschig S, Gasparini F, Rueegg D, Stoehr N, Flor PJ, Vranesic I, Prezeau L, Pin JP, Thomsen C, and Kuhn R (1999) CPCCOEt, a noncompetitive metabotropic glutamate receptor 1 antagonist, inhibits receptor signaling without affecting glutamate binding. Mol Pharmacol 55:453-461.

Luebke AE, Dahl GP, Roos BA, and Dickerson IM (1996) Identification of a protein that confers calcitonin gene-related peptide responsiveness to oocytes by using a cystic fibrosis transmembrane conductance regulator assay. Proc Natl Acad Sci USA 93:3455-3460.

Lüllman H, Ohnesorge FK, Schauwecker G-C, and Wasserman O (1969) Inhibition of the actions of carbachol and DFP on guinea pig isolated atria by alkane-bisammonium compounds. Eur J Pharmacol 6:241-247.

Lutz M and Kenakin T (1999) Quantitative Molecular Pharmacology and Informatics in Drug Discovery, Wiley, New York.

Mack M, Luckow B, Nelson PJ, Cihak J, Simmons G, Clapham PR, Signoret N, Marsh M, Stangassinger M, Borlat F, et al. (1998) Aminooxypentane-RANTES induces CCR5 internalization but inhibits recycling: a novel inhibitory mechanism of HIV infectivity. J Exp Med 187:1215-1224.

Maggio R, Vogel Z, and Wess J (1993a) Coexpression studies with mutant muscarinic/adrenergic receptors provide evidence for intermolecular "cross-talk" between G-protein-linked receptors. Proc Natl Acad Sci USA 90:3103-3107.

Maggio R, Vogel Z, and Wess J (1993b) Reconstitution of functional muscarinic receptors by co-expression of amino- and carboxyl-terminal receptor fragments. FEBS Lett 319:195-200.

Manivet P, Mouillet-Richard S, Callebert J, Nebigil CG, Maroteaux L, Hosoda S, Kellermann O, and Launay JM (2000) PDZ-dependent activation of nitric-oxide synthases by the serotonin 2B receptor. $J$ Biol Chem 275:9324-9331. 

regulation of a mammalian myocardial muscarinc receptor system. Evidence for
homo- and heterotropic cooperativity in ligand binding analyzed by computerassisted curve fitting. J Biol Chem 260:7410-7421.

Max SI, Liang JS, and Potter LT (1993) Stable allosteric binding of m1-toxin to m1 muscarinic receptors. Mol Pharmacol 44:1171-1175.

McLatchie LM, Fraser NJ, Main MJ, Wise A, Brown J, Thompson N, Solari R, Lee MG, and Foord SM (1998) RAMPs regulate the transport and ligand specificity of the calcitonin-receptor-like receptor. Nature (Lond) 393:333-339.

McVey M, Ramsay D, Kellett E, Rees S, Wilson S, Pope AJ, and Milligan G (2001) Monitoring receptor oligomerization using time-resolved fluorescence resonance energy transfer and bioluminescence resonance energy transfer. The human deltaopioid receptor displays constitutive oligomerization at the cell surface, which is not regulated by receptor occupancy. J Biol Chem 276:14092-14099.

Mellado M, Rodriguez-Frade JM, Aragay A, del Real G, Martin AM, Vila-Coro AJ, Serrano A, Mayor F Jr, and Martinez AC (1998) The chemokine monocyte chemotactic protein 1 triggers Janus kinase 2 activation and tyrosine phosphorylation of the CCR2B receptor. J Immunol 161:805-813.

Meller E, Puza T, Diamond J, Lieu H-D, and Bohmaker K (1992) Comparative effects of receptor inactivation, $17 \beta$-estradiol and pertussis toxin on dopaminergic inhibition of prolactin secretion in vitro. J Pharmacol Exp Ther 263:462-469.

Menten P, Struyf S, Schutyser E, Wuyts A, De Clercq E, Schols D, Proost P, and Van Damme J (1999) The LD78beta isoform of MIP-1alpha is the most potent CCR5 agonist and HIV-1-inhibiting chemokine. J Clin Invest 104:R1-R5.

Mijares A, Lebesgue D, Argibay J, and Hoebeke J (1996) Anti-peptide antibodies sensitive to the "active" state of the $\beta_{2}$-adrenergic receptor. FEBS Lett 399:188191.

Mijares A, Lebesgue D, Wallukat G, and Hoebeke J (2000) From agonist to antagonist: Fab fragments of an agonist-like monoclonal anti- $\beta_{2}$-adrenoceptor antibody behave as antagonists. Mol Pharmacol 58:373-379.

Mohr K and Tränkle C (1994) Allosteric effects of the alkane-bis-ammonium compound W84 and of tacrine on $\left[{ }^{3} \mathrm{H}\right]$ pirenzepine binding at $\mathrm{M}_{1}$-receptors in rat cerebral cortex. Pharmacol Toxicol 75:391-394.

Molderings GJ, Menzel S, Kathmann M, Schlicker E, and Gothert M (2000) Dual interaction of agmatine with the rat $\alpha_{2 \mathrm{D}}$-adrenoceptor: competitive antagonism and allosteric activation. Br J Pharmacol 130:1706-1712.

Monnot C, Bihoreau C, Conchon S, Curnow KM, Corvol P, and Clauser E (1996) Polar residues in the transmembrane domains of the type I angiotensin II receptor are required for binding and coupling. Reconstitution of the binding site by coexpression of two deficient mutants. J Biol Chem 271:1507-1513.

Monod J, Changeux J-P, and Jacob F (1963) Allosteric proteins and cellular control systems. J Mol Biol 6:306-329.

Monod J and Jacob F (1961) General conclusions: teleonomic mechanisms in cellular metabolism, growth and differentiation. Cold Spring Harbor Symp Quant Biol 26:389-401.

Monod J, Wyman J, and Changeux J-P (1965) On the nature of allosteric transitions: a plausible model. J Mol Biol 12:88-118.

Motulsky HJ and Insel PA (1983) Influence of sodium on the $\alpha_{2}$-adrenergic receptor system of human platelets. Role for intraplatelet sodium in receptor binding. J Biol Chem 258:3913-3919.

Mousli M, Bronner C, Landry Y, Bockaert J, and Rouot B (1990) Direct activation of GTP-binding regulatory proteins (G-proteins) by substance $\mathrm{P}$ and compound 48/80. FEBS Lett 259:260-262.

Musser B, Mudumbi RV, Liu J, Olson RD, and Vestal RE (1999) Adenosine A receptor-dependent and -independent effects of the allosteric enhancer PD 81,723. $J$ Pharmacol Exp Ther 288:446-454.

Nanoff C, Mitterauer T, Roka F, Hohenegger M, and Freissmuth M (1995) Species differences in $\mathrm{A} 1$ adenosine receptor/G protein coupling: identification of a membrane protein that stabilizes the association of the receptor/G protein complex. Mol Pharmacol 48:806-817.

Nanoff C, Waldhoer M, Roka F, and Freissmuth M (1997) G protein coupling of the rat $\mathrm{A}_{1}$-adenosine receptor: partial purification of a protein which stabilizes the receptor-G protein association. Neuropharmacology 36:1211-1219.

Neubig RR (1994) Membrane organization in G-protein mechanisms. FASEB $J$ 8:939-946.

Neubig RR (1998) Specificity of receptor-G protein coupling. Protein structure and cellular determinants. Sem Neurosci 9:189-197.

Neve KA, Cox BA, Henningsen RA, Spanoyannis A, and Neve RL (1991) Pivotal role for aspartate- 80 in the regulation of dopamine $\mathrm{D}_{2}$ receptor affinity for drugs and inhibition of adenylyl cyclase. Mol Pharmacol 39:733-739.

Ng GY, George SR, Zastawny RL, Caron M, Bouvier M, Dennis M and O'Dowd BF
$J$ Biol Chem 270:4205-4208.
Onaran HO, Costa T, and Rodbard D (1993) $\beta \gamma$-Subunits of guanine nucleotidebinding proteins and regulation of spontaneous receptor activity: thermodynamic model for the interaction between receptors and guanine nucleotide-binding protein subunits. Mol Pharmacol 43:245-256.

Onaran HO, Scheer A, Cotechia S, and Costa T (2000) A look at receptor efficacy. From the signalling network of the cell to the intramolecular motion of the receptor, in The Pharmacology of Functional, Biochemical and Recombinant Receptor Systems (Kenakin T and Angus JA eds) pp 215-259, Springer, Berlin.

Overton MC and Blumer KJ (2000) G-protein-coupled receptors function as oligomers in vivo. Curr Biol 10:341-344.

Pagano A, Ruegg D, Litschig S, Stoehr N, Stierlin C, Heinrich M, Floersheim P, Prezeau L, Carroll F, Pin JP, et al. (2000) The non-competitive antagonists 2-methyl-6-(phenylethynyl)pyridine and 7-hydroxyiminocyclopropan[b]chromen1a-carboxylic acid ethyl ester interact with overlapping binding pockets in the transmembrane region of group I metabotropic glutamate receptors. J Biol Chem 275:33750-33758.

Palczewski K, Kumasaka T, Hori T, Behnke CA, Motoshima H, Fox BA, Le Trong I, Teller DC, Okada T, Stenkamp RE, et al. (2000) Crystal structure of rhodopsin: a G protein-coupled receptor. Science (Wash DC) 289:739-745.

Park P, Sum CS, Hampson DR, Van Tol HH, and Wells JW (2001) Nature of the oligomers formed by muscarinic $\mathrm{m} 2$ acetylcholine receptors in Sf9 cells. Eur $J$ Pharmacol 421:11-22.

Paton WDM and Rang HP (1965) The uptake of atropine, and related drugs by intestinal smooth muscle of the guinea-pig in relation to acetylcholine receptors. Proc R Soc Lond B Biol Sci 163:1-44.

Picard L, Simmons G, Power CA, Meyer A, Weiss RA, and Clapham PR (1997) Multiple extracellular domains of CCR-5 contribute to human immunodeficiency virus type 1 entry and fusion. $J$ Virol 71:5003-5011.

Pizard A, Marchetti J, Allegrini J, Alhenc-Gelas F, and Rajerison RM (1998) Negative cooperativity in the human bradykinin $\mathrm{B}_{2}$ receptor. J Biol Chem 273:13091315

Polastron J, Mur M, Mazarguil H, Puget A, Meunier J-C, and Jauzac P (1994) SK-N-BE: a human neuroblastoma cell line containing two subtypes of $\delta$-opioid receptors. J Neurochem 62:898-906.

Popova JS, Johnson GL, and Rasenick MM (1994) Chimeric G $\alpha$ s/G $\alpha$ i2 proteins define domains on $\mathrm{G} \alpha$ s that interact with tubulin for $\beta$-adrenergic activation of adenylyl cyclase. J Biol Chem 269:21748-21754.

Potter LT, Ballesteros LA, Bichajian LH, Ferrendelli CA, Fisher A, Hanchett HE, and Zhang R (1991) Evidence for paired $\mathrm{M}_{2}$ muscarinic receptors. Mol Pharmacol 39:211-221.

Potter LT, Ferrendelli CA, and Hanchett HE (1988) Two affinity states of M1 muscarine receptors. Cell Mol Neurobiol 8:181-191.

Potter LT, Ferrendelli CA, Hanchett HE, Hollifield MA, and Lorenzi MV (1989) Tetrahydroaminoacridine and other allosteric antagonists of hippocampal M1 muscarine receptors. Mol Pharmacol 35:652-660.

Proska J and Tucek S (1994) Mechanisms of steric and cooperative actions of alcuronium on cardiac muscarinic acetylcholine receptors. Mol Pharmacol 45:709717.

Ralevic V and Burnstock G (1998) Receptors for purines and pyrimidines. Pharmacol Rev 50:413-492.

Ray K and Hauschild BC (2000) Cys-140 is critical for metabotropic glutamate receptor-1 dimerization. $J$ Biol Chem 275:34245-34251.

Robb S, Cheek TR, Hannan FL, Hall LM, Midgley JM, and Evans PD (1994) Agonist-specific coupling of a cloned Drosophila octopamine/tyramine receptor to multiple second messenger systems. EMBO $J$ 13:1325-1330.

Rocheville M, Lange DC, Kumar U, Patel SC, Patel RC, and Patel YC (2000a) Receptors for dopamine and somatostatin: formation of hetero-oligomers with enhanced functional activity. Science (Wash DC) 288:154-157.

Rocheville M, Lange DC, Kumar U, Sasi R, Patel RC, and Patel YC (2000b) Subtypes of the somatostatin receptor assemble as functional homo- and heterodimers. J Biol Chem 275:7862-7869.

Roess DA, Horvat RD, Munnelly H, and Barisas BG (2000) Luteinizing hormone receptors are self-associated in the plasma membrane. Endocrinology 141:45184523 .

Roettger BF, Ghanekar D, Rao R, Toledo C, Yingling J, and Miller LJ (1997) Antagonist-stimulated internalization of the G protein-coupled cholecystokinin receptor. Mol Pharmacol 51:357-362.

Roychowdhury S, Wang N, and Rasenick MM (1993) G protein binding, and G protein activation by nucleotide transfer involve distinct domains on tubulin: 
Chem 271:30052-30060.

Scarselli M, Armogida M, Chiacchio S, DeMontis MG, Colzi A, Corsini GU, and Maggio $R$ (2000) Reconstitution of functional dopamine $D_{2 s}$ receptor by coexpression of amino- and carboxyl-terminal receptor fragments. Eur J Pharmacol 397:291-296.

Scarselli M, Novi F, Schallmach E, Lin R, Baragli A, Colzi A, Griffon N, Corsini GU, Sokoloff P, Levenson R, et al. (2001) D2/D3 dopamine receptor heterodimers exhibit unique functional properties. J Biol Chem 276:30308-30314.

Scherer PE, Okamoto T, Chun M, Nishimoto I, Lodish HF, and Lisanti MP (1996) Identification, sequence and expression of caveolin-2 defines a caveolin gene family. Proc Natl Acad Sci USA 93:131-135.

Scherer PE, Tang Z, Chun M, Sargiacomo M, Lodish HF, and Lisanti MP (1995) Caveolin isoforms differ in their $\mathrm{N}$-terminal protein sequence and subcellular distribution. Identification and epitope mapping of an isoform-specific monoclonal antibody probe. J Biol Chem 270:16395-16401.

Schetz JA, Chu A, and Sibley DR (1999) Zinc modulates antagonist interactions with $\mathrm{D}_{2}$-like dopamine receptors through distinct molecular mechanisms. J Pharmacol Exp Ther 289:956-964.

Schetz JA and Sibley DR (1997) Zinc allosterically modulates antagonist binding to cloned $\mathrm{D}_{1}$ and $\mathrm{D}_{2}$ dopamine recpetors. J Neurochem 68:1990-1997.

Schetz JA and Sibley DR (2001) The binding-site crevice of the D4 dopamine receptor is coupled to three distinct sites of allosteric modulation. J Pharmacol Exp Ther 296:359-363.

Schols D, Struyf S, Van Damme J, Este JA, Henson G, and De Clercq E (1997) Inhibition of T-tropic HIV strains by selective antagonization of the chemokine receptor CXCR4. J Exp Med 186:1383-1388.

Schulz A, Grosse R, Schultz G, Gudermann T, and Schoneberg T (2000) Structural implication for receptor oligomerization from functional reconstitution studies of mutant V2 vasopressin receptors. J Biol Chem 275:2381-2389.

Schwartz TW and Rosenkilde MM (1996) Is there a "lock" for all agonist "keys" in 7TM receptors. Trends Pharmacol Sci 17:213-216.

Seifert R, Gether U, Wenzel-Seifert K, and Kobilka BK (1999) Effects of guanine, inosine and xanthine nucleotides on $\beta_{2}$-adrenergic receptor $/ \mathrm{G}_{\mathrm{s}}$ interactions: evidence for multiple receptor conformations. Mol Pharmacol 56:348-358.

Sigel E and Buhr A (1997) The benzodiazepine binding site of $\mathrm{GABA}_{\mathrm{A}}$ receptors. Trends Pharmacol Sci 18:425-429.

Simmons G, Clapham PR, Picard L, Offord RE, Rosenkilde MM, Schwartz TW, Buser R, Wells TN, and Proudfoot AE (1997) Potent inhibition of HIV-1 infectivity in macrophages and lymphocytes by a novel CCR5 antagonist. Science (Wash DC) 276:276-279.

Sinkins WG, Kandel M, Kandel SI, Schunack W, and Wells JW (1993) Protein-linked receptors labeled by $\left[{ }^{3} \mathrm{H}\right]$ histamine in guinea pig cerebral cortex. I. Pharmacological characterization. Mol Pharmacol 43:569-582.

Sinkins WG and Wells JW (1993) Protein-linked receptors labeled by $\left[{ }^{3} \mathrm{H}\right]$ histamine in guinea pig cerebral cortex. II. Mechanistic basis for multiple states of affinity. Mol Pharmacol 43:583-594.

Spedding M, Sweetman AJ, and Weetman DF (1975) Antagonism of adenosine 5 '-triphosphate-induced relaxation by $2-2$ '-pyridylisatogen in the taenia of guinea-pig caecum. Br J Pharmacol 53:575-583.

Spengler D, Waeber C, Pantaloni C, Holsboer F, Bockaert J, Seeburg PH, and Journot L (1993) Differential signal transduction by five splice variants of the PACAP receptor. Nature (Lond) 365:170-175.

Spooren WP, Gasparini F, Salt TE, and Kuhn R (2001) Novel allosteric antagonists shed light on $\mathrm{mglu}_{5}$ receptors and CNS disorders. Trends Pharmacol Sci 22:331337.

Steinberg GH, Eppel JG, Kandel M, Kandel SI, and Wells JW (1985a) $\mathrm{H}_{2}$ histaminic receptors in rat cerebral cortex. 1. Binding of $\left[{ }^{3} \mathrm{H}\right]$ histamine. Biochemistry 24: 6095-6107.

Steinberg GH, Kandel M, Kandel SI, and Wells JW (1985b) $\mathrm{H}_{2}$ histaminic receptors in rat cerebral cortex. 2. Inhibition of $\left[{ }^{3} \mathrm{H}\right]$ histamine by $\mathrm{H}_{2}$ antagonists. Biochemistry 24:6107-6115.

Steinberg GH, Kandel M, Kandel SI, and Wells JW (1985c) $\mathrm{H}_{2}$ histaminic receptors in rat cerebral cortex. 3. Inhibition of $\left[{ }^{3} \mathrm{H}\right]$ histamine by $\mathrm{H}_{2}$ agonists. Biochemistry 24:6115-6125.

Stockton JM, Birdsall NJM, Burgen ASV, and Hulme EC (1983) Modification of the binding properties of muscarinic receptors by gallamine. Mol Pharmacol 23:551557.

Strader CD, Fong TM, Tota MR, and Underwood D (1994) Structure and function of G protein-coupled receptors. Annu Rev Biochem 63:101-132.

Strittmatter SM, Cannon SC, Ross EM, Higashijima T, and Fishman MC (1993)
Eomas EA, Carson MJ, Neal MJ, and Sutcliffe JG (1997) Unique allosteric reguProc Natl Acad Sci USA 94:14115-14119.

Thron CD (1973) On the analysis of pharmacological experiments in terms of an allosteric receptor model. Mol Pharmacol 9:1-9.

Tränkle C, Mies-Klomfass E, Cid MHB, Holzgrabe U, and Mohr K (1998) Identification of a $\left[{ }^{3} \mathrm{H}\right]$ Ligand for the common allosteric site of muscarinic acetylcholine $\mathrm{M}_{2}$ receptors. Mol Pharmacol 54:139-145.

Tränkle C and Mohr K (1997) Divergent modes of action among cationic allosteric modulators of muscarinic $\mathrm{M}_{2}$ receptors. Mol Pharmacol 51:674-682.

Tränkle C, Weyand O, Schroter A, and Mohr K (1999) Using a radioalloster to test predictions of the cooperativity model for gallamine binding to the allosteric site of muscarinic acetylcholine $\mathrm{M}_{2}$ receptors. Mol Pharmacol 56:962-965.

Tucek S (1997) Is the $\mathrm{R}$ and $\mathrm{R}^{*}$ dichotomy real? Observations of allosteric phenomena on $G$ protein-coupled receptors point to problems in the interpretation of agonist-receptor-G protein interactions. Trends Pharmacol Sci 18:414-416.

Tucek S and Proska J (1995) Allosteric modulation of muscarinic acetylcholine receptors. Trends Pharmacol Sci 16:205-212.

Ullmer C, Schmuck K, Figge A, and Lubbert H (1998) Cloning and characterization of MUPP1, a novel PDZ domain protein. FEBS Lett 424:63-68.

Urwyler S, Mosbacher J, Lingenhoehl K, Heid J, Hofstetter K, Froestl W, Bettler B, and Kaupmann K (2001) Positive allosteric modulation of native and recombinant $\gamma$-aminobutyric acid $_{\mathrm{B}}$ receptors by 2,6-di-tert-butyl-4-(3-hydroxy-2,2-dimethylpropyl)-phenol (CGP7930), and its aldehyde analog CGP13501. Mol Pharmaco 60:963-971.

Van den Brink FG (1969) The model of metaffinoid interaction, in Histamine and Antihistamines. Molecular Pharmacology, Structure-Activity Relations, Gastric Acid Secretion, pp 56-62, Drukkerij Gebr. Janssen N.V., Nijmegen, The Netherlands.

Vaught JL, Rothman RB, and Westfall TC (1982) Mu and delta receptors: their role in anlalgesia and in the differential effects of opioid peptides on analgesia. Life Sci 30:1443-1455.

Venter JC and Fraser CM (1983) The structure of $\alpha$ - and $\beta$-adrenergic receptors. Trends Pharmacol Sci 4:256-258.

Vila-Coro AJ, Mellado M, Martin de Ana A, Lucas P, del Real G, Martinez AC, and Rodriguez-Frade JM (2000) HIV-1 infection through the CCR5 receptor is blocked by receptor dimerization. Proc Natl Acad Sci USA 97:3388-3393.

Wade SM, Lim WK, Lan KL, Chung DA, Nanamori M, and Neubig RR (1999) $G_{i}$ activator region of $\alpha_{2 \mathrm{~A}}$-adrenergic receptors: distinct basic residues mediate $\mathrm{G}$ versus $\mathrm{G}_{\mathrm{s}}$ activation. Mol Pharmacol 56:1005-1013.

Wang N, Yan K, and Rasenick MM (1990) Tubulin binds specifically to the signaltransducing proteins, $\mathrm{G}_{\mathrm{s}} \alpha$ and $\mathrm{G}_{\mathrm{i}} \alpha 1$. J Biol Chem 265:1239-1242.

Watson C, Chen G, Irving P, Way J, Chen WJ, and Kenakin T (2000) The use of stimulus-biased assay systems to detect agonist-specific receptor active states: implications for the trafficking of receptor stimulus by agonists. Mol Pharmacol 58:1230-1238.

Watson N, Linder ME, Druey KM, Kehrl JH, and Blumer KJ (1996) RGS family members: GTPase-activating proteins for heterotrimeric G-protein $\alpha$-subunits Nature (Lond) 383:172-175.

Waugh DJ, Gaivin RJ, Damron DS, Murray PA, and Perez DM (1999) Binding, partial agonism and potentiation of $\alpha_{1}$-adrenergic receptor function by benzodiazepines: a potential site of allosteric modulation. J Pharmacol Exp Ther 291:11641171

Weber G (1972) Ligand binding and internal equilibria in proteins. Biochemistry 11:864-878.

Weber G (1975) Energetics of ligand binding to proteins. Adv Prot Chem 29:1-83.

Weiss JM, Morgan PH, Lutz MW, and Kenakin TP (1996a) The cubic ternary complex receptor-occupancy model I. Model description. J Theor Biol 178:151-167.

Weiss JM, Morgan PH, Lutz MW, and Kenakin TP (1996b) The cubic ternary complex receptor-occupancy model II. Understanding apparent affinity. $J$ Theor Biol 178:169-182.

Weiss JM, Morgan PH, Lutz MW, and Kenakin TP (1996c) The cubic ternary complex receptor-occupancy model III. Resurrecting efficacy. $J$ Theor Biol 181: 381-397.

Wess J (1993) Mutational analysis of muscarinic acetylcholine receptors: structural basis of ligand/receptor/G protein interactions. Life Sci 53:1447-1463.

White JH, Wise A, Main MJ, Green A, Fraser NJ, Disney GH, Barnes AA, Emson P, Foord SM, and Marshall FH (1998) Heterodimerization is required for the forma-

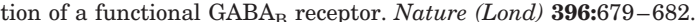

Wiens BL, Nelson CS, and Neve KA (1998) Contribution of serine residues to constitu- 
